\title{
SIRE RANKING BASED UPON PUREBRED VERSUS CROSSBRED PROGENY PERFORMANCE \\ IN SHINE
}

\author{
By \\ DAVID GORDON MCLAREN \\ Higher National Diploma \\ Welsh Agricultural College \\ Aberystwyth, Wales
}

1980
Submitted to the Faculty of the Graduate College of the Oklahoma State University
in partial fulfillment of the requirements for the Degree of MASTER OF SCIENCE
December, 1982


SIRE RANKING BASED UPON PUREBRED VERSUS

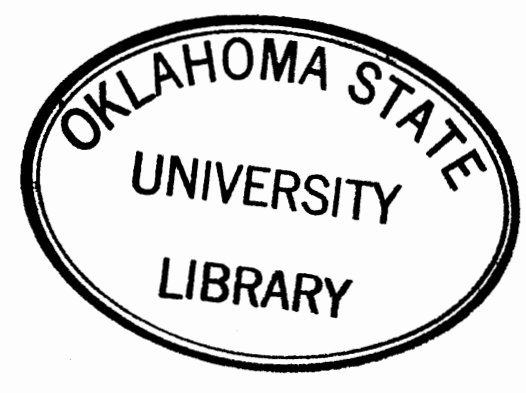

CROSSBRED PROGENY PERFORMANCE

IN SWINE

Thesis Adviser:

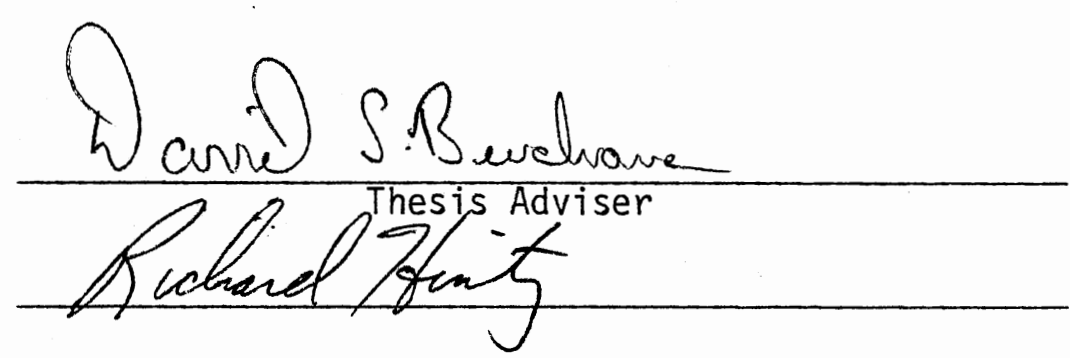

Chasker. Mupwed

Muman $M$ dura 


\section{ACKNOWLEDGMENTS}

Sincere appreciation and thanks are extended to Drs. D. S. Buchanan and R. L. Hintz for their guidance, encouragement, and assistance, both during the course of this study and throughout my graduate career to date. Thanks are also extended to Dr. C. V. Maxwell for his help and advice while serving on my M.S. committee.

I would also like to express my gratitude to Dr. J. V. Whiteman and the OKlahoma State University Animal Science Department for this unique opportunity to continue my education.

Special thanks go to my wife Sally, and to my parents, for their understanding and encouragement during my graduate program.

Thanks are also extended to Sharon Phillips for her expert and efficient typing of this manuscript. 
TABLE OF CONTENTS

Chapter

Page

I. INTRODUCTION . . . . . . . . . . . . . . . 1

II. REVIEW OF LITERATURE . . . . . . . . . . . . . 3

Introduction. . . . .......... 3

Results of Experimental Evaluation of Selection

for Specific Combining Ability. . . . . . . 4

Drosophilia.............. 4

Mice ................ . 5

Tribolium. ............. . 6

Poultry. . . . . . . . . . . . . . 7

Swine. . . . . . . . . . . . . 8

Results of Experimental Estimation of Genetic

Parameters and Expected Response to Alternative

Selection Methods ........... . 10

Poultry. . ............... 11

Mice................ 18

Cattle.............. 18

Sheep. . . . . . . . . . . . 21

Swine. . . . . . . . . . . 21

III. MATERIALS AND METHODS. . . . . . . . . . . . 30

Experimental Design . . . . . . . . . . . 30

Management and Data Collection. . . . . . . 32

Statistical Analysis. . . . . . . . . . . . 34

Models Used in Analyses. .. . . . . . 34

Variance Component Estimation. . . . . . 38

Heritability Estimation. . . . . . . . 39

Best Linear Unbiased Predictors of Sire

Breeding Value ............. 41

Genetic and Rank Correlation Estimation. . . 44

IV. RESULTS AND DISCUSSION . . . . . . . . . . . 48

Analyses of Variance for Fixed Effects. . . . . 48

Main Effects............. 48

Interactions ............. . . 48

Generalized Least Squares Means for Genetic

Effects .. . . . . . . . . . . . 54

Breed of Dam . . . . . . . . . . . . 55

Breed of Sire and Type....... . . . 57 
Variance Component Estimates. . . . . . . 64

Heritability Estimates. . . . . . . .... 68

Best Linear Unibased Predictors of Sire Breeding Value . . . . . . . . . . . . . . . 72

Genetic and Rank Correlation Estimates. . . . 73

Results. . . . . . . . . . . . . 73

Comparison With Results of Other Workers . . 78

Discussion . . . . . . . . . . . 79

Expected Response to Selection.... . . . 80

V. SUMMARY. . . . . . . . . . . . . . . 86

BIBLIOGRAPHY. . . . . . . . . . . . . . . . 90

APPENDIXES. . . . . . . . . . . . . . . . 98

APPENDIX A - TABLES. . . . . . . . . . . . . . 99

APPENDIX B - FIGURES . . . . . . . . . . . 137 


\section{LIST OF TABLES}

Table

Page

I. Literature Estimates of the Genetic Correlation $\left(r_{g}\right)$ Between Purebred and Crossbred Paternal Half-Sibs. . 13

II. 1444 Data Set - Number of Sires, Litters, and Progeny by Sire Breed for Traits Analyzed. . . . . . . . 35

III. 1620 Data Set - Number of Sires, Litters, and Progeny

by Sire Breed for Traits Analyzed. . . . . . . . 36

IV. Generalized Least Squares Analyses of Variance for

Fixed Effects for Pig Birth Weight . . . . . . . 49

V. Generalized Least Squares Analysis of Variance for

Fixed Effects for 21-Day Pig Weight. . . . . . . 50

VI. Generalized Least Squares Analyses of Variance for

Fixed Effects for 42-Day Pig Weight. . . . . . . 51

VII. Generalized Least Squares Analyses of Variance for

Fixed Effects for Postweaning Average Daily Gain . . 52

VIII. Generalized Least Squares Analyses of Variance for

Fixed Effects for Probed Backfat Thickness at

99.8 Kilograms . . . . . . . . . . . 53

IX. Breed of Dam Generalized Least Squares Means . . . . . 56

X. Purebred and Crossbred Generalized Least Squares

Means for Pig Birth Weight $(\mathrm{kg})$ by Breed of Sire . . 58

XI. Purebred and Crossbred Generalized Least Squares

Means for 21-Day Pig Weight (kg) by Breed of Sire. . 59

XII. Purebred and Crossbred Generalized Least Squares

Means for 42-Day Pig Weight $(\mathrm{kg})$ by Breed of Sire. , 60

XIII. Purebred and Crossbred Generalized Least Squares

Means for Postweaning Average Daily Gain (kg/day)

by Breed of Sire.............. . 61

XIV. Purebred and Crossbred Generalized Least Squares

Means for Probed Backfat Thickness at $99.8 \mathrm{~kg}(\mathrm{~mm})$

by Breed of Sire... . . . . . . . . . . . . 62 
Table

Page

XV. Variance Component Estimates From Purebred Ana?yses. - 65

XVI. Variance Component Estimates From Crossbred

Analyses .............. 66

XVII. Variance Component Estimates From Pooled Data Set

Analyses............. 67

XVIII. Heritability Estimates . . . . . . . . . 69

XIX. Genetic and Rank Correlation Coefficient Estimates . 74

$X X$. Numbers Required for an Approximate Standard Error of .2 on Genetic Correlation Coefficients Estimated

From Variance Components . . . . . . . . . 76

XXI. Ratio of Expected Response per Generation (R) Comparing Selection for Specific Combining Ability With Mass Selection to Improve Crossbreds . . . . . . 82

XXII. Adjustment Factors . . . . . . . . . . . 100

XXIII. 1444 Data Set - Number of Sires, Litters, and Progeny With Birth Weight Records by Farrowing Season and Sire Breed ............... . 101

XXIV. 1444 Data Set - Number of Sires, Litters, and Progeny With 21- and 42-Day Weight Records by Farrowing Season and Sire Breed. . . . . . . . . . . 102

XXV. 1444 Data Set - Number of Sires, Litters, and Progeny With Postweaning Average Daily Gain Records by

Farrowing Season and Sire Breed. . . . . . . . 103

XXVI. 1444 Data Set - Number of Sires, Litters, and Progeny With Probed Backfat Thickness Records by Farrowing Season and Sire Breed. .. . . . . . . . . 104

XXVII. 1620 Data Set - Number of Sires, Litters, and Progeny With Birth Weight Records by Farrowing Season and Sire Breed . . . . . . . . . . . . . 105

XXVIII. 1620 Data Set - Number of Sires, Litters, and Progeny With 42-Day weight Records by Farrowing Season and Sire Breed ................. 106

XXIX. 1620 Data Set - Number of Sires, Litters, and Progeny With Postweaning Average Daily Gain and Probed Backfat Thickness Records by Farrowing Season and Sire Breed. . . . . . . . . . . . . . 107 
Table

Page

XXX. Heritability and Variance Component Ratios. . . . . 108

XXXI. Observed Significance Levels of Differences Between

Breed of Dam Generalized Least Squares Means. . . . 109

XXXII. Observed Significance Levels of Differences Between Breed of Sire Generalized Least Squares Means for Probed Backfat Thickness. . . . . . . . 110

XXXIII. Variance Component Coefficients (k-Values) for Purebred and Crossbred Analyses ......... 111

XXXIV. Variance Component Coefficients (k-Values) for Pooled Anatyses. . . . . . . . . 112

XXXV. 1444 Data Set - Duroc Sire Breeding Values Obtained From Mixed Model Solutions. . . . . . . . . . 113

XXXVI. 1444 Data Set - Hampshire Sire Breeding Values Obtained From Mixed Model Solutions . . . . . . . . . 115

XXXVII. 1444 Data Set - Yorkshire Sire Breeding Values Obtained From Mixed Model Solutions . . . . . . . . . 117

XXXVIII. 1620 Data Set - Sire Breeding Values Obtained From Mixed Model Solutions .......... 119

XXXIX. 1444 Data Set - Duroc Sire Ranks Based Upon Breeding Values Obtained From Mixed Model Solutions. . . . 122

XL. 1444 Data Set - Hampshire Sire Ranks Based Upon Breeding Values Obtained From Mixed Model Solutions .............. . . 124

XLI. 1444 Data Set - Yorkshire Sire Ranks Based Upon Breeding Vaiues Obtained From Mixed Model Solutions . . . . . . . . . . . 126

XLII. 1620 Data Set - Sire Ranks Based Upon Breeding Values Obtained From Mixed Model Solutions. . . . . 128

XLIII. Upper and Lower 95 Percent Confidence Limits on Population Correlation Coefficients . . . . . . 131

XLIV. Genetic and Rank Correlation Estimates for Pig Birth Weight by Breed of Sire........ 132

XLV. Genetic and Rank Correlation Estimates for 21-Day Pig Weight by Breed of Sire......... 133 
Table

XLVI. Genetic and Rank Correlation Estimates for 42-Day

Pig Weight by Breed of Sire . . . . . . . . 134

XLVII. Genetic and Rank Correlation Estimates for Postweaning Average Daily Gain by Breed of Sire . . . 135

XLVIII. Genetic and Rank Correlation Estimates for Probed Backfat Thickness at $99.8 \mathrm{~kg}$ by Breed of Sire . . 136 


\section{LIST OF FIGURES}

Figure

1. Additive Relationship Matrix for Duroc Sires, 1444 Data Set.................. 138

2. Additive Relationship Matrix for Hampshire Sires, 1444 Data Set. . . . . . . . . . . . . . 139

3. Additive Relationship Matrix for Yorkshire Sires, 1444 Data Set. . . . . . . . . . . . . . . 140

4. Path Diagram Demonstrating the Correlations Between Sires' Additive Genetic Value and That of Their Offspring................. 14

5. Variance - Covariance Matrices for the Sire and Sire by Type Interaction Terms. . . . . . . . . . . . 142 


\section{CHAPTER I}

\section{INTRODUCTION}

Commercial swine production in the United States is based largely upon crossbreeding. It has been estimated that 90 percent or more of hogs marketed in this country are crossbred (Warwick and Legates, 1979). Given the importance of crossbreeding to the swine industry, it is easy to agree with Comstock (1960, p. 79) when he asserted that "the primary criterion of genetic value in the breeds should be the performance of the crossbred offspring rather than performance of the purebreds themselves."

This poses the question as to whether, in order to achieve continued genetic improvement in the market hog population, selection of purebred parents should be based upon intra-population selection (purebred selection), or upon the performance of their crossbreds. Selection based upon crossbred progeny performance, however, necessitates progeny testing and, as such, is unlikely to increase, and may indeed decrease, progress unless selection based upon individual performance is relatively inaccurate as compared to using progeny records.

The National Swine Improvement Federation (Robison, 1981) recommends various indices based upon individual performance that allow potential breeding stock to be ranked for selection. However, if selection based upon purebred performance is to be effective in 
improving performance of the crossbred population, the genetic correlation between performance in the purebreds and crossbreds must be relatively high (Enfield, 1960). In addition, the correlation between sire ranking based upon purebred and crossbred progeny should also be high. Low or negative genetic and rank correlations might suggest that some system of selection for combining ability (such as reciprocal recurrent selection) should perhaps be considered in order to obtain maximum genetic progress.

The objectives of the study were: 1) to estimate sire breeding values based upon both purebred and crossbred progeny for pig birth weight, 21-day weight, 42-day weight, postweaning average daily gain, and probed backfat thickness at 99.8 kilograms live weight; 2) to rank the sires for the above traits according to their breeding values and calculate the correlation between the two rankings; 3 ) to estimate the genetic correlation for the above traits between purebred and crossbred progeny having the same sire; and 4) to evaluate the expected response to alternative selection schemes using genetic parameter estimates obtained in this study. 
CHAPTER II

\title{
REVIEW OF LITERATURE
}

\author{
Introduction
}

The breeding techniques known as recurrent selection (Hu11, 1945) and reciprocal recurrent selection (Comstock et al., 1949) were developed to exploit maximum heterosis for yield in corn. Both are methods of selecting for specific combining ability and involve progeny testing and selection within at least one segregating population for improved crossbred performance. Recurrent selection utilizes an inbred or single cross tester, while reciprocal recurrent selection involves two segregating populations, each serving as the tester for the other.

Lack of response to intra-population selection for certain performance traits in swine during the development of mildly inbred lines led Dickerson (1952) and Dickerson et al. (1954) to suggest that selection may be made more efficient if directed toward improvement of crosses between complementary strains. Comstock and Robinson (1957) subsequently outlined a modified form of reciprocal recurrent selection for application to animal populations. This consists essentially of mating two breed cross females with males of a third breed, thus utilizing maternal heterosis, and selecting purebred replacements on the basis of crossbred progeny performance. 
A number of breeding experiments have been carried out involving various animal species to evaluate the utility of reciprocal recurrent selection in animal populations, and while results from studies with economic species are somewhat limited, experiments with laboratory animals have provided useful experimental models.

\author{
Results of Experimental Evaluation of Selection \\ for Specific Combining Ability
}

Drosophila

Drosophila melanogaster has been the predominant laboratory species for the experimental evaluation of different methods of selection. Two experiments reported by Bell et al. (1955) compared intrapopulation selection with inbreeding and hybridization, recurrent selection, and reciprocal recurrent selection in this species. The first experiment spanned 16 generations of selection based upon an index combining egg numbers and egg size. In the second experiment, spanning 39 generations, selection was based solely upon egg numbers. While the largest overall response in egg size, a highly heritable trait, was achieved with intra-population selection, results of the first experiment showed this method to be inferior to all other methods for increasing egg production, a more highly heterotic trait. Initial rapid response in egg production to intra-population selection peaked early in the second experiment and essentially plateaued, apparently as the result of a loss of additive genetic variance (Brown and Be11, 1961). The populations under inbreeding and hybridization, recurrent selection, and reciprocal recurrent selection 
showed continuous improvement, surpassing the plateaued population at about the 15th generation. However, in both experiments the response under both recurrent schemes apparently plateaued in late generations despite the presence of genetic variation in the segregating lines.

Results more favorable to reciprocal recurrent selection were reported by Kojima and Kelleher (1963) for egg production in Drosophila. While 13 cycles of full-sib family selection resulted in no significant increase in egg numbers, a linear increase totalling 25 percent was achieved with 10 cycles of reciprocal recurrent selection. This increase under reciprocal recurrent selection ceased after the tenth generation and remained essentially plateaued for the remaining six cycles of selection without achieving maximum heterosis, a similar result to that obtained by Bell et al. (1955). Rasmuson (1956) conducted three separate experiments with Drosophila to compare intra-population selection and reciprocal recurrent selection for egg numbers, egg hatchability, and body weight. The experiments were conducted over 20,13, and 6 cycles of selection, respectively, and in all three cases, crossbred animals produced by reciprocal recurrent selection were found to be slightly superior to those produced by intra-population selection. However, overall responses were small and sometimes negative with extreme fluctuation between cycles.

Mice

Bowman (1962) conducted two experimental studies of recurrent selection, one involving selection for increased litter size in mice 
over a few cycles of selection and the other selection for low bristle number in Drosophila for 14 generations. Although alternative methods were not included, responses observed were close to or less than those theoretically expected from an additive gene model. Hansson and Lindvist (1962) compared selection based on progeny testing within a closed population with rotational crossbreeding plus selection based upon crossbred performance for improvement of six week body weight in mice. The results of seven generations of selection indicated that intra-population selection was superior to the combination of recurrent selection and rotational crossbreeding for improvement of this moderate to highly heritable trait.

\section{Tribolium}

The relative inefficiency of reciprocal recurrent selection for improvement of highly heritable traits in Tribolium was demonstrated by Bell and Moore (1958, 1972). They compared reciprocal recurrent selection with intra-population selection for increasing pupal weight over 17 and 24 generations. In both cases, intra-population selection was found to be markedly superior, due largely to the greater selection pressure possible with this method.

Wong and Boylan (1970) practiced intra-population selection for increased pupal weight in Tribolium for 22 generations, concurrently mating males from the selected population with females from an inbred line to produce crossbred progeny. Response in the selected line was in agreement with that theoretically predicted, and response in the crossioreds was about one-half of that achieved in the selected line. 
MCNew and Bell (1976) reported the results of an experiment to compare reciprocal recurrent selection to intra-population selection in populations of Tribolium that had been subjected to 30 generations of purebred selection for increased larval weight, and as such were thought to be possibly near a response plateau. However, after 11 generations of selection, gains made by the two kinds of crossbreds were approximately equal, with no advantage of reciprocal recurrent selection over intra-population selection being detected. Taken together, research with laboratory animals would seem to suggest that intra-population selection for improvement of a moderate to highly heritable trait will also result in improvement of crossbred performance when selected populations are crossed, and that in such situations reciprocal recurrent selection will prove less efficient than intra-population selection as long as appreciable additive genetic variance is present in the purebred populations.

\section{Pouttry}

Possible application of methods of selection for specific combining ability were first discussed with reference to poultry by Be11 et al. $(1950,1952)$.

Kreuger et a1. (1961), applying comparable selection intensities over three cycles of selection for improved hatchability, fertility, and nine-week body weight in chickens, found intra-population selection to be equal or superior to reciprocal recurrent selection for all traits.

Griesbach (1962) evaluated reciprocal recurrent selection over five generations for increased 10-week weight in broilers and found 
no advantage for reciprocal recurrent selection over intra-population selection.

Saadeh et a1. (1968) compared intra-population selection and reciprocal recurrent selection for increased egg production in chickens over seven cycles of selection. Crossbred performance was improved under both schemes, but under reciprocal recurrent selection the parental strains showed less improvement than under intrapopulation selection, suggesting that reciprocal recurrent selection exploited some non-additive genetic variance. While overall selection responses for the two methods were of equal magnitude with no indication of a plateauing effect, initially the response rate for intrapopulation selection was greater than that for reciprocal recurrent selection, while the reverse was true for terminal generations.

Swine

A reciprocal selection program for feeding and carcass traits involving Duroc and Beltsville No. 1 lines was carried out in Stil1water, Oklahoma, between 1951 and 1959 (Whatiey et al., 1960). During this period feeding records were obtained on 637 pigs and slaughter records on 406 pigs. Selection response was not evaluated in this study, and the absence of control lines precluded inference as to the relative effectiveness of the reciprocal scheme. Subsequent selection was based upon crossbred gilt productivity (litter size and 21-day weight). Six cycles of reciprocal selection involving the same lines as above were carried out between 1961 and 1970 (Omtvedt, 1971). The productivity of crossbred gilts under the 
reciprocal selection scheme was not found to diverge from productivity of the control line gilts.

Krehbiel et a1. (1971a, 1971b) and Dickerson et a1. (1974) reported the results of an experiment carried out between 1953 and 1967 at Miles City, Montana, to compare alternative selection methods in swine. Nine cycles of mass selection was compared to five cycles of a modified form of reciprocal recurrent selection, based upon both purebred and crossbred progeny performance, using Montana No. 1 and Yorkshire swine. Selection was based upon an index combining both preweaning litter performance and postweaning gain to 140 days of age. In this study, reciprocal recurrent selection appeared to be at least as effective as the purebred scheme for improving preweaning (litter size and weight) and postweaning (gain and index) performance, the main advantage of the progeny test selection method being found for litter size in crosses.

Biswas et a1. (1971) compared five generations of reciprocal recurrent seiection with seven generations of intra-population selection for improving crossbred progeny performance. Foundation stocks of Duroc and Yorkshire swine were used for both methods, the data being analyzed separately for single cross and three breed cross (Poland China sires on single cross gilts) matings. Traits investigated were litter size, litter weight and average pig weight at birth, 21 or 56 and 154 days of age.

Aithough the power of the test to evaluate the alternative selection procedures was 10w, significant differences were found in the single cross data for litter size born and average pig weight at birth and 21 days of age, and in the three breed cross data for 
average pig weight at 21 and 154 days of age. Where significant differences were obtained, reciprocal recurrent selection was superior to intra-population selection for litter size, whereas the reverse was true for average pig weights. Somewhat confusing results were obtained for five traits, namely average weight at 154 days of age for single cross pigs and litter size and weight at 21 and 154 days of age for three breed crosses. Contrary to expectation, reciprocal recurrent selection seemed to be superior to intra-population selection for these traits in the early generations and inferior in later generations.

One further experiment aimed at assessing the relative effectiveness of reciprocal recurrent selection and intra-population selection in swine has been reported by Hetzer et al. (1977) and Bereskin and Hetzer (1981). Carried out between 1955 and 1971 at Beltsville, Maryland, this study is similar to that reported by Krebhiel et al. (1971a, 1971b) and Dickerson (1974). Six cycles of reciprocal recurrent selection in two Beltsville strains of swine combined purestrain and crossbred progeny performance in an index of preweaning (1itter size and weight) traits and postweaning growth and carcass traits. Selection in two control strains from the same foundation stock was based primarily upon purestrain preweaning performance. Hetzer et al. (1977) concluded that reciprocal recurrent selection was at least moderately superior to purestrain selection for preweaning traits; and results for postweaning gain reported by Bereskin and Hetzer (1981) show a significant positive response to reciprocal recurrent selection among crossbred progeny, but a significant negative response in parental strains. Results relating to 
carcass yield and a comparison of expected and estimated genetic response have yet to be published.

While Biswas et al. (1971) suggested that five cycles of reciprocal recurrent selection might be inadequate to establish any true superiority the system might have over intra-population selection, the results of the three experiments discussed above would seem to be in general agreement, supporting the view that any advantage for reciprocal recurrent selection would probably be observed for lowly heritable highly heterotic traits such as litter size.

\author{
Results of Experimental Estimation of Genetic \\ Parameters and Expected Response to \\ Alternative Selection Methods
}

In attempting to evaluate the possible effectiveness of selection for specific combining ability, the central question is whether a procedure such as reciprocal recurrent selection will improve the cross more rapidly than conventional selection in the parent populations. Enfield (1960) and Comstock (1961) outlined the genetic parameters required to estimate the expected progress in crossbreds from various intra- and inter-population selection schemes. These include the sire component of variance in the population under selection and in the crossbred population, and the covariance of sire effects between the purebred and crossbred populations.

One parameter which will provide some indication of the relative effectiveness of intra-population selection for improving the cross is the correlation between the intra-population effects of genes and 
their effects in the population cross. For intra-population selection to be effective in improving crossbred performance, this genetic correlation must be relatively high (Comstock and Robinson, 1957). Estimates of this correlation reported in experiments with mice, poultry, sheep, cattle, and swine are given in Table I.

\section{Poultry}

Genetic correlation estimates for poultry have been reported by Comstock (1956), Comstock and Robinson (1957), Enfield (1960), Hale and Clayton (1965), Krause et al. (1965), Biswas and Craig (1969), Pirchner (1976), and Merg1 (1977).

Comstock and Robinson (1957) estimated the genetic correlation between purebred and crossbred progeny having a common sire as ranging from .24 to .87 for eight week weight in chickens, with a mean over six different crosses of .62 .

Enfield (1960) also found high genetic correlations between purebred and crossbred New Hampshire and Rhode Island paternal halfsib families of .75 for male and .95 for female eight week week, .93 for mature female body weight and .92 for egg production.

Genetic correlations between purebred and crossbred Light Sussex and Brown Leghorn chickens reported by Hale and Clayton (1965) were .59 to 1.17 for egg production, .75 to .84 for egg weight, .83 to 1.01 for days to first egg, and .75 to .91 for pullet weight. Biswas and Craig (1969), in a study which involved White Leghorn and Red Randombred strains of chickens, found high positive genetic correlation between purebreds and crossbreds of .94 for egg production and .79 for days to first egg. 


\section{TABLE I}

LITERATURE ESTIMATES OF THE GENETIC CORRELATION

$(r g)$ BETWEEN PUREBRED AND CROSSBRED PATERNAL HALF-SIBS

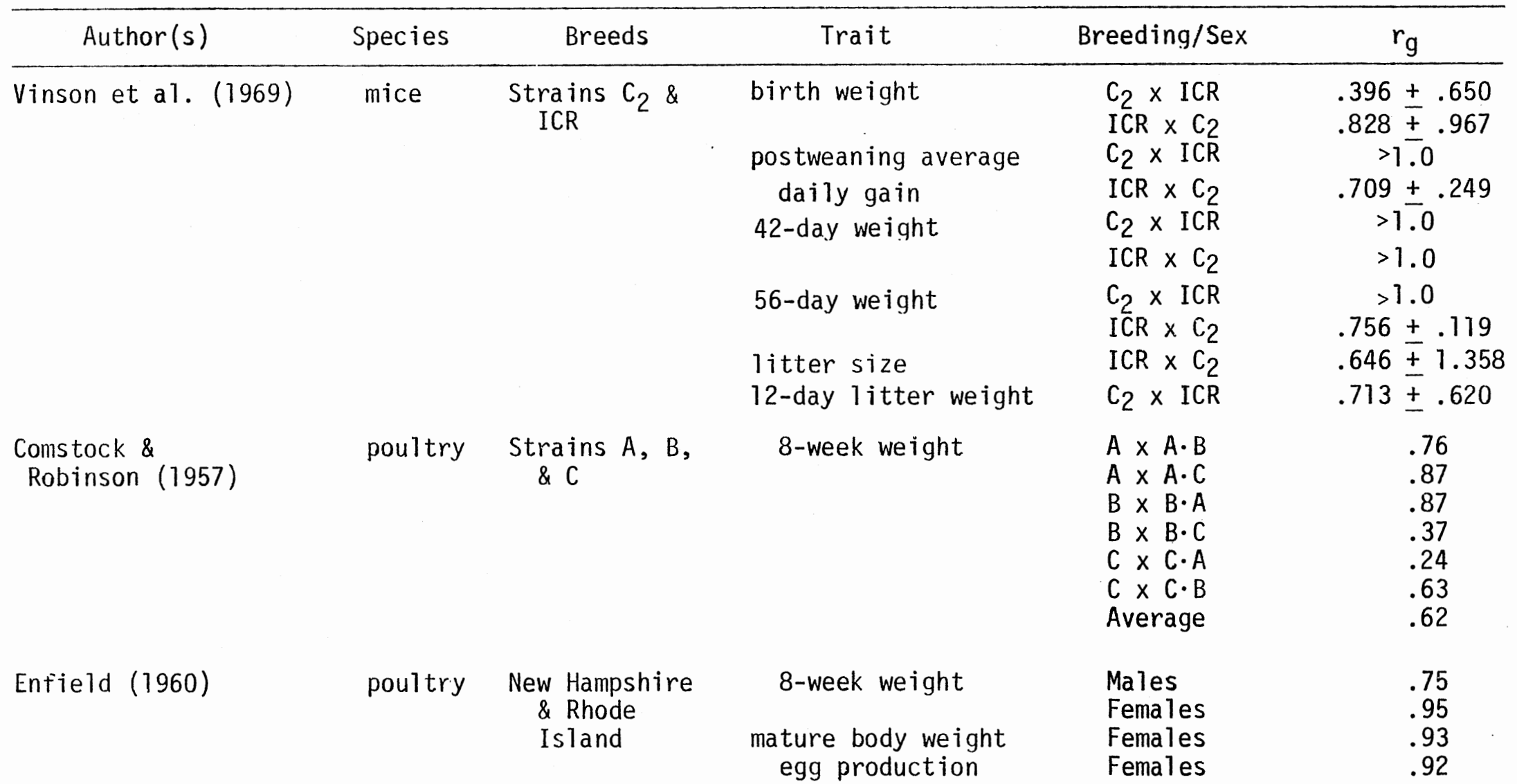


TABLE I (Continued)

\begin{tabular}{|c|c|c|c|c|c|}
\hline Author(s) & Species & Breeds & Trait & Breeding/Sex & $r_{g}$ \\
\hline $\begin{array}{l}\text { Krause et al. } \\
\quad(1965)\end{array}$ & poultry & $\begin{array}{l}\text { White Leghorn, } \\
\text { Strains A, B }\end{array}$ & $\begin{array}{l}\text { Female sexual } \\
\text { maturity } \\
\text { Female survivors' } \\
\text { percent production }\end{array}$ & $\begin{array}{l}B \times B \cdot A \\
A \times A \cdot B \\
B \times B \cdot A \\
A \times A \cdot B\end{array}$ & $\begin{array}{r}.17 \pm .22 \\
.24 \pm .22 \\
.26 \pm .27 \\
-.35 \pm .30\end{array}$ \\
\hline $\begin{array}{l}\text { Hale \& Clayton } \\
\qquad(1965)\end{array}$ & poultry & $\begin{array}{l}\text { Light Sussex } \\
\text { (LS) \& Brown. } \\
\text { Leghorn (BL) }\end{array}$ & $\begin{array}{l}\text { egg production, } \\
126-250 \text { days } \\
\text { egg production, } \\
250-450 \text { days } \\
\text { egg production, } \\
126-450 \text { days } \\
\text { egg weight } \\
\text { days to first egg } \\
\text { pullet weight }\end{array}$ & $\begin{array}{l}B L \times L S \\
L S \times B L \\
B L \times L S \\
L S \times B L \\
B L \times L S \\
L S \times B L \\
B L \times L S \\
L S \times B L \\
B L \times L S \\
L S \times B L \\
B L \times L S \\
L S \times B L\end{array}$ & $\begin{array}{r}.59 \\
1.17 \\
.85 \\
1.08 \\
.64 \\
1.10 \\
.75 \\
.84 \\
1.01 \\
.83 \\
.91 \\
.75\end{array}$ \\
\hline $\begin{array}{l}\text { Biswas \& Craig } \\
\text { (1969) }\end{array}$ & poultry & $\begin{array}{l}\text { Corne11 Random- } \\
\text { bred White } \\
\text { Leghorn (CC) } \\
\text { \& NC-47 Regional } \\
\text { Red Randombred } \\
\text { (RR) }\end{array}$ & $\begin{array}{l}\text { rate of lay, lst } \\
\text { egg to } 260 \text { days } \\
\text { days to 1st egg }\end{array}$ & $\begin{array}{l}C C \times R R \\
R R \times C C \\
\text { Average } \\
C C \times R R \\
R R \times C C \\
\text { Average }\end{array}$ & $\begin{array}{l}.92 \pm .08 \\
.96 \pm .05 \\
.94 \pm .05 \\
.70 \pm .09 \\
.89 \pm .03 \\
.79 \pm .05\end{array}$ \\
\hline Pirchner (1976) & poultry & 2 Leghorn lines & $\begin{array}{l}\text { percent egg produc- } \\
\text { tion, } 10 \text { months } \\
\text { age to sexual maturity } \\
\text { egg weight \& } \\
\text { specific gravity } \\
\text { body weight }\end{array}$ & & $\begin{array}{l}.5-.7 \\
.6-.7 \\
\sim 1.0 \\
\sim 1.0\end{array}$ \\
\hline
\end{tabular}


TABLE I (Continued)

\begin{tabular}{|c|c|c|c|c|c|}
\hline Author (s) & Species & Breeds & Trait & Breeding/Sex & $r_{\mathrm{g}}$ \\
\hline Mergl (1977) & poultry & $\begin{array}{l}2 \text { White Leghorn } \\
\text { I ines }\end{array}$ & $\begin{array}{l}\text { part record egg } \\
\text { production }\end{array}$ & & low, + \\
\hline Salah et al. (1970) & sheep & $\begin{array}{l}\text { Hampshire, Shrop- } \\
\text { shire, Southdown } \\
\text { \& Merino }\end{array}$ & weaning weight & & .82 \\
\hline Dunn et al. (1970) & cattle & $\begin{array}{l}\text { Angus, Hereford, } \\
\text { \& Shorthorn }\end{array}$ & $\begin{array}{l}\text { birth weight } \\
\text { weaning score } \\
\text { adjusted weaning } \\
\text { weight } \\
\text { adjusted final } \\
\text { weight } \\
\text { final carcass grade } \\
\text { fat thickness } \\
\text { rib eye area } \\
\text { actual cutability } \\
\text { average }\end{array}$ & $\begin{array}{l}\text { steers } \\
\text { heifers } \\
\text { steers } \\
\text { heifers } \\
\text { steers } \\
\text { heifers } \\
\text { steers } \\
\text { heifers }\end{array}$ & $\begin{array}{r}1.21 \\
.47 \\
1.45 \\
2.64 \\
1.52 \\
.35 \\
.83 \\
.18 \\
2.57 \\
.37 \\
3.82 \\
1.09 \\
.96\end{array}$ \\
\hline $\begin{array}{l}\text { Koger et a1. } \\
(1975)\end{array}$ & cattle & $\begin{array}{l}\text { (Trial 1) An- } \\
\text { gus }\end{array}$ & $\begin{array}{l}\text { birth weight } \\
205 \text {-day weight } \\
\text { condition score } \\
20 \text {-month weight } \\
\text { ratio }\end{array}$ & & $\begin{array}{r}.90 \pm .01 \\
1.00 \pm .03 \\
.56 \pm .24 \\
.74 \pm .03\end{array}$ \\
\hline
\end{tabular}


TABLE I (Continued)

\begin{tabular}{|c|c|c|c|c|c|}
\hline Author(s) & Species & Breeds & Trait & Breeding/Sex & $r_{g}$ \\
\hline Koger et a1. (1975) & cattle & $\begin{array}{l}\text { (Trial 2) Angus }(A), \\
\text { Brahman }(B), \& \\
\text { Hereford }(H)\end{array}$ & $\begin{array}{l}\text { birth weight } \\
\text { 205-day weight } \\
\text { condition score }\end{array}$ & $\begin{array}{l}\text { A sire } \\
\text { B sire } \\
H \text { sire } \\
\text { A sire } \\
\text { B sire } \\
H \text { sire } \\
\text { A sire } \\
\text { B sire } \\
\text { H sire }\end{array}$ & $\begin{array}{r}.70 \pm .34 \\
1.08 \pm .02 \\
1.13 \pm .02 \\
1.04 \pm 1.43 \\
1.24 \pm 1.17 \\
.98 \pm .92 \\
1.01 \pm .14 \\
1.16 \pm .19 \\
.90 \pm .23\end{array}$ \\
\hline $\begin{array}{l}\text { Robison et al. } \\
(1964)\end{array}$ & swine & $\begin{array}{l}\text { Duroc }(D) \& \\
\text { Yorkshire }(Y)\end{array}$ & $\begin{array}{l}\text { 140-day weight } \\
\text { 140-day backfat } \\
\text { no. pigs farrowed } \\
\text { no. pigs raised }\end{array}$ & $\begin{array}{l}\text { D sire } \\
\text { Y sire } \\
\text { D sire } \\
\text { Y sire } \\
\text { D sire } \\
\text { D sire }\end{array}$ & $\begin{array}{c}.22 \\
.72 \\
.21 \\
>1.0 \\
-.74 \\
<-1.0\end{array}$ \\
\hline $\begin{array}{c}\text { Taylor et al. } \\
\text { (1965) }\end{array}$ & swine & 2 strains & $\begin{array}{l}\text { 1itter weight at } \\
21 \text { days } \\
\text { 1itter weight at } \\
56 \text { days } \\
1 \text { itter weight at } \\
56 \text { days }\end{array}$ & & $\begin{array}{r}.185 \\
.612 \\
-.383\end{array}$ \\
\hline $\begin{array}{l}\text { Stanislawa (1966) } \\
\text { \& Stanislaw et al. } \\
(1967)\end{array}$ & swine & $\begin{array}{l}\text { Duroc, Belts- } \\
\text { ville No. } 1 \\
\text { \& Hampshire }\end{array}$ & $\begin{array}{l}\text { 56-day weight } \\
\text { average daily } \\
\text { gain } \\
\text { probed backfat }\end{array}$ & & $\begin{array}{r}1.25 \\
.33 \\
.75\end{array}$ \\
\hline
\end{tabular}


TABLE I (Continued)

\begin{tabular}{|c|c|c|c|c|c|}
\hline Author (s) & Species & Breeds & Trait & Breeding/Sex & $r_{g}$ \\
\hline Standal (1968) & swine & $\begin{array}{l}\text { Landrace \& York- } \\
\text { shire }\end{array}$ & $\begin{array}{l}\text { birthweight } \\
21 \text {-day weight } \\
\text { average daily gain } \\
\text { age at } 90 \mathrm{~kg} \\
\text { carcass length } \\
\text { backfat thickness } \\
\text { eye muscle area } \\
\text { weight of right ham } \\
\text { length of leg } \\
\text { score for type }\end{array}$ & & $\begin{array}{r}.70 \\
.83 \\
.33 \\
1.45 \\
.85 \\
.41 \\
1.13 \\
1.11 \\
.56 \\
1.02\end{array}$ \\
\hline $\begin{array}{l}\text { Rempel (1969), } \\
\text { Wong }(1969), \& \\
\text { Wong et a1. } \\
\text { (1971) }\end{array}$ & swine & $\begin{array}{c}\text { Minnesota } \\
\text { No. } 1 \\
\text { No. } 2 \\
\text { No. } 3\end{array}$ & $\begin{array}{l}\text { weaning weight } \\
\text { average daily gain } \\
\text { probed backfat } \\
\text { index } \\
\text { feed efficiency } \\
\text { litter size }\end{array}$ & 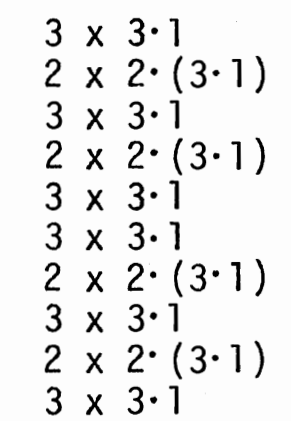 & $\begin{array}{c}<-1.0 \\
-.10 \pm .84 \\
.55 \pm .13 \\
.38 \mp .23 \\
>1.0 \\
.47 \pm .58 \\
.39 \pm .16 \\
.09 \pm .36 \\
>1.0 \\
.74+.26\end{array}$ \\
\hline
\end{tabular}

$a_{r_{g}}$ calculated from genetic parameter estimates given by author. 
Krause et al. (1965), in contrast to other workers, found with two White Leghorn lines that the genetic correlation for egg production was positive $(.26+.27)$ when one line served as the sire and negative $(-.35+.30)$ when the other line was the sire. Genetic correlations of $.17+.22$ and $.24+.22$ were obtained for female sexual maturity.

Pirchner (1976) reports genetic correlations for two Leghorn 1 ines of .5 to .7 for percentage egg production up to the tenth month of age, .6 to .7 for age at sexual maturity, and approximately 1.0 for egg weight, egg specific gravity, and body weight. However, Mergl (1977) reports only low genetic correlations between purebreds and crossbreds of two white Leghorn lines for egg production. While some contradictory results have been obtained with poultry, the majority of studies would suggest that conventional intrapopulation or purebred selection should effectively improve crossbred performance for the traits investigated.

Mice

Vinson et a1. (1969) reported high positive genetic correlations (.65 to $>1.0)$ between purebred and crossbred half-sib family means for 12-, 42-, and 56-day weight and postweaning average daily gain in mice. However, with one line as the sire, the genetic correlation for birth weight was low and the covariance for weaning weight and litter size negative, while the reverse was found when the other line served as the sire (i.e., a high correlation and positive covariances). These results were similar to those obtained by krause et al. (1965) for egg production in poultry. Expected response to three 
methods of selection (mass selection, half-sib family selection, and reciprocal recurrent selection) were also calculated. For the seven traits studied, expected response to mass selection was estimated to be greater than that for reciprocal recurrent selection for all traits except litter size.

\section{Cattle}

Relatively few studies involving cattle, sheep, and swine have evaluated the possible effectiveness of selection for specific combining ability, due partly to the large amounts of data required to obtain precise parameter estimates.

Miguel and Cartwright (1963) reported similar heritability estimates for birth weight, weaning weight, and feedlot gain in purebred and crossbred groups of Hereford and Brahman cattle, leading the authors to suggest that selection in either population should be effective.

Gregory et a1. (1965, 1966a, 1966b) and Jilek et a1. (1968) reported that among crosses of British beef breeds, sire by breed of dam interactions were generally nonsignificant for both pre- and postweaning traits, indicating no significant specific combining ability for the sires.

A small study by Willis et al. (1970) investigated genotype by nutrition interaction in cattle. It was noted that one Charolais and two Holstein bulls, with a total of 30 crossbred and 32 purebred progeny, ranked differently on the basis of progeny average daily gain for the two progeny groups. 
Dim (1974) ranked 28 Ayrshire, Friesian, and Red and White breed dairy sires based upon estimated breeding values for fat corrected milk production calculated from purebred and crossbred progeny groups. While each sire had an average of only 25 purebred and 16 crossbred progeny, ranking based upon purebred and crossbred records was almost the same. The best agreement was found in the ranking of very good or very poor sires.

A study reported by Dunn et a1. (1970) found no differences in the sire component of variance for nine weight, score, and carcass traits in 350 purebred and 387 crossbred progeny of 49 Angus, Hereford, and Shorthorn sires. As in Miguel and Cartwright's (1963) study, no significant differences were found between heritability estimates from the crossbred and purebred groups. Estimates of the genetic correlation between purebred and crossbred half-sib family means were found to be high, with a mean of 1.0 for the 12 correlations calculated. This indicated that mass selection in purebred populations would be effective in improving crossbred performance. Koger et al. (1975) reported the results of two trials to evaluate specific combining ability of beef sires for birthweight, preweaning condition score, 205-day weight, and postweaning gain ratio. The first trial involved 30 Angus sires with a total of 683 purebred and crossbred progeny, and the second trial consisted of 21 Angus, Brahman, and Hereford sires with 1,400 purebred and crossbred progeny records. Average heritability estimates for purebred, Angus-Hereford crosses, and Brahman-British crosses were .37, .41, and .32, respectively. These agreed generally with the findings of Miguel and Cartwright (1963) and Dunn et a1. (1970). Sire by breed of dam 
interaction was found to be nonsignificant for all traits in this study, in agreement with the findings of Gregory et al. $(1965,1966 \mathrm{a}$, 1966b) and Jilek et al. (1968). Estimates of the genetic correlation between paternal half-sib families were generally high, averaging .96 , in agreement with correlations reported by Dunn et al. Although Benyshek (1979) reported evidence of significant sire by breed of dam interaction in his analys is of over 150,000 Limousin weaning weight records, most of the data reported for cattle would suggest that differences among sires of the same breed for specific combining ability are small. Therefore, evaluating sires on the basis of purebred or crossbred progeny should be of nearly equal effectiveness in improving additive genetic value.

Sheep

Basset and Shelton.(1966) reported similar heritability estimates for slaughter size and 120-day weight for purebred Rambouillet and Hampshire or Suffolk cross Rambouillet lambs, although a lower heritability estimate for birthweight in the crossbreds suggested a loss of additive genetic variance.

Salah et al. (1970) analyzed data from 44 Hampshire, Shropshire, Southdown, and Merino sires with a total of 1,008 purebred and crossbred progeny. They reported heritability estimates for weaning weight of $.26+.14$ and $.12+.10$ for the purebreds and crossbreds, respectively. These estimates did not differ significantly, despite a suspected underestimation of crossbred heritability. The genetic correlation between purebred and crossbred half-sib performance obtained from variance and covariance components was .82 . 
While Hupp et al. (1977) demonstrated recurrent selection to be effective for improving growth rate in sheep, the limited results available would suggest that selection based upon purebred performance would also effectively improve crossbred performance.

Swine

While more studies aimed at evaluating reciprocal recurrent selection for specific combining ability have been reported with swine than with cattle or sheep, results are somewhat conflicting and inconclusive.

Data from 56 sires of Minnesota swine lines having both purebred and crossbred progeny were used by Enfield and Rempel (1962) to estimate the covariance of sire effects in purebred and crossbred populations. They reported estimates of $-2.42+3.67$ for weaning weight, $.0040+.0018$ for average daily gain, and $.0005+.0007$ for probed backfat thickness. Estimates of heritability in the crossbreds were $-.17, .42$, and .07 for weaning weight, average daily gain and backfat thickness, respectively, lower than the literature estimates of .18 for weaning weight and .41 for backfat reported by Hutchens (1980), but comparable to that for average daily gain (.38).

Wilson et a1. (1962) analyzed data involving 45 boars with an average of 3.5 purebred and 2.5 crossbred daughters per sire. They obtained a measure of the relative performance of a boar's purebred and crossbred daughters by regression of their performance based on sire progeny group means. Traits investigated were number of pigs farrowed and weaned per litter and litter weights at birth and 56 days of age. Bowman (1960) demonstrated that a negative value for 
such a regression could only occur if overdominance were present, although a non-negative regression does not preclude overdominance. All four regressions reported by Wilson et al. (1962) were small and negative, but nonsignificant.

Robison et a1. (1964) reported a study involving data from 13 Duroc and Yorkshire boars with a mean of 36 purebred and 126 crossbred progeny per sire. Genetic correlations between purebred and crossbred half-sib family means were .22 and .72 for 140-day weight and .21 and 1.0 for probed backfat at 140 days of age for the Durocs and Yorkshires, respectively. Rank correlations for 140-day weight of .08 and .16 and for backfat thickness of .67 and .12 were found for Duroc and Yorkshire sires, respectively. It was also possible to calculate the genetic correlation between purebred and crossbred performance for number farrowed and number raised in the Durocs, each of five sires having a mean of six purebred and 28 crossbred daughters that produced litters. These correlations were -.74 and -1.0 , respectively, with corresponding rank correlations of -.70 for both traits.

Taylor et a1. (1965) estimated sire components of variance and covariance for litter size and weight at birth, 21 and 56 days of age in a study involving 35 boars, each with an average of 11.7 purebred daughters $(8.9$ producing crossbred litters and 2.8 producing purebred litters) and 1.7 crossbred daughters. The genetic correlation between this latter group and the two purebred groups was estimable in only three cases, due to negative variance component estimates. Genetic correlations of .185 for 7 itter weight at 21 days of age and of 
.612 for litter weight at 56 days of age between the purebred daughters having purebred litters and the crossbred daughters, and of .383 between the purebred daughters having crossbred litters and the crossbred daughters are reported. The fact that of the 12 covariance components all but two were negative suggested that non-additive gene effects may be important sources of variation in the traits studied.

Taken together, these results, particularly for litter traits, suggest that selection on the basis of purebred performance might be relatively ineffective in achieving improvement of crossbred populations.

Data from the study reported by Robison et a]. (1964) represented part of a larger data set involving 76 Duroc and Yorkshire sires with over 8,000 purebred and crossbred progeny records subsequently investigated by Louca and Robison (1967). Estimates of heritabilities and sire variance components in the purebred and crossbred populations were found to be markedly dissimilar for 154day weight. Heritability estimates for 154-day weight in the purebreds ranged from $.65+.24$ for females to $.81+.35$ for barrows, in contrast to estimates of $.00+.04$ and $.03+.04$ for crossbred females and barrows, respectively.

The sire component of variance represented 13.4 percent and 17.8 percent of total variation for purebred female and barrow pigs and .0 percent and .7 percent of total variance in the crossbreds. This indicated a rather large reduction in additive genetic variance and further questioned the effectiveness of purebred selection for improved crossbred performance. 
Stanislaw (1966) and Stanislaw et al. (1967) reported similar heritability estimates for postweaning average daily gain and probed backfat thickness in purebred and crossbred populations of swine totalling 6,686 individuals produced by 99 Duroc, Hampshire, and Beltsville No. 1 boars. However, a higher estimate of heritability of 56-day weight was found in the crossbreds than in the purebreds. Genetic parameter estimates reported allow calculation of the genetic correlation for 56-day weight, postweaning average daily gain and backfat thickness of $1.25, .33$, and .75 , respectively. Estimated sire components of covariance between purebred and crossbred populations were 1.61 for 56-day weight, .0013 for postweaning average daily gain and .0023 for backfat thickness, in contrast to the negative sire component estimates for weaning weight obtained by Enfield and Rempel (1962). Using the method described by Comstock (1961) to compare expected response in crossbreds from different methods of selection, Stanislaw's results reported in 1967 indicate that, while mass selection among the purebreds should result in greater improvement of crossbred 56-day weight and backfat thickness than reciprocal recurrent selection, the converse appears to be true for postweaning average daily gain. Stanislaw (1966) also pointed out that there was no similarity in the rank of sires based upon their purebred and crossbred progeny performance, and that boars selected on the basis of their performance in reciprocal recurrent selection programs would not necessarily be the same as those selected in intra-population selection schemes.

Standal (1968) published results of a study involving 39 Landrace and Yorkshire sires with a total of 2,701 purebred and crossbred 
progeny. Of 10 traits investigated (birth weight, 21-day weight, postweaning average daily gain, age at 90 kilograms, and six carcass traits), heritability estimates were on average higher in the crossbreds than the purebreds, with the exception of birth weight, where the converse was true. Significant sire by type of breeding (pureor cross-breeding) interactions, indicative of different ranking (or spacing) of sires based upon purebred or crossbred progeny performance, were found for pooled birth weight data, 21-day weight with Landrace as the sire breed, and four and five of six carcass traits in barrows and gilts, respectively. Estimates of the correlation between sire genotypes for purebred and crossbred performance ranged from .41 to 1.45, averaging .94 for all 10 traits. Estimation of the ratio of response in crossbred performance from mass selection in the purebreds to response from selection based upon crossbred performance for birth and 21-day weight, postweaning average daily gain, age at 90 kilograms, and backfat thickness demonstrated that reciprocal recurrent selection should be more effective than intra-population selection for all five traits where selection intensity is the same for both methods of selection. However, Comstock (1961) suggested the ratio of selection intensity of reciprocal recurrent to intrapopulation selection may range from .4 to .8 , being larger when programs are large. On the basis of Standal's data, a ratio of .67 would result in reciprocal recurrent selection being superior to intra-population selection for backfat thickness and 21-day weight on ly, and for backfat thickness alone if this ratio fell to .50. In addition, generation interval is not taken into account in this calculation and Standal estimated that for traits measurable on the 
live animal reciprocal recurrent selection would increase the generation interval 25 to 50 percent over that for purebred mass selection, reducing the advantage of reciprocal recurrent selection by the same amount. The author therefore concluded that, provided the additive genetic variance within the purebreds is high and the genetic correlation between purebred and crossbred progeny performance is close to unity, reciprocal recurrent selection probably has little to offer in terms of practical swine breeding.

Results of an experiment involving 181 sires with a total of 6,890 purebred and crossbred progeny conducted at the University of Minnesota between 1959 and 1971 have been reported by Rempel (1969), Wong (1969), Wong et al. (1971), and Shrestha (1974). Minnesota No. 1, No. 2, and No. 3 breeds of swine were used to compare the effectiveness of purebred and crossbred selection schemes in improving crossbred performance. Intra-population mass selection was employed exclusively in the Minnesota No. l's. Selection in the Minnesota No. 2 's was based upon the performance of the three breed cross $2(3 \times 1)$, and selection in the Minnesota No. 3's was based upon the performance of a single $3 \times 1$ cross. The criterion of selection in all cases was an index including number born alive, postweaning average daily gain, feed efficiency, and probed backfat thickness; with the exception that in the Minnesota No. 3's maternal performance (litter size and litter weight weaned) was the selection criteria in alternate years. Findings reported by Rempel (1969), Wong (1969), and Wong et al. (1971) agreed with those of Standal (1968), indicating the advantage of intra-population selection over reciprocal recurrent selection for 
improvement of crossbred swine. Estimates of heritability for weaning weight, postweaning average daily gain, backfat thickness, feed efficiency, litter size, and the index were not significantly different for the purebreds and crossbreds. The genetic covariances between crossbred and purebred paternal half-sibs were positive for all traits except weaning weight. The negative sire component of covariance obtained for weaning weight, while agreeing with that reported by Enfield and Rempel (1962), disagreed with that obtained by Stanislaw (1966) and Stanislaw et al. (1967). The genetic correlation of $.74+.26$ obtained for litter size differs from the large negative genetic correlation of -.74 for number farrowed and -1.0 for number raised found in the smaller study reported by Robison et al. (1964). Calculation of the expected ratio of genetic change in the crossbreds from intra-population selection and reciprocal recurrent selection indicated intra-population selection to be superior to reciprocal recurrent selection for a 11 traits except weaning weight, feed efficiency in one cross, and for postweaning average daily gain in another cross when selection intensity ratio rose to .8 .

Despite some contradictory findings discussed above, it would appear that, with the exception of lowly heritable traits, selection on the basis of purebred performance in swine should prove more practical than selection based upon crossbred progeny performance for increasing the efficiency of crossbred market hog production. However, given the importance of crossbreeding to the swine industry, there have been relatively few studies reported in the literature aimed at assessing these alternative selection procedures. This 
present study is the result of both the need for further clarification of this aspect of selection in swine and the availability of suitable data sets for analysis. 


\section{CHAPTER III}

\section{MATERIALS AND METHODS}

\section{Experimental Design}

The data used in this study were from two projects carried out by the Oklahoma State University Agricultural Experiment Station in cooperation with the USDA. These are project number 1444, titled Genetic Evaluation of Purebred and Crossbred Performance Involving Three Breeds of Swine, and project number H-1620, titled Improvement of Efficiency in the Production of Quality Pork. The two data sets (designated 1444 and 1620) have been analyzed separately in this study.

The first data set. (1444) consisted of purebred and crossbred 1itters produced by Duroc, Hampshire, and Yorkshire swine at the Fort Reno Experiment Station during the spring and fall farrowing seasons of 1971 and 1973. Details of this experiment have been reported by Johnson and Omtvedt (1973), Johnson et a1. (1973), and Young et a1. (1976a, 1976b). Each of approximately six boars of each breed were mated to two females of each breed each season to produce purebred and twobreed cross litters. While only gilt litters were farrowed in both spring seasons, about half of these gilts were retained to produce litters in the subsequent fall farrowing seasons. A different group of boars was used each breeding season.

Foundation herds consisting of approximately five boars and 30 sows of each of the chree breeds were maintained at the Stillwater 
Experimental Swine Farm. Duroc and Yorkshire herds were established in 1969 by sampling boars and gilts from several purebred herds. The Hampshire herd was formed by purchasing boars from several sources and mating them to females from the existing $0 \mathrm{~K} 14$ Hampshire research herd. New boars were introduced to each herd semi-annually in order to maintain a broad genetic base and minimize inbreeding.

Boars and gilts to be used for producing experiment 1444 litters at Fort Reno were selected from within the foundation herds on the basis of growth rate, probed backfat thickness, and soundness.

The second data set (1620) consisted of purebred and crossbred Titters produced by Duroc, Landrace, Spotted, and Yorkshire swine at the Stillwater Experimental Swine farm during the fall of 1976 and the spring and fall of 1977 and 1978. Details of this experiment have been reported by Gaugler (1980), Hutchens (1980), and Hutchens et al. (1981). Approximately four boars of each breed were mated at random to females of each breed to produce a total of approximately six purebred litters and four of each of the three possible two-breed cross litters each season. Females ranged from gilts to seventh parity sows. Boars were used for between one and four breeding seasons. The Duroc and Yorkshire foundation herds are as described for experiment 1444. The Landrace and Spotted herds were establ ished in the spring of 1976 with the purchase of four boars and 25 gilts of each breed from several different sources. One or more boars in each herd was replaced semi-annually in order to maintain a broad genetic base and minimize inbreeding. Replacement gilts were obtained by within herd selection based upon an index involving growth rate and probed backfat thickness. 
Management and Data Collection

In both experiments the breeding season extended over an eightweek period starting in mid May and mid November each year. Females were hand mated and maintained throughout gestation in pasture lots. Litters were farrowed in confinement during March and April (spring farrowing) and September and October (fall farrowing). Weights on all fully-formed piglets were recorded within 12 hours of birth.

Three to seven days after farrowing, females and their litters in experiment 1444 were moved to an open front nursery barn and housed at one litter to a pen. Litters in experiment 1620 were moved one to two weeks post-farrowing to either pasture lots holding three to four litters per lot or to an open front confinement building with one litter per pen. Piglets were allowed access to creep feed from 21 days of age and were weaned at approximately 42 days of age in both experiments. Individual pig weights were recorded at approximately 21 and 42 days of age in experiment 1444 and at 42 days of age only in experiment 1620. Actual weights were adjusted to a 21 or 42 day basis (Appendix A, Table XXII).

In experiment 1444 all male pigs were castrated after 42-day weights had been obtained, except in the spring and fall of 1971 when two males in each purebred litter were left intact. Therefore, postweaning records on intact males have not been included in the 1444 data set analyzed in this study. In experiment 1620 the majority of purebred litters and about half the crossbred litters contained two intact males in all five seasons and these records were included in the 1620 data set analyzed. 
Pigs were moved to a confinement finishing house for gain test at approximately two weeks postweaning in experiment 1444 and penned in groups of around 15 pigs per pen by breeding group. A one-week adjustment period was allowed before the pigs were weighed on test at approximately nine weeks of age. A 16 percent crude protein milosoybean meal ration was self-fed until average pig weight per pen was approximately 54.4 kilograms, after which a 14 percent crude protein ration was self-fed for the duration of the test period. Pigs were weighed off test weekly at 99.8 kilograms live weight, at which time gilts were probed for backfat thickness. The average of three ultrasonic probes taken approximately four centimeters from the midline at the area of the first rib, last rib, and last lumbar vertebra were used. Backfat thickness records on barrows were obtained by carcass measurement. On average 10 purebred and 46 crossbred barrows representing all possible breed groups were slaughtered for carcass evaluation each season. Measurements were taken down the midline in the same area as probed backfat measurements in the gilts and averaged. In experiment 1620, pigs were moved to either an open front confinement building with either 10 gilts or boars to a pen, or to pasture lots with approximately 50 gilts and barrows per 1ot. Pigs were weighed on gain test when moved at approximately two weeks postweaning (eight weeks of age). A 14 percent crude protein corn or milo based ration was self-fed for the duration of the test period. Gilts were weighed off test at 90.7 kilograms and boars and barrows at 99.8 kilograms 1 ive weight. A11 pigs were probed for backfat thickness as described for the gilts in experiment 1444 . 
Postweaning performance traits investigated in this study were average daily gain from the first day on test to 99.8 kilograms, and probed backfat thickness at 99.8 kilograms. Actual off test 1 ive weight, age, and backfat thickness was adjusted to a 99.8 kilogram basis (Appendix A, Tabie XXII).

The data sets analyzed in this study consist of the progeny records of all boars with two or more purebred and crossbred progeny. Tables II and III show the distribution of the number of sires and number of purebred and crossbred litters and progeny by sire breed for each trait analyzed in the two data sets. Tables XXIII to XXIX (Appendix $A$ ) show the same distribution by farrowing season for the two data sets.

\section{Statistical Analysis}

Models Used in Analyses.

The following model was assumed in analyzing individual pig birth weight, 21-day weight, and 42-day weight for the 1444 data set:

$$
\begin{aligned}
Y_{i j k \text { Imnopq }}= & \mu+F_{i}+x_{j}+T_{k}+B_{1}+D_{m}+P_{n}+S(F B)_{0 i 1} \\
& +F B_{i 1}+F D_{i m}+F P_{i n}+F T_{i k}+B P_{1 n}+D P_{m n} \\
& +F T_{n k}+X T_{j k}+B T_{1 k}+F B T_{i 1 k}+T S(F B)_{k 0} i 1 \\
& +B L_{p}+e_{i j k 1 \text { mnopq }}
\end{aligned}
$$

where:

$$
\begin{aligned}
y_{i j k 1 \mathrm{mnopq}}= & \text { observation on the } q^{\text {th }} \text { individual of the } k^{\text {th }} \text { type and } j^{\text {th }} \\
& \text { sex sired by the oth sire of the ith sire breed, having } \\
& \text { been born in the ith farrowing season with the pth litter } \\
& \text { size born and having an nth parity dam of the mth breed; }
\end{aligned}
$$


TABLE II

1444 DATA SET - NUMBER OF SIRES, LITTERS, AND PROGENY BY SIRE BREED FOR TRAITS ANALYZED

\begin{tabular}{|c|c|c|c|c|c|}
\hline \multirow{2}{*}{$\operatorname{Trait}(\mathrm{s})^{\mathrm{a}}$} & \multirow{2}{*}{$\begin{array}{l}\text { Sire } \\
\text { Breed }^{b}\end{array}$} & \multirow{2}{*}{$\begin{array}{l}\text { Number } \\
\text { of Sires }\end{array}$} & \multicolumn{3}{|c|}{ Number of Litters (Progeny) } \\
\hline & & & Purebred & Crossbred & Total \\
\hline BW & D & 22 & $45(393)$ & $78(728)$ & $123(1121)$ \\
\hline BW & $H$ & 22 & $44(369)$ & $70(680)$ & $114(1049)$ \\
\hline BW & $\gamma$ & 23 & $44(422)$ & $90(867)$ & $134(1289)$ \\
\hline BW & Total & 67 & $133(1184)$ & $238(2275)$ & $371(3459)$ \\
\hline$W 21 / 42$ & D & 22 & $42(216)$ & $77(560)$ & $119(776)$ \\
\hline W21/42 & H & 20 & $38(204)$ & $67(477)$ & $105(681)$ \\
\hline W21/42 & $\mathrm{Y}$ & 23 & $43(321)$ & $88(642)$ & $131(963)$ \\
\hline W21/42 & Tota 1 & 65 & $123(741)$ & $232(1679)$ & $355(2420)$ \\
\hline$A D G$ & $D$ & 22 & $41(182)$ & $78(520)$ & $119(702)$ \\
\hline$A D G$ & H & 20 & $38(159)$ & $67(420)$ & $105(579)$ \\
\hline$A D G$ & $Y$ & 23 & $43(257)$ & $88(572)$ & $131(829)$ \\
\hline$A D G$ & Total & 65 & $122(598)$ & $233(1512)$ & $355(2110)$ \\
\hline $\mathrm{BF}$ & D & 20 & $35(102)$ & $72(317)$ & $107(419)$ \\
\hline$B F$ & H & 17 & $34(90)$ & $57(229)$ & $91(379)$ \\
\hline$B F$ & Y & 22 & $47(751)$ & $83(326)$ & $124(477)$ \\
\hline $\mathrm{BF}$ & Total & 59 & $110(343)$ & $212(872)$ & $322(1215)$ \\
\hline
\end{tabular}

\footnotetext{
$a_{B W}=$ Birth Weight, $W 21 / 42=21-$ and 42 -day Weights, $A D G=$ Postweaning Avorage Daily Gain, $B F=$ Probed Backfat Thickness ar. $99.8 \mathrm{~kg}$. $b_{D}=$ Duroc, $H=$ Hampshire, $Y=$ Yorkshire.
} 
TABLE III

1620 DATA SET - NUMBER OF SIRES, LITTERS, AND

PROGENY BY SIRE BREED FOR TRAITS ANALYZED

\begin{tabular}{|c|c|c|c|c|c|}
\hline Trait (s) ${ }^{a}$ & $\begin{array}{l}\text { Sire } \\
\text { Breedb }\end{array}$ & $\begin{array}{l}\text { Number } \\
\text { of Sires }\end{array}$ & $\frac{\text { Number }}{\text { Purebred }}$ & $\frac{f \text { Litters ( }}{\text { Crossbred }}$ & $\frac{\text { geny) }}{\text { Tota } 1}$ \\
\hline BW & D & 10 & $28(295)$ & $65(641)$ & $93(936)$ \\
\hline BW & $L$ & 9 & $29(306)$ & $63(628)$ & $92(934)$ \\
\hline BW & $S$ & 8 & $24(214)$ & $55(641)$ & $79(855)$ \\
\hline BW & $Y$ & 8 & $23(259)$ & $64(630)$ & $87(889)$ \\
\hline BW & Total & 35 & $104(1074)$ & $247(2540)$ & $351(3614)$ \\
\hline W42 & D & 10 & $28(170)$ & $65(483)$ & $93(653)$ \\
\hline W42 & $L$ & 8 & $27(223)$ & $57(429)$ & $84(652)$ \\
\hline W42 & $S$ & 8 & $23(749)$ & $55(457)$ & $78(606)$ \\
\hline W42 & Y & 8 & $23(160)$ & $64(471)$ & $87(631)$ \\
\hline W42 & Total & 34 & $101(702)$ & $241(1840)$ & $342(2542)$ \\
\hline$A D G / B F$ & D & 10 & $26(127)$ & $63(297)$ & $89(424)$ \\
\hline$A D G / B F$ & $L$ & 8 & $26(141)$ & $56(258)$ & $82(399)$ \\
\hline$A D B / B F$ & $S$ & 8 & $22(106)$ & $55(272)$ & $77(378)$ \\
\hline$A D G / B F$ & $Y$ & 7 & $21(91)$ & $62(271)$ & $83(362)$ \\
\hline$A D G / B F$ & Total & 33 & $95(465)$ & $236(1098)$ & $331(1563)$ \\
\hline
\end{tabular}

$a_{B W}=$ Birth Weight, $W 42=42$-day Weight, $A D G / B F=$ Postweaning Average Daily Gain and Probed Backfat Thickness at $99.8 \mathrm{~kg}$.

$b_{D}=$ Duroc, $L=$ Landrace, $S=$ Spotted, $Y=$ Yorkshire. 
$\mu=$ population mean;

$F_{i}=$ fixed effect of the $i$ th farrowing season, $i=1,2,3,4$;

$x_{j}=$ fixed effect of the $j$ th' sex $^{\prime} j=1,2$;

$T_{k}=\begin{gathered}\text { fixed effect of the } k \text { th type, } \\ \text { bred); }\end{gathered}$

$B_{1}=$ fixed effect of the 1 th breed of sire, $1=1,2,3$;

$D_{m}=$ fixed effect of the $m^{\text {th }}$ breed of dam, $m=1,2,3$;

$P_{n}=$ fixed effect of the $n$th parity, $n=1,2$; $\begin{aligned} S(F B)_{0 i 1}= & \text { random effect of the } o^{\text {th }} \text { sire within the } i^{\text {th }} \text { farrowing } \\ \text { season and } 1 \text { th sire breed; } & \end{aligned}$

$\begin{aligned} & F B_{i 1}=\text { interaction of the } i^{\text {th }} \text { farrowing season and the } i^{\text {th }} \text { breed } \\ & \text { of sire; }\end{aligned}$

$\begin{aligned} & F D_{i m} \text { interaction of the } i \text { th farrowing season and the } m^{\text {th }} \text { breed } \\ & \text { of dam; }\end{aligned}$

$\mathrm{FP}_{\text {in }}=$ interaction of the $i^{\text {th }}$ farrowing season and the $n^{\text {th }}$ parity;

$\mathrm{FT}_{i k}=$ interaction of the $i^{\text {th }}$ farrowing season and the $k^{\text {th }}$ type;

$\mathrm{BP}_{1 \mathrm{n}}=$ interaction of the $7^{\text {th }}$ breed of sire and the $n^{\text {th }}$ parity;

$\mathrm{DP}_{\mathrm{mn}}=$ interaction of the $\mathrm{m}^{\text {th }}$ breed of dam and the $\mathrm{n}^{\text {th }}$ parity;

$P T_{n k}=$ interaction of the $n^{\text {th }}$ parity and the $k^{\text {th }}$ type;

$X T_{j k}=$ interaction of the $j^{\text {th }}$ sex and the $k^{\text {th }}$ type;

$B T_{7 k}=$ interaction of the $1^{\text {th }}$ breed of sire and the $k^{\text {th }}$ type;

$\mathrm{FBT}_{i 1 \mathrm{~K}}=$ interaction of the ${ }^{\text {th }}$ farrowing season and the $7^{\text {th }}$ breed of sire and the $k^{\text {th }}$ type;

$\begin{aligned} T S(F B)_{k 0 i 1}= & \text { interaction of the } k^{\text {th }} \text { type and the } o^{\text {th }} \text { sire within the } \\ & i \text { th farrowing season and the } 7_{\text {th }} \text { sire breed; }\end{aligned}$

$\beta L_{p}=1$ inear effect due to the $p^{\text {th }}$ litter size born;

$e_{i j k 1 \mathrm{mnopq}}=$ random error associated with the $i j k 1 \mathrm{mnopq}$ th record.

The model assumed in analyzing postweaning average daily gain and probed backfat thickness at 99.8 kilograms for the 1444 data set 
included a year-season farrowed by sex interaction term but did not include the covariable litter size born. In all other respects, the model was the same as that for the preweaning traits.

Similar preweaning and postweaning models were used in analyzing pig birth weight, 42-day weight, postweaning average daily gain, and probed backfat thickness at 99.8 kilograms for the 1620 data set. Sire nested within breed of sire replaced sire nested within yearseason farrowed by breed of sire, and the year-season by breed of sire by type interaction term was dropped from all models. Changes in the levels of main effects were $i=1,2,3,4,5 ; j=1,2,3 ; 1=1,2,3,4 ; m=1,2,3,4$; and $n=1,2,3$ ( $n=3$ representing all parities greater than the second). Apart from these differences, all the remaining terms in both models are as defined in the corresponding 1444 data set models.

The Statistical Analysis System (SAS) general linear models procedure for type III sums of squares was used to conduct preliminary analyses in which the interaction of breed of dam and type and the interactions of sex and year-season farrowed, breed of sire, breed of dam, and parity were included in the models. With the exception of sex by year-season farrowed in postweaning models, these fixed effects did not remove significant amounts of variation and were therefore not included in the final models.

\section{Variance Component Estimation}

Sire, sire by type interaction, and residual variance components were estimated for the following individual pig traits: birth weight, 21-day weight (1444 data set only), 42-day weight, postweaning average daily gain, and probed backfat thickness at 99.8 kilograms. 
These estimates were obtained using the SAS general 1 inear models (GLM) procedure for type II sums of squares (Barr et al., 1976; Helwig and Council, 1979). Sire and sire by type interaction were specified as random effects in the model, and variance components were estimated by equating type II mean squares to their expected values.

Variance component estimates obtained in this way were found to be identical to estimates obtained using a Fortran program developed by Hintz (unpublished, 1979) to obtain estimates by Henderson's Method 3 (after Henderson, 1953). Also known as the "fitting constants method," Henderson's Method 3 for variance component estimation utilizes reductions in sums of squares due to fitting both the full model and different sub-models. By equating these reductions to their expected values under the full model, unbiased variance component estimates are obtained from a mixed model analysis, even though certain elements of the model are correlated (Henderson, 1953). Thus, the variance component estimates obtained by using the SAS GLM procedure are unbiased estimates.

\section{Heritability Estimation}

Paternal half-sib estimates of heritability were calculated separately for both purebred and crossbred populations according to the formula:

$$
\hat{n}_{x}^{2}=\frac{4 V_{s}}{V_{s}+V_{e}}
$$


where

$$
\begin{aligned}
& \hat{h}_{x}^{2}=\text { heritability estimate of trait } x ; \\
& V_{s}=\text { estimated sire component of variance for trait } x ; \\
& V_{e}=\text { estimated residual component of variance for trait } x ;
\end{aligned}
$$

and for the complete data sets (including both purebred and crossbred progeny) by the formula:

$$
\hat{n}_{x}^{2}=\frac{4 V_{s}}{V_{s}+V_{s t}+V_{e}}
$$

where $V_{s t}=$ estimated sire by type component of variance for trait $X$ and the other terms are defined as above.

Models used to obtain the above variance component estimates were as described above with breed of dam and interaction terms including breed of dam deleted for purebred analyses, and type and type interaction terms deleted for both purebred and crossbred analyses.

Approximate standard errors of the heritability estimates were calculated using the formula given by Swiger et a1. (1964):

$$
V\left(\hat{h}^{2}\right)=\frac{1}{a_{i i^{\prime}}^{2}} \cdot\left[\frac{2(n \cdot-1)(1-t)^{2} \cdot(1+(k-1) t)^{2}}{k^{2}(n \cdot-s)(s-1)}\right]
$$

where

$$
\begin{aligned}
n .-1 & =\text { corrected total d.f. } \\
s-1 & =\text { sire d.f. } \\
n .-s & =\text { error d.f. } \\
k & =\text { sire } k \text { value from expected mean squares } \\
t & =\frac{V_{s}}{V_{s}} V_{e}^{-} \text {or } \frac{V_{s}}{V_{s} V_{s t}+V_{e}} \\
a_{i j}{ }^{\prime} & =\text { the additive relationship between members of each sire } \\
& \text { group }=.25 .
\end{aligned}
$$


This formula does not take into account adjustments made for fixed effects, and as such yields minimum estimates of these standard errors (Vesely and Robinson, 1970).

Best Linear Unbiased Predictors of Sire Breeding Value

The linear model assumed in the analyses was:

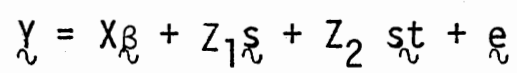

where

$\stackrel{y}{\sim}$ is a vector of observations;

$X$ is a known design matrix of fixed effects;

$\beta$ is an unknown vector of fixed effects;

$Z_{1}$ is a known design matrix for sires;

$Z_{2}$ is a known design matrix for sire $x$ type interaction;

$s$ is a random vector of one-half the additive genetic effect of the sires, having a multivariate distribution with mean zero and a non-singular variance-covariance matrix $G_{7}$;

st is a random vector of one-half the additive genetic effect of sire by type interaction deviations, having a multivariate distribution with mean zero and a non-singular variancecovariance matrix G2;

e is a random vector of residual effects including environmental and other genetic effects having a multivariate distribution with mean zero and a non-singular variance-covariance matrix $R$; and

s and st are uncorrelated with e but correlated with each other, $\left.\operatorname{cov} Y_{s, s t}\right)=$ one-half the sire component of variance. 
Assuming that the elements of e are uncorrelated and that all records have a common variance, $V_{e}$, then the solution of the equations:

$$
\left[\begin{array}{cccc}
x^{\prime} x & x^{\prime} z_{1} & x^{\prime} z_{2} \\
z_{1}^{\prime} x & z_{1}^{\prime} z_{1}+A_{1}^{-1} \frac{v_{e}}{v_{s}} & z_{1}^{\prime} z_{2}+c^{-1} \frac{v_{e}}{v_{s}} \\
z_{2}^{\prime} x & z_{2}^{\prime} z_{1}+c^{\prime}-1 \frac{v_{e}}{v_{s}} & z_{2}^{\prime} z_{2}+A_{2}^{-1} \frac{v_{e}}{v_{s t}}
\end{array}\right] \cdot\left[\begin{array}{c}
\hat{\beta} \\
\hat{s} \\
\sim \\
\hat{s}_{\sim}^{t} \\
z^{\prime} y \\
z \\
z^{\prime} y \\
2^{v}
\end{array}\right]
$$

where $A_{7}, A_{2}$, and $C$ are as defined in Appendix $B$ and $V_{e}, V_{s}$, and $V_{s t}$ represent the residual, sire, and sire by type interaction variance component estimates respectively; yields $\underset{\sim}{\hat{\beta}}$ as the best 1 inear unbiased estimates (BLUE) of functions of the fixed effects (Henderson et al.. 1959; Henderson, 1973), and $\hat{\sim}$ and $\hat{s t}$ as the best linear unbiased predictors (BLUP) of the random effects (Henderson, 1963, 1973) for the class of linear models assumed.

Estimates of the residual to sire variance component ratios were obtained from literature heritability estimates. The absence of literature estimates for the residual to sire by type interaction variance component ratios resulted in ratios obtained from analyses in this study being added to the diagonal of the respective equations. Heritabilities and variance component ratios used are given in Appendix A (Table XXX).

Given the size of the matrices involves, solutions were obtained by iteration in order to save computer time. 
In addition, solutions were also obtained after making further simplifying assumptions--namely, assuming no covariance between the sire and sire by type effects, and assuming $G_{2}$ to be $I V_{s t}$ where I is an identity matrix with order equal to the number of sire by type subclasses and $V_{s t}$ is equal to the variance component for this interaction. These further assumptions allowed the above equations to be simplified to:

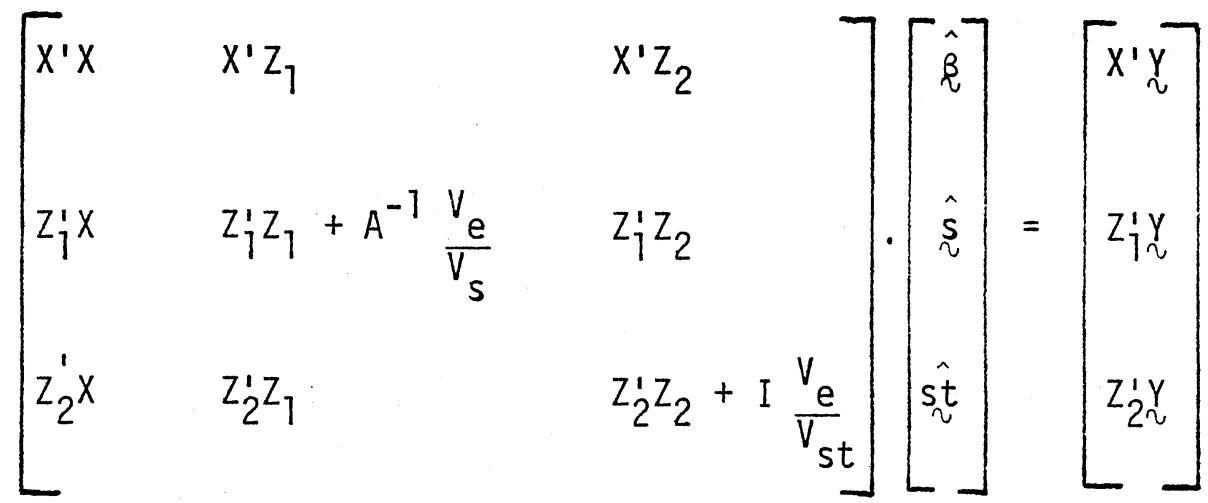

where $A$ is the additive relationship matrix of the sires and is simply I for the 1620 data set. In this case, the direct inverse was utilized to obtain solutions, the assumption of no covariance between the sire and sire by type interaction effects allowing absorbtion of the interaction equations to save computer time. Solutions obtained by this method were used as priors for the iteration method.

Fixed effects were examined by the use of reduction sums of squares. The effect of adding one fixed effect to the model over and above having the remaining fixed effects in it was tested by the $F$ test, where the sums of squares for the added fixed effects were calculated by the difference in reductions of the total model and of the total model excluding the fixed effect of interest. Differences among means were tested, utilizing the $t$ test, only where the overall 
$F$ test for the effect proved significant at the five percent level. This procedure is a protected form of the least significant difference (LSD) procedure (Snedecor and Cochran, 1967).

Computer programs developed by Hintz (unpublished, 1979) were used for the above mixed model analyses.

Genetic and Rank Correlation Estimation

Falconer (1952) extended the concept of genetic correlation between traits by proposing that the phenotypic expressions of the same genotype in two different environments be considered as two different traits, since the genes that control a character in one environment may be different, at least in part, from those that control the character in the other.

The intra-class method for determining genetic correlation in terms of genetic and genotype by environment variance components from two-way classification analysis of variance was presented by Dickerson (1962) and further discussed by Yamada (1962). Use of this method to estimate the correlation between sire breeding values obtained in two or more environments has been reported by Vesely and Robinson (1970), Pani et a1. (1973), Koger et a1. (1975), Sorensen (1977), Nunn et a1. (1978), Buchanan and Nielsen (1979), Tanjik and Horst (1979), Tess et a]. (1979), and Massey and Benyshek (1981).

Considering the expression of a sire's genotype in purebred and crossbred progeny as two different traits, then the intra-class correlation of sire breeding values across environments, where the expected mean square for sires contains the interaction component, may be estimated as: 


$$
r_{g}=\frac{v_{s}}{v_{s}+V_{s t}}
$$

where $V_{s}$ and $V_{s t}$ represent the estimated sire and sire by type interaction components of variance, respectively (Yamada, 1962).

By definition, the product-moment genetic correlation between measurements under two environments is estimated by:

$$
r_{g}=\frac{\operatorname{cov}_{G_{12}}}{\left(V_{G_{1}} \cdot V_{G_{2}}\right)^{1 / 2}}
$$

where $\operatorname{coV}_{G_{12}}, V_{G_{1}}$, and $V_{G_{2}}$ represent the estimated genetic covariance and variances, respectively.

However, expressing the formula for intra-class correlation in terms of variance and covariance components, then:

$$
\begin{aligned}
& r_{g}=\frac{V_{s}}{V_{s}+V_{s t}}=\frac{\operatorname{cov}_{G_{12}}}{1 / 2\left(V_{G_{1}}+V_{G_{2}}\right)} \\
& \text { (Yamada, 1962) }
\end{aligned}
$$

Thus, if the two between group genetic variances are not equal, the interaction variance component is inflated by any effects of the environments on the scaling of genetic effects, resulting in underestimation of the true product-moment genetic correlation (Dickerson, 1962; Yamada, 1962).

By taking the differences in the denominators of formulae (1) and (2) into consideration, that is:

$$
1 / 2\left(V_{G_{1}}+V_{G_{2}}\right)-\left(V_{G_{1}} \cdot V_{G_{2}}\right)^{1 / 2}=1 / 2\left(V_{G_{1}}{ }^{1 / 2}-V_{G_{2}}{ }^{1 / 2}\right)^{2}
$$


the interaction component can be corrected for this bias. The adjusted intra-class correlation calculated as:

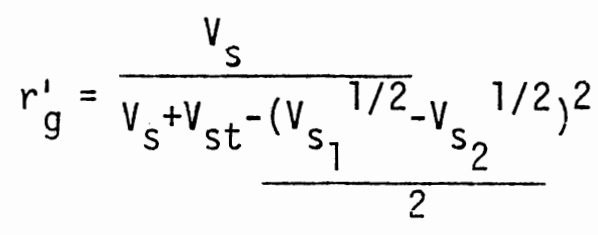

will give the same result as the product-moment genetic correlation (Dickerson, 1962; Yamada, 1962).

This formula was therefore used to obtain estimates of the genetic correlation between purebred and crossbred progeny of the same sire. Approximate standard errors associated with these estimates were calculated according to the formula presented by Robertson (1959):

$$
V\left(r_{g}\right)=\frac{\left[n t\left(1-r_{g}{ }^{2}\right)+(1-t)\right]^{2}+r_{g}^{2}(1-t)^{2}}{(N-1) n^{2} t^{2}}+\frac{r_{g}{ }^{2}(1-t)^{2}}{N(n-1) n^{2} t^{2}}
$$

where $V\left(r_{g}\right)=$ variance of the intra-class correlation estimate

$$
\begin{aligned}
N-1= & \text { sire d.f. } \\
N(n-1)= & \text { residual d.f. } \\
n= & k-\text { value for the sire by type interaction variance } \\
& \text { component } \\
t= & \begin{array}{l}
\text { intra-class correlation, assumed to be the same in } \\
\text { both environments and calculated as: }
\end{array}
\end{aligned}
$$

$$
\frac{v_{s}}{V_{s}+V_{s t}+V_{e}}
$$

The genetic correlation between purebred and crossbred progeny of the same sire was also estimated as the product-moment correlation between sire BLUPs of breeding value for purebred and crossbred progeny. 
For the 1444 data set these breeding values were calculated as:

$$
\text { B.V. }=\hat{S}(F B)_{0 i 1}+\hat{T S}(F B)_{k o i l}+\hat{F B T} \hat{T}_{i 1 k}
$$

where,

$\hat{S}(F B)_{0 i 1}=$ BLUP of one-half of the additive genetic effect of the $0^{\text {th }}$ sire within the $i_{\text {th }}$ farrowing season and $7^{\text {th }}$ sire breed;

$T S(F B)_{\text {koil }}=$ BLUP of one-half of the additive genetic effect of the interaction of the $k$ th type and oth sire nested as above;

$\hat{F B T}_{i 1 k}=$ BLUE of the fixed effect of the interaction of the $i$ th farrowing season with the 7 th breed of sire and the $k^{\text {th }}$ type.

For the 1620 data set, breeding values were calculated as:

$$
\text { B.V. }=\hat{S}(B)_{01}+\hat{T S}(B)_{k 01}+\hat{B T}_{1 k}
$$

where,

$$
\begin{aligned}
\hat{S}(B)_{01}= & \begin{array}{l}
\text { BLUP of one-half of the additive genetic effect of the } \\
\text { oth sire vithin the } 1 \text { th sire breed; }
\end{array} \\
\hat{T S}(B)_{k 01}= & \begin{array}{l}
\text { BLUP of one-half of the additive genetic effect of the } \\
\text { interaction of the kth type and oth sire nested within } \\
\text { breed of sire; }
\end{array} \\
\hat{B T}_{1 k}= & \begin{array}{l}
\text { BLUE of the fixed effect of the interaction of the } 1 \text { th } \\
\text { breed of sire and the } k \text { th type. }
\end{array}
\end{aligned}
$$

In addition to calculating the correlation between breeding values, sires were ranked based upon their breeding values for purebred and crossbred progeny and the Spearman-rho correlation coefficient between sire rankings calculated. 
CHAPTER IV

\section{RESULTS AND DISCUSSION}

\section{Analyses of Variance for Fixed Effects}

The analyses of variance for individual pig birth weight, 21-day weight, 42-day weight, postweaning average daily gain, and probed backfat thickness at 99.8 kilograms are presented in Tables IV-VIII.

\section{Main Effects}

Year-season farrowed, sex, and breed of dam accounted for a significant amount of variation for all traits in both data sets, with the exceptions of sex for 21-day weight and breed of dam for 42-day weight in the 1444 data set. Type accounted for a significant amount of variation for all traits with the exceptions of birth weight in the 1444 data set and probed backfat in both data sets, approaching significance $(P<.10)$ in these cases. Parity was significant for a11 preweaning traits in both data sets, but for postweaning traits in the 1620 data set only. Breed of sire explained a significant amount of variation for probed backfat only, failing to approach significance $(P>.10)$ for all other traits except average daily gain in the 1444 data set.

\section{Interactions}

Year-season by breed of dam interaction was significant for al1 


\section{TABLE IV}

GENERALIZED LEAST SQUARES ANALYSES OF VARIANCE FOR FIXED EFFECTS FOR PIG BIRTH WEIGHT

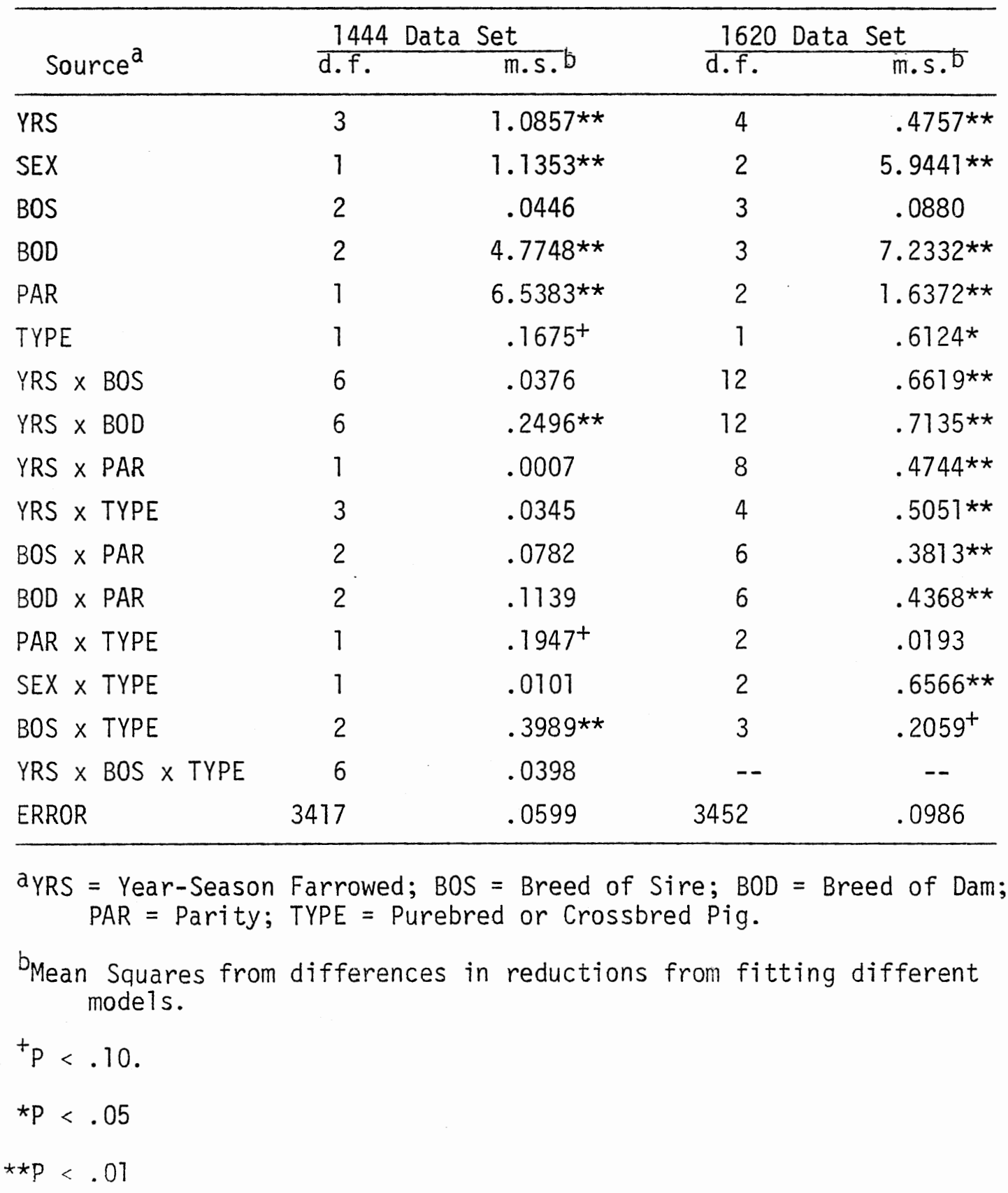


TABLE $V$

GENERALIZED LEAST SQUARES ANALYSIS OF VARIANCE FOR FIXED EFFECTS FOR 27-DAY PIG WEIGHTC

\begin{tabular}{|c|c|c|}
\hline Source ${ }^{a}$ & d.f. & m.s.b \\
\hline YRS & 3 & $9.8055 * \star$ \\
\hline SEX & 1 & 1.0109 \\
\hline BOS & 2 & .5273 \\
\hline BOD & 2 & $18.3035 * *$ \\
\hline PAR & 1 & $44.4557 * \star$ \\
\hline TYPE & 1 & $6.2094 *$ \\
\hline YRS $\times$ BOS & 6 & 1.0577 \\
\hline YRS $\times$ BOD & 6 & $4.7083^{* *}$ \\
\hline YRS $\times$ PAR & 1 & $12.3563^{\star \star *}$ \\
\hline YRS $\times$ TYPE & 3 & 1.0022 \\
\hline BOS $\times$ PAR & 2 & $10.5422 * \star$ \\
\hline$B O D \times P A R$ & 2 & .3853 \\
\hline PAR $\times$ TYPE & 1 & 1.1608 \\
\hline SEX $\times$ TYPE & 1 & .0007 \\
\hline BOS $\times$ TYPE & 2 & 1.4191 \\
\hline YRS $\times$ BOS $\times$ TYPE & 6 & .9555 \\
\hline ERROR & 2445 & 1.1829 \\
\hline \multirow{2}{*}{\multicolumn{3}{|c|}{$\begin{array}{l}\text { aYRS = Year-Season Farrowed; BOS = Breed of Sire; BOD = Breed of } \\
\text { Dam; PAR = Parity; TYPE = Purebred or Crossbred pig. } \\
\text { b } \\
\text { Dean Squares from differences in reductions from fitting differ- } \\
\text { ent models. }\end{array}$}} \\
\hline & & \\
\hline \multicolumn{3}{|c|}{${ }^{{ }^{c}} 7444$ data set only } \\
\hline \multicolumn{3}{|l|}{${ }^{i} p<.10$} \\
\hline \multicolumn{3}{|l|}{$\star p<.05$} \\
\hline$* P<.01$ & & \\
\hline
\end{tabular}


TABLE VI

GENERAL IZED LEAST SQUARES ANALYSES OF VARIANCE

FOR FIXED EFFECTS FOR 42-DAY PIG WEIGHT

\begin{tabular}{|c|c|c|c|c|}
\hline \multirow[b]{2}{*}{ Source ${ }^{a}$} & \multicolumn{2}{|c|}{1444 Data Set } & \multicolumn{2}{|c|}{1620 Data Set } \\
\hline & d.f. & m.s.b & d.f. & m.s. \\
\hline YRS & 3 & $56.1467 * \star$ & 4 & $92.6182 * \star$ \\
\hline SEX & 1 & $31.5018 *$ & 2 & $439.6896 * *$ \\
\hline BOS & 2 & 4.7293 & 3 & 3.7063 \\
\hline BOD & 2 & .5578 & 3 & $47.2642 * \star$ \\
\hline PAR & 1 & 134.9781 ** & 2 & $144.6235^{\star \star *}$ \\
\hline TYPE & 1 & $58.7879 * *$ & 1 & $87.3682 * \star$ \\
\hline YRS $\times$ BOS & 6 & 1.1000 & 12 & 9.9948 \\
\hline YRS $\times B O D$ & 6 & $37.6529 * *$ & 12 & $15.9307^{\star \star}$ \\
\hline YRS $\times$ PAR & 1 & $48.6149 * *$ & 8 & $45.1994 * *$ \\
\hline YRS $\times$ TYPE & 3 & .6139 & 4 & 11.5609 \\
\hline BOS $\times$ PAR & 2 & 5.5736 & 6 & $13.4217 *$ \\
\hline$B O D \times P A R$ & 2. & .4700 & 6 & 4.1344 \\
\hline PAR $\times$ TYPE & 1 & 14.7534 & 2 & $15.9716^{+}$ \\
\hline SEX $\times$ TYPE & 1 & .0017 & 2 & 5.2717 \\
\hline BOS X TYPE & 2 & $24.7269 *$ & 3 & 6.2365 \\
\hline YRS $\times$ BOS $\times$ TYPE & 6 & 3.7610 & -- & -- \\
\hline ERROR & 2379 & 5.5446 & 2470 & 6.2124 \\
\hline
\end{tabular}

$a_{Y R S}=$ Year-Season Farrowed $;$ BOS $=$ Breed of Sire; BOD $=$ Breed of Dam; PAR = Parity; TYPE = purebred or crossbred pig.

bMean Squares from differences in reductions from fitting different models.

${ }^{+} p<.10$

$* \mathrm{P}<.05$

$\star * P<.01$ 
TABLE VII

GENERALIZED LEAST SQUARES ANALYSES OF VARIANCE FOR FIXED EFFECTS FOR POSTWEANING AVERAGE DAILY GAIN

\begin{tabular}{|c|c|c|c|c|}
\hline \multirow[b]{2}{*}{ Source ${ }^{a}$} & \multicolumn{2}{|c|}{1444 Data Set } & \multicolumn{2}{|c|}{1620 Data Set } \\
\hline & d.f. & m.s. & d.f. & m.s. \\
\hline YRS & 3 & $.0537 * \star$ & 4 & $.2640 * \star$ \\
\hline SEX & 1 & $1.7964 * \star$ & 2 & $.6898 * *$ \\
\hline BOS & 2 & $.0148^{+}$ & 3 & .0012 \\
\hline BOD & 2 & $.1027 \star \star$ & 3 & $.0394 * \star$ \\
\hline PAR & 1 & .0004 & 2 & $.0217 *$ \\
\hline TYPE & 1 & $.5484 \star \star$ & 1 & $.4003 * \star$ \\
\hline YRS $\times$ BOS & 6 & .0071 & 12 & $.0179 * *$ \\
\hline YRS $\times B O D$ & 6 & $.0303^{* *}$ & 12 & $.0127 *$ \\
\hline YRS $\times$ PAR & 1 & .0121 & 8 & $.0176 * \star$ \\
\hline YRS $\times$ TYPE & 3 & $.0182 *$ & 4 & $.0298 * *$ \\
\hline BOS $\times$ PAR & 2 & .0010 & 6 & $.0196 * \star$ \\
\hline BOD $\times P A R$ & 2 & $.0312 \star \star$ & 6 & .0112 \\
\hline PAR $\times$ TYPE & 1 & .0087 & 2 & $.0461 * *$ \\
\hline SEX $\times$ TYPE & 1 & .0048 & 2 & $.0244 *$ \\
\hline BOS $\times$ TYPE & 2 & $.0283^{\star}$ & 3 & $.0174 *$ \\
\hline YRS $\times$ SEX & 3 & .0062 & 8 & $.0351 * *$ \\
\hline YRS $\times$ BOS $\times$ TYPE & 6 & .0083 & -- & -- \\
\hline ERROR & 2069 & .0064 & 1484 & .0066 \\
\hline
\end{tabular}

aYRS = Year-Season Farrowed; BOS = Breed of Sire; BOD = Breed of Dam; PAR = Parity; TYPE = purebred or crossbred pig.

bean Squares from differences in reductions from fitting different models.

${ }^{+} p<.10$

$* P<.05$

$\star \star P<.01$ 
TABLE VIII

GENERALIZED LEAST SQUARES ANALYSES OF VARIANCE

FOR FIXED EFFECTS FOR PROBED BACKFAT THICK-

NESS AT 99.8 KILOGRAMS

\begin{tabular}{|c|c|c|c|c|}
\hline \multirow[b]{2}{*}{ Source ${ }^{\mathrm{a}}$} & \multicolumn{2}{|c|}{1444 Data Set } & \multicolumn{2}{|c|}{1620 Data Set } \\
\hline & d.f. & m.s.b & d.f. & m.s.b \\
\hline YRS & 3 & $585.56 * *$ & 4 & $960.76 * \star$ \\
\hline SEX & 1 & $1444.93 * *$ & 2 & $3349.46 * *$ \\
\hline BOS & 2 & $171.87 * *$ & 3 & $96.15^{\star \star *}$ \\
\hline BOD & 2 & $124.97 * *$ & 3 & $86.76^{* *}$ \\
\hline PAR & 1 & 7.60 & 2 & $133.88 * *$ \\
\hline TYPE & 1 & $47.19^{+}$ & 1 & $39.79^{+}$ \\
\hline YRS $\times$ BOS & 6 & 5.12 & 12 & $20.66^{*}$ \\
\hline YRS $\times B O D$ & 6 & $47.35 \star \star$ & 12 & $35.00 * *$ \\
\hline YRS $\times$ PAR & 1 & 33.50 & 8 & $49.40 * \star$ \\
\hline YRS $\times$ TYPE & 3 & 25.64 & 4 & 21.43 \\
\hline BOS $\times$ PAR & 2. & 1.76 & 6 & $21.93^{+}$ \\
\hline$B O D \times P A R$ & 2 & 7.53 & 6 & $58.49 * *$ \\
\hline PAR $\times$ TYPE & 1 & 8.32 & 2 & 6.58 \\
\hline SEX $\times$ TYPE & 1 & 7.97 & 2 & 9.30 \\
\hline BOS $\times$ TYPE & 2 & $57.65^{* *}$ & 3 & 10.17 \\
\hline YRS $\times$ SEX & 3 & 19.71 & 8 & $26.76^{*}$ \\
\hline YRS $\times$ BOS $\times$ TYPE & 6 & $23.45^{+}$ & -- & -- \\
\hline ERROR & 1171 & 12.40 & 1484 & 11.82 \\
\hline
\end{tabular}

aYRS $_{\text {Y }}$ Year-Season Farrowed; BOS = Breed of Sire; BOD = Breed of Dam; PAR = Parity; TYPE = purebred or crossbred pig.

b Mean Squares from differences in reduction from fitting different models.

$t_{p}<.10$

$* P<.05$

$\star \star P<.01$ 
traits in both data sets. Year-season by breed of sire interaction was significant in the 1620 data set for birth and the postweaning traits, but failed to reach significance for any trait in the 1444 data set. Year-season by parity interaction was significant for all preweaning traits in both data sets, with the exception of birth weight in the 1444 data set, and significant for postweaning average daily gain and probed backfat thickness in the 1620 data set. Yearseason by type interaction failed to reach significance except for postweaning average daily gain in both data sets and birth weight in the 1444 data set. Year-season by sex interaction was significant only for postweaning traits in the 1620 data set. Breed of sire by parity interaction was significant for preweaning traits and postweaning average daily gain in the 1620 data set, but only for 21-day weight in the 1444 data set. Breed of dam by parity interaction reached significance for postweaning average daily gain in the 1444 data set, and for birth weight and probed backfat thickness in the 1620 data set. Sex by type interaction was significant for birth weight and postweaning average daily gain in the 1620 data set, parity by type interaction for only average daily gain in the 1620 data set. Breed of sire by type interaction was significant for birth weight, 42-day weight, postweaning average daily gain, and probed backfat thickness in the 1444 data set, but for only average daily gain in the 1620 data set.

Generalized Least Squares Means for Genetic Effects

The genetic fixed effects included in the analyses of variance were breed of sire, breed of dam, and type (purebred and crossbred). 
Breed of Dam

Generalized least squares means for breed of dam are presented in Table IX.

Breed of dam by parity interaction was significant for postweaning average daily gain in the 1444 data set, and for birth weight and probed backfat thickness in the 1620 data set. Parity, however, did not represent a significant main effect for any of these traits. Breed of dam by year-season farrowed interaction was significant for a11 traits in both data sets. However, with the exceptions of one year-season for postweaning average daily gain and probed backfat thickness in both data sets, dam breeds ranked either the same as or not significantiy different from main effect breed of dam ranking. Hence, main effect means are presented in Table IX, despite significant interactions.

In the 1444 data set, pigs with Hampshire dams were significantly heavier at birth than those with Duroc dams, and these in turn were significantiy heavier at birth than those with Yorkshire dams. Dam breed means for birth weight were also significantly different between al1 breeds in the 1620 data set. Ranking from heaviest to Tightest was Landrace, Duroc, Spotted, and Yorkshire. While Hampshire and Yorkshire dams did not differ from each other significantly for pig 21-day weight in the 1444 data set, both had significantly heavier pigs than Duroc dams. Landrace, Duroc, and Spotted dams in the 1620 data set failed to differ significantly from each other for 42-day pig weight, although the difference between Landrace and Duroc means $(P=.105)$ and Landrace and Spotted means $(P=.122)$ approached significance. All three dam breeds had significantly higher means than 
TABLE IX

BREED OF DAM GENERALIZED LEAST SQUARES MEANS

\begin{tabular}{lcccccc}
\hline \multirow{2}{*}{ Trait $^{+}$} & Data & Set & \multicolumn{5}{c}{ Buroc } & York & Hamp & Landrace & Spot \\
\hline BW & 1444 & $1.27 \pm .02^{\mathrm{a}}$ & $1.14 \pm .02^{\mathrm{b}}$ & $1.31 \pm .02^{\mathrm{c}}$ & -- & - \\
BW & 1620 & $1.45 \pm .02^{\mathrm{a}}$ & $1.23 \pm .02^{\mathrm{b}}$ & -- & $1.50 \pm .03^{\mathrm{C}}$ & $1.35 \pm .03^{\mathrm{d}}$ \\
& & & & & & \\
W21 & 1444 & $4.61 \pm .08^{\mathrm{a}}$ & $5.00 \pm .08^{\mathrm{b}}$ & $4.95 \pm .08^{\mathrm{b}}$ & -- & - \\
W42* & 1444 & $10.78 \pm .17$ & $10.83 \pm .17$ & $10.78 \pm .17$ & -- & -- \\
W42 & 1620 & $11.10 \pm .20^{\mathrm{a}}$ & $10.45 \pm .20^{\mathrm{b}}$ & -- & $11.42 \pm .27^{\mathrm{a}}$ & $11.12 \pm .22^{\mathrm{a}}$ \\
ADG & 1444 & $.704 \pm .007^{\mathrm{a}}$ & $.671 \pm .007^{\mathrm{b}}$ & $.670 \pm .007^{\mathrm{b}}$ & -- & -- \\
ADG & 1620 & $.702 \pm .008^{\mathrm{a}}$ & $.674 \pm .008^{\mathrm{b}}$ & -- & $.678 \pm .009^{\mathrm{b}}$ & $.695 \pm .009^{\mathrm{a}}$ \\
BF & 1444 & $31.78 \pm .47^{\mathrm{a}}$ & $30.39 \pm .40^{\mathrm{b}}$ & $30.62 \pm .40^{\mathrm{b}}$ & -- & - \\
BF & 1620 & $26.72 \pm .35^{\mathrm{a}}$ & $25.67 \pm .35^{\mathrm{bc}}$ & -- & $26.85 \pm .37^{\mathrm{a}}$ & $26.38 \pm .37^{\mathrm{ac}}$ \\
\hline
\end{tabular}

${ }^{{ }_{B}} \mathrm{WW}=$ Birth Weight $(\mathrm{kg}), W 21=21$-day Weight $(\mathrm{kg}) ; W 42=42$-day Weight $(\mathrm{kg}), A D G=$ Postweaning Average Daily Gain (kg/day); $B F=$ Probed Backfat Thickness at $99.8 \mathrm{~kg}(\mathrm{~mm})$.

* = Overal1 F test for Breed of Dam not significant $(P>.5)$.

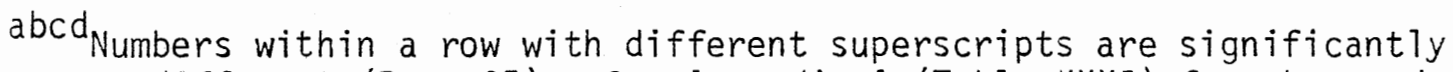
different $(P<.05)$. See Appendix A (Table XXXI) for observed significance levels. 
Yorkshire dams for this trait. Pigs with Duroc dams were found to have significantly faster postweaning average daily gains and higher probed backfat thicknesses at 99.8 kilograms than those with Hampshire or Yorkshire dams in the 1444 data set. Hampshire and Yorkshire dam means did not differ significantly from each other for these traits. In the 1620 data set, Duroc and Spotted dam means, while not differing significantly from each other, were significantly higher for postweaning average daily gain than Yorkshire or Landrace means. Yorkshire and Landrace dam means did not differ significantly for this trait. Pigs with Landrace or Duroc dams were found to have significantly higher probed backfat thickness than pigs with Yorkshire dams. The Spotted dam mean was intermediate, approaching significant difference from Yorkshire $(P=.057)$ and Landrace $(P=.160)$ means.

Breed of Sire and Type

Generalized least squares means for breed of sire by type interaction are presented in Tables $X$ to XIV. Differences among breed of sire means were tested for probed backfat thickness only as breed of sire did not account for a significant amount of variation for any other trait. Breed of sire by year-season interaction was significant for probed backfat in the 1620 data set, but sire breed ranking was essentially the same in all year-seasons. A significant amount of variation in probed backfat thickness was accounted for by the breed of sire by type interaction in the 1444 data set, and by the breed of sire by year-season interaction in the 1620 data set. Sire breed ranking was essentially the same across types or year-seasons in these cases. 
TABLE $X$

PUREBRED AND CROSSBRED GENERALIZED LEAST SQUARES

MEANS FOR PIG BIRTH WEIGHT $(\mathrm{kg})$ BY

BREED OF SIRE

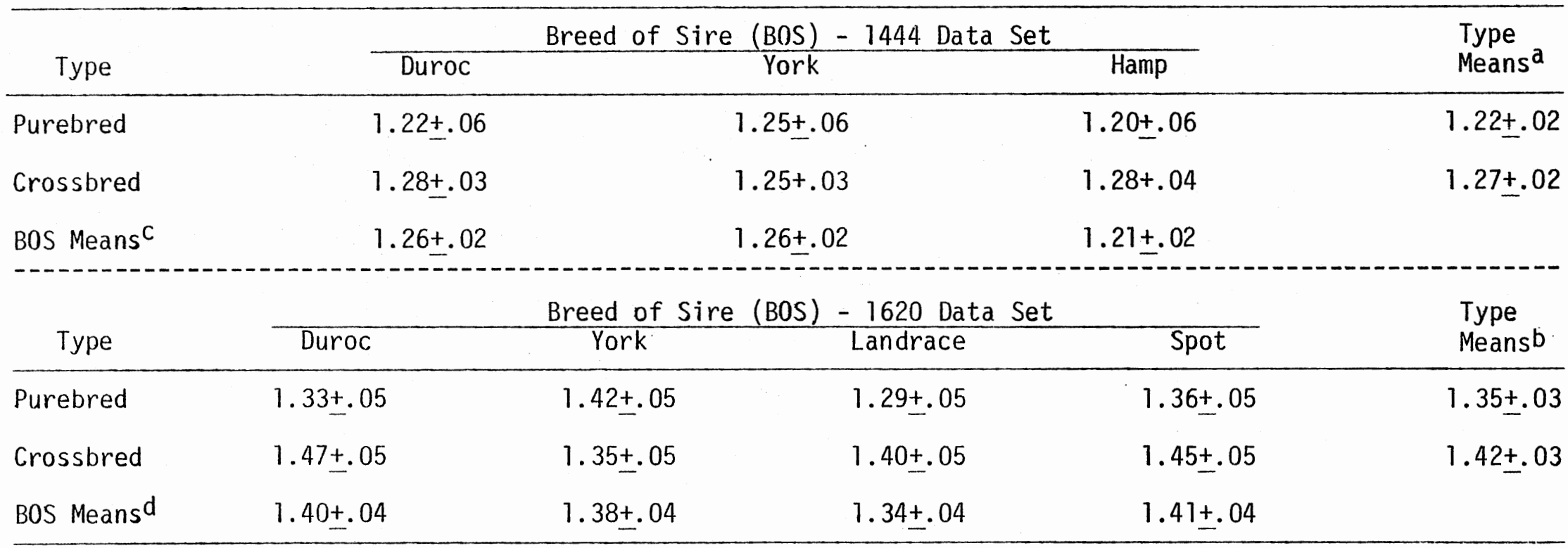

aoverall $F$ test not significant for Type (1444 data set), $P=.093$.

b Type means significantly different, $P=.031$.

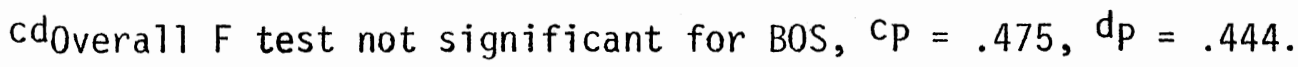


TABLE XI

PUREBRED AND CROSSBRED GENERALIZED LEAST SQUARES

MEANS FOR 21-DAY PIG WEIGHT $(\mathrm{kg})$ BY

BREED OF SIRE

\begin{tabular}{|c|c|c|c|c|}
\hline \multirow[b]{2}{*}{ Type } & \multicolumn{3}{|c|}{ Breed of Sire (BOS) - 1444 Data Set } & \multirow{2}{*}{$\begin{array}{l}\text { Type } \\
\text { Means }\end{array}$} \\
\hline & Duroc & York & Hamp & \\
\hline Purebred & $4.71 \pm .31$ & $5.01 \pm .29$ & $4.48 \pm .33$ & $4.73 \pm .09$ \\
\hline Crossbred & $4.76 \pm .16$ & $4.97 \pm .13$ & $5.25 \pm .18$ & $4.98+.08$ \\
\hline BOS Means ${ }^{b}$ & $4.70+.11$ & $4.94+.10$ & $4.92+.12$ & \\
\hline
\end{tabular}

aType means significantly different, $P=.014$.

$b_{0 v e r a 11} F$ test not significant for BOS, $P=.659$. 
TABLE XII

PUREBRED AND CROSSBRED GENERALIZED LEAST SQUARES

MEANS FOR 42-DAY PIG WEIGHT $(\mathrm{kg})$ BY

BREED OF SIRE

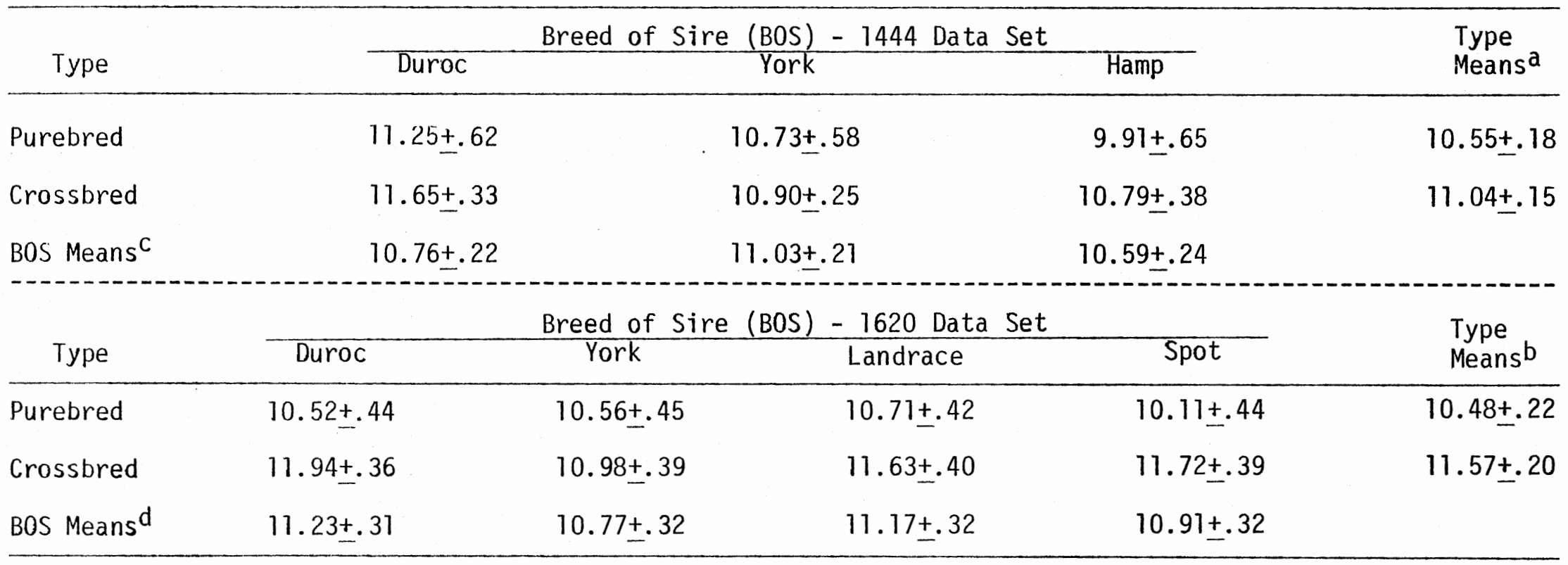

${ }^{a b}$ Type means significantly different, $a p=.018, b p<.001$.

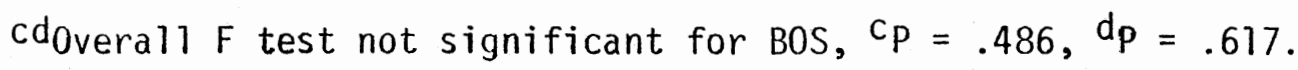


TABLE XIII

PUREBRED AND CROSSBRED GENERALIZED LEAST SQUARES

MEANS FOR POSTWEANING AVERAGE DAILY GAIN

( $\mathrm{kg} /$ day) BY BREED OF SIRE

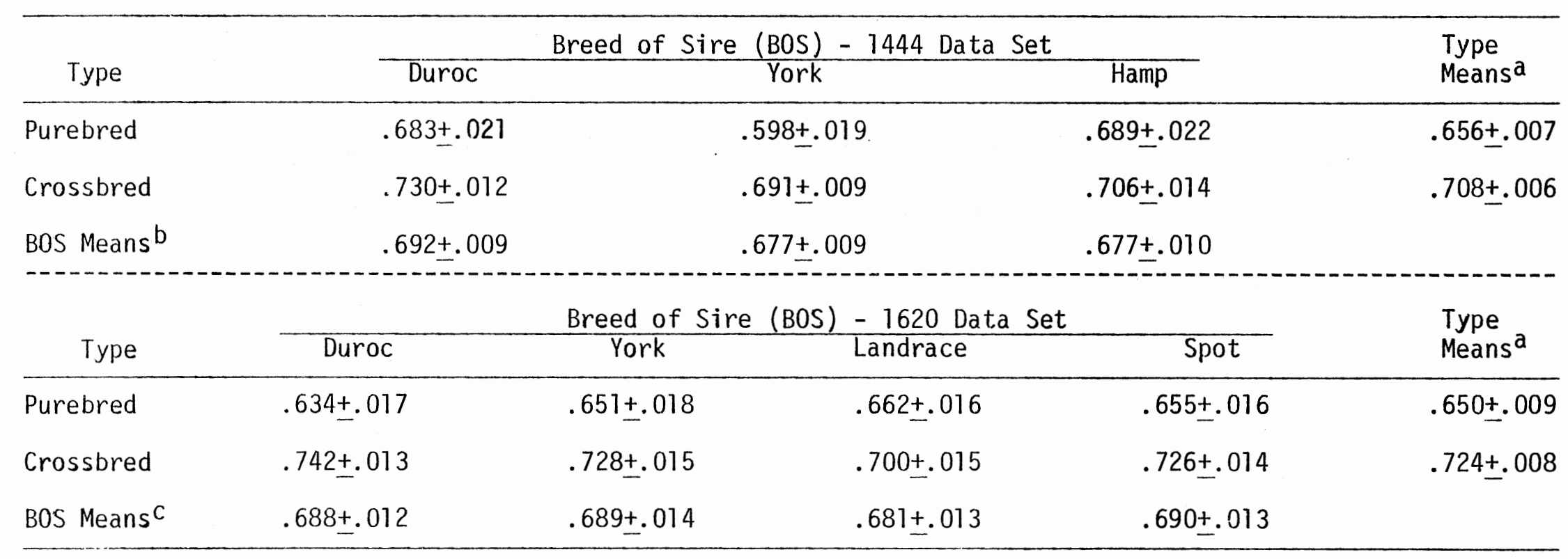

aType means significantly different, $P<.001$.

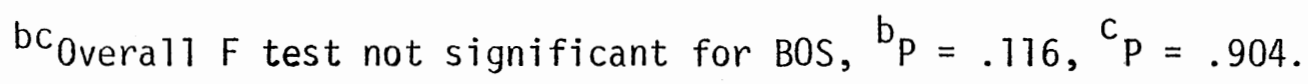


TABLE XIV

PUREBRED AND CROSSBRED GENERALIZED LEAST SQUARES

MEANS FOR PROBED BACKFAT THICKNESS AT 99.8

$\mathrm{kg}(\mathrm{mm})$ BY BREED OF SIRE

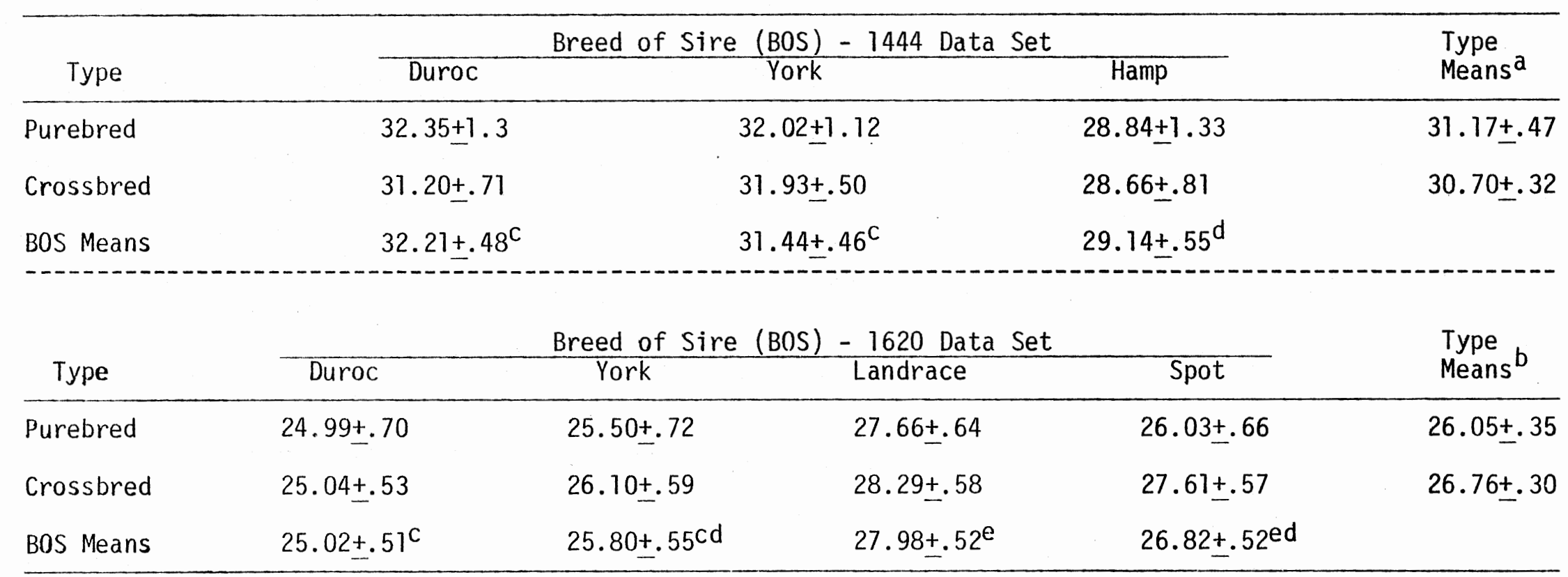

aboverall $F$ test not significant for type, $a_{p}=.056, b_{p}=.065$.

cde Numbers within a row with different superscripts are significantly different $(P<.05)$. See Appendix $A$ (Table XXXII) for observed significance levels. 
In the 1444 data set, pigs sired by Hampshire boars had significantly lower probed backfat thicknesses than pigs sired by either Duroc or Yorkshire boars; these sire breeds not differing significantly from each other for this trait. In the 1620 data set, the Duroc sire mean was significantly lower than Spotted and Landrace sire means for probed backfat thickness. The Yorkshire mean was intermediate between the Duroc and Spotted means, and was significantly lower for probed backfat thickness than the Landrace mean. The Spotted sire mean approached significant difference from Yorkshire $(P=.167)$ and Landrace $(P=.108)$ means.

The breed of sire by type interaction proved significant for birth weight, 42-day weight, postweaning average daily gain, and probed backfat thickness in the 1444 data set. Types, however, ranked the same across breeds of sire for all traits, with the exceptions of birth weight in the 1620 data set and 21-day weight in the 1444 data set. In both cases, no significant difference was found between Yorkshire purebred and crossbred means. Type by year-season proved to be a significant source of variation for postweaning average daily gain in both data sets, and for birth weight in the 1620 data set. Type by parity was significant for postweaning average daily gain in the 1620 data set. Types ranked identically in a11 cases except for birth weight in the 1620 data set, where no significant difference between type means was detected.

Type means indicate that crossbred pigs had significantly heavier birth weights (1620 data set on7y), 27-day weights, and 42-day weights than purebred pigs. Crossbreds also had significantly faster rates of postweaning gain than purebreds. 


\section{Variance Components Estimates}

Sire, nested within sire breed (1620 data set) and year-season by sire breed (1444 data set), and the sire by type interaction, were significant sources of variation $(P<.05)$ in all variance component analyses, highly significant $(P<.01)$ for all but probed backfat thickness in the 1620 data set. The significant interaction would suggest that individual sire effects vary dependent upon whether the sire is mated to a dam of his own or of another breed.

Sire and residual variance component estimates, along with total phenotypic variance estimates, are presented separately for the purebreds (Table XV) and crossbreds (Table XVI). In addition to these statistics, Table XVII.also shows the variance component estimates for the sire by type interaction from pooled (crossbred and purebred) analyses. Variance component coefficients (k-values) involved in obtaining these estimates are given in Appendix A (Tables XXXII and XXXIV).

In general, sire by type interaction variance component estimates were approximately twice those of the corresponding sire variance component estimates for postweaning traits. This is as might be expected from a strictly additive genetic model, interaction variance including both sire and dam comporients. For preweaning traits, however, the ratio of interaction to sire variance component estimates tended to be somewhat larger (ranging from approximately 2 to 28), suggesting that the interaction variance included some non-additive genetic components such as dominance.

Phenotypic variances from each analysis (purebred, crossbred, and pooled) were of comparable magnitudes. 
TABLE XV

VARIANCE COMPONENT ESTIMATES FROM

PUREBRED ANALYSES

\begin{tabular}{lcccr}
\hline Trait $^{\mathrm{a}}$ & Data Set & $v_{\mathrm{s}}{ }^{\mathrm{b}}$ & $v_{\mathrm{e}}{ }^{\mathrm{c}}$ & $\mathrm{v}_{\mathrm{p}}{ }^{\mathrm{d}}$ \\
\hline BW & 1444 & .0067 & .0512 & .0579 \\
BW & 1620 & .0160 & .0924 & .1084 \\
W21 & 1444 & .3311 & .9512 & 1.2823 \\
W42 & 1444 & 1.2124 & 5.0700 & 6.2824 \\
W42 & 1620 & 1.4908 & 5.4666 & 6.9574 \\
ADG & 1444 & .0007 & .0063 & .0070 \\
ADG & 1620 & .0009 & .0060 & .0069 \\
BF & 1444 & 1.8238 & 13.1127 & 14.9365 \\
BF & 1620 & 2.3094 & 12.8039 & 15.1133 \\
\hline
\end{tabular}

$\mathrm{a}_{\mathrm{BW}}=$ Birth Weight; $W 21=21$-day Weight; $W 42=42$-day Weight; $A D G=$ Postweaning Average Daily Gain; $B F=$ Probed Backfat Thickness at $99.8 \mathrm{~kg}$.

bsire within breed of sire (1620 data set), within year-season by breed of sire (1444 data set) variance component estimate.

$\mathrm{C}_{\text {Residual variance component estimate. }}$

dPhenotypic variance estimate $\left(V_{S}+V_{e}\right)$. 
TABLE XVI

VARIANCE COMPONENT ESTIMATES FROM CROSSBRED ANALYSES

\begin{tabular}{lcccr}
\hline Trait $^{a}$ & Data Set & $v_{s}{ }^{b}$ & $V_{e}{ }^{c}$ & $V_{p}{ }^{d}$ \\
\hline BW & 1444 & .0095 & .0645 & .0740 \\
BW & 1620 & .0091 & .0947 & .1038 \\
W21 & 1444 & .1271 & 1.1667 & 1.2938 \\
W42 & 1444 & .9990 & 5.6862 & 6.6852 \\
W42 & 1620 & .4625 & 6.0726 & 6.5351 \\
ADG & 1444 & .0008 & .0065 & .0073 \\
ADG & 1620 & .0010 & .0068 & .0078 \\
BF & 1444 & 2.0170 & 12.1976 & 14.2146 \\
BF & 1620 & .8773 & 11.4004 & 12.2777 \\
\hline
\end{tabular}

$a_{\mathrm{BW}}=$ Birth Weight; $W 21=21$-day Weight, $W 42=42$-day Weight; $A D G=$ Postweaning Average Daily Gain; BF = Probed Backfat Thickness at $99.8 \mathrm{~kg}$.

bsire within breed of sire (1620 data set), within year-season by breed of sire (1444 data set) variance component estimate.

CResidual variance component estimate.

dPhenotypic variance estimate $\left(V_{S}+V_{e}\right)$. 
TABLE XVII

VARIANCE COMPONENT ESTIMATES FROM

POOLEDA DATA SET ANALYSES

\begin{tabular}{lccccc}
\hline Traitb & Data Set & $V_{s}{ }^{c}$ & $V_{s t}{ }^{d}$ & $V_{e}{ }^{e}$ & $v_{p}{ }^{f}$ \\
\hline BW & 1444 & .0003 & .0083 & .0600 & .0686 \\
BW & 1620 & -.0016 & .0115 & .0982 & .1081 \\
W21 & 1444 & -.0185 & .2010 & 1.1130 & 1.2955 \\
W42 & 1444 & .3479 & .6861 & 5.5122 & 6.5462 \\
W42 & 1620 & -.1143 & .6986 & 6.1492 & 6.7335 \\
ADG & 1444 & .0002 & .0005 & .0065 & .0072 \\
ADG & 1620 & .0003 & .0005 & .0066 & .0074 \\
BF & 1444 & .5954 & 1.3507 & 12.5083 & 14.4544 \\
BF & 1620 & .5430 & .5300 & 11.8614 & 12.9344 \\
\hline
\end{tabular}

ancluding both purebred and crossbred progeny.

$b_{B W}=$ Birth Weight; $W 21=21$-day Weight; $W 42=42$-day Weight; $A D G=$ Postweaning Average Dai7y Gain; $B F=$ Probed Backfat Thickness at $99.8 \mathrm{~kg}$.

CSire within breed of sire (1620 data set), within year-season by breed of sire (1444 data set) variance component estimate.

dsire (nested as above) by type (purebred or crossbred progeny) interaction variance component estimate.

Residua] variance component estimate.

fPhenotypic variance estimate $\left(V_{S}+V_{S t}+V_{e}\right)$. 
Heritability Estimates

Strictly speaking, the sire components of variance estimated from the crossbred analyses yjeld biased estimates of the additive genetic variance in the crossbred population, even in the absence of epistasis (Stuber and Cockerham, 1966). However, the ratio of four times the sire component of variance to the total phenotypic variance (heritability) may be regarded as comparable statistics in purebred and crossbred populations.

Estimated heritabilities and their standard errors from purebred, crossbred, and pooled analyses are presented in Table XVIII.

Weighted average heritability estimates for the purebred, crossbred, and pooled data sets, respectively, were as follows: .52, .43, -.02 for birth weight; $1.03, .39,-.06$ for 21 -day weight (1444 data set on $1 y) ; .81, .43, .07$ for 42 -day weight; $.45, .46, .14$ for postweaning average daily gain; and $.56, .41, .17$ for probed backfat thickness at 99.8 kilograms.

Heritability estimates for the different traits within each of the types of analysis (purebred, crossbred, and pooled) did not differ significantly from each other $(P>.05)$. Purebred and crossbred heritability estimates for the different traits did not differ significantly from each other $(P>.05)$, except for 21 -day weight $(P<.05)$. However, the standard errors reported are approximations and as such represent minimum standard errors (Vesely and Robison, 1970). Thus, even 21-day weight heritability estimates may not truly differ statistically between the purebreds and crossbreds.

Louca and Robison (1967), Stanislaw et a1. (1967), and Standal (1968) reported no significant differences $(P<.05)$ between purebred 
TABLE XVIII

HERITABILITY ESTIMATES

\begin{tabular}{lcccc}
\hline & & $\hat{h}^{2}{ }^{b}$ & $\hat{h}_{C B}{ }^{c}$ & $\hat{h}_{P}^{2 d}$ \\
\hline BW & 1444 & $.46 \pm .12$ & $.51 \pm .11$ & $.02 \pm .02$ \\
BW & 1620 & $.59 \pm .18$ & $.35 \pm .10$ & $-.06 \pm .00$ \\
W21 & 1444 & $1.03 \pm .20$ & $.39 \pm .10$ & $-.06 \pm .01$ \\
$W 42$ & 1444 & $.77 \pm .18$ & $.60 \pm .12$ & $.27 \pm .06$ \\
W42 & 1620 & $.86 \pm .24$ & $.28 \pm .09$ & $-.07 \pm .00$ \\
ADG & 1444 & $.39 \pm .15$ & $.42 \pm .10$ & $.13 \pm .05$ \\
ADG & 1620 & $.52 \pm .24$ & $.52 \pm .16$ & $.16 \pm .07$ \\
BF & 1444 & $.49 \pm .23$ & $.57 \pm .15$ & $.16 \pm .08$ \\
BF & 1620 & $.61 \pm .26$ & $.29 \pm .12$ & $.17 \pm .08$ \\
\hline
\end{tabular}

$a_{B W}=$ Birth Weight; $W 21=21$-day Weight; $W 42=42$-day Weight; $A D G=$ Postweaning Average Daily Gain; BF = Probed Backfat Thickness at $99.8 \mathrm{~kg}$.

baternal half-sib heritability estimate from purebred progeny data.

CPaternal half-sib heritability estimate from crossbred progeny data.

dPaternal half-sib heritability estimate from pooled progeny data. 
and crossbred heritability estimates for birth weight, postweaning average daily gain, and probed backfat thickness, in agreement with the findings of this study. However, crossbred heritability estimates reported for 21- and 56-day weights (Stanislaw et al., 1967 and Standal, 1968) were greater than purebred estimates. The reverse was found to be the case for 27- and 42-day weight in this study, purebred estimates exceeding crossbred estimates (significantly so for 21-day weight).

From analyses of these data, selection for the traits investigated might be expected to be effective in either the purebred or the crossbred population, a comparable amount of additive genetic variation existing in each, with the possible exception of 21-day weight.

The purebred and crossbred heritabilities are high for birth weight, 21-day weight, and 42-day weight when compared to weighted literature estimates of. .19 for birth weight and .15 for 42 -day weight (Hutchens and Hintz, 1981), and of .16 for 21-day weight (Edwards and Omtvedt, 1971; Strang and Smith, 1979, and Valarezo and Quijandria, 1979). However, they are similar to weighted heritability estimates of .38 and .39 reported for postweaning average daily gain and probed backfat thickness, respectively, by Hutchens and Hintz (1981).

As Louca and Robison (1967) point out, wide differences between heritability estimates reported by different studies are not unusual, given that they refer to different populations and environments, and given the contribution of sampling erors and their associate biases. All heritability estimates obtained in this study are within the range of those reported by Hutchens and Hintz (1981). 
Nonetheless, the heritability estimates from pooled (purebred and crossbred) analyses were low when compared to weighted literature estimates. They are also consistently lower than these obtained from either purebred or crossbred analyses, significantly so $(P<.05)$ for preweaning traits in both data sets--reflecting the importance of the sire by type interaction.

Should sire ranking change when based upon breeding values obtained from either purebred or crossbred progeny, as suggested by a significant sire by type interaction, then analyzing pooled (purebred and crossbred progeny) data, including sire by type interaction in the model might be expected to yield estimates of sire components of variance less than those obtained from separate analyses of purebred and crossbred data. The implication of this is that if a sire's breeding value is estimated from both types of progeny, then the accuracy of selection for improvement of both purebred and crossbred progeny performance is low. By removing the sire by type interaction from the model, the resultant heritability estimate from pooled data will reflect more the accuracy of selection for improvement of either purebred or crossbred progeny performance if a sire's breeding value is estimated from either purebred or crossbred progeny. Taking this approach for postweaning traits in the 1620 data set resulted in heritability estimates of .33 and .27 for postweaning average daily gain and probed backfat thickness, respectively. While lower than weighted average estimates of .52 and .38 obtained for the above traits, respectively, from separate purebred and crossbred analyses, omission of the significant interaction most likely resulting in biased variance component estimates, they are far more comparable than those obtained with interaction included in the model. 
Best Linear Unbiased Predictors of Sire Breeding Value

Best linear unbiased predictors (BLUPS) of sire breeding value for purebred and crossbred progeny, obtained by solution of the equations given in Chapter III, with matrices as defined in Appendix B, are given in AppendiX A (Tables XXXV to XXXVIII). Sire ranks based upon these breeding values are presented in Tables XXXIX to XLII.

Correlation coefficients between solutions obtained as above and additional solutions obtained, assuming $C=0$ and $G_{2}=I V_{s t}$, although generally high, were consistently lower for the 1620 data set than for the 1444 data set. The product-moment correlation coefficients between sire breeding values obtained by the two methods, averaged over purebred and crossbred progeny for all traits, were .998 and .870 for the 1444 and 1620 data sets, respectively.

Genetic and rank correlation coefficients calculated from breeding values obtained assuming $C=0$ and $G_{2}=I V_{\text {st }}$ were lower for al1 traits than those calculated from breeding values obtained without making these simplifying assumptions. Under these assumptions, genetic correlation coefficients were, on average, 12 and 69 percent lower, and rank correlation coefficients 11 and 87 percent lower, for the 1444 and 1620 data sets, respective1y.

These results might suggest that failure to include the covariances between sire and sire by type interaction terms in the equations may bias downwards the genetic and rank correlation coefficients calculated from the solution vector. 
Genetic and Rank Correlation Estimates

Results

Correlation coefficients of sire breeding values for purebred and crossbred progeny, and for sire ranking based upon breeding values, are presented in Table XIX for all traits investigated in both data sets. Genetic (breeding value) correlation coefficients were estimated from both variance component analyses and mixed model solutions.

The large standard errors associated with genetic correlation estimates from variance component analyses, themselves approximations and most likely underestimating the true standard error, reflect the inefficiency of this method unless numbers are large.

Robertson (1959) stated that the variance of the genetic correlation coefficient is minimized when:

$$
n . t=\frac{\left(1+r_{g}^{2}\right)^{1 / 2}}{1-r_{g}^{2}}
$$

where $n$ represents the interaction variance $k$ value from analys is of variance, $t$ the intra-class correlation, and $r_{g}$ the genetic correlation. The expected variance of the genetic correlation coefficient where $t$ is small and $n$ is large, Robertson gave as approximately:

$$
V\left(r_{g}\right) \simeq \frac{\left[1+n t\left(1-r_{g}^{2}\right)\right]^{2}+r_{g}^{2}}{(N-1) n^{2} t^{2}}
$$

From these formulae it is possible to establish the number of sire groups $(N)$ and number of progeny per sire in each of the two classes (purebred and crossbred) that would result in the desired 
TABLE XIX

GENETIC AND RANK CORRELATION COEFFICIENT ESTIMATES

\begin{tabular}{|c|c|c|c|c|}
\hline Traita & Data Set & $r_{g}^{\prime}+s . e . b$ & $r_{g}^{c}$ & $r_{r}^{d}$ \\
\hline$B W$ & 1444 & $.04 \pm>1.0$ & $.53 * *$ & $.55^{\star *}$ \\
\hline$B W$ & 1620 & $-.17 \pm>1.0$ & .27 & .17 \\
\hline W21 & 1444 & $-.12 \pm>1.0$ & $.45^{\star \star}$ & $.53^{\star *}$ \\
\hline W42 & 1444 & $.34 \pm .30$ & $.46 \star \star$ & $.43 * *$ \\
\hline W42 & 1620 & $-.26 \pm>1.0$ & $.48 * \star$ & $.42 \star$ \\
\hline$A D G$ & 1444 & $.32 \pm .48$ & $.54 \star \star$ & $.57 \star \star$ \\
\hline$A D G$ & 1620 & $.36 \pm .51$ & $.40 *$ & $.46 * \star$ \\
\hline$B F$ & 1444 & $.31 \pm .61$ & $.80 * \star$ & $.85^{\star \star}$ \\
\hline$B F$ & 1620 & $.60+.48$ & $.90 * *$ & $.86 * \star$ \\
\hline
\end{tabular}

$a_{B W}=$ Birth Weight; $W 21=21$-day Weight; $W 42=42$-day Weight, $A D G=$ Postweaning Average Daily Gain; BF = Probed Backfat Thickness at $99.8 \mathrm{~kg}$.

bIntra-class correlation coefficient of sire breeding values for purebred and crossbred progeny from variance component analyses, \pm approximate standard error.

CProduct-moment correlation coefficient of sire breeding values for purebred and crossbred progeny from mixed model solutions ( $95 \%$ confidence intervals given in Appendix A (Table XLIII).

${ }^{d}$ Spearman rank correlation coefficient, ranks based upon sire breeding values for purebred and crossbred progeny from mixed mode 1 solutions (95\% confidence intervals given in Appendix $A$ (Table XLIII).

${ }^{*} \mathrm{P}<.05$ (under $\mathrm{H}_{0}:$ rho $=0$ ).

$\star * P<.01$ (under $H_{0}$ : rho $=0$ ). 
approximate standard error of the genetic correlation. The effects of varying $r_{g}$ and $t$ on the number of sire groups and progeny in each class required to produce an approximate standard error of .2 are given in Table $\mathrm{XX}$.

It can be appreciated from Table XX that both as heritability declines, and as the genetic correlation increases, increasing numbers of progeny per sire are required to produce a given standard error; although total number of animals required decreases somewhat both as heritability and the genetic correlation increase.

In this study, the standard error of the genetic correlation coefficient was greater than unity for four of the five preweaning correlations, heritability being low or negative in these cases. Intra-class correlation for the remaining genetic correlations ranged from .03 to .05 , requiring between 30 and 50 progeny per sire class to obtain an approximate standard error of .2 on a genetic correlation estimate of $.5,20$ to 40 progeny for the same standard error on a correlation of .3. The range of $k$ values in these cases was 7 to 14 (Appendix $A$, Table XXXIV), explaining the large standard errors (from .3 to .6) obtained.

Thus, while the genetic correlation coefficients calculated by this method are low, only that for 42-day weight in one data set is significantly $(P<.05)$ Tess than unity (the expectation of the correlation when the interaction effect is zero), and then only marginally so. However, genetic correlations for preweaning traits were generally lower than those obtained for postweaning average daily gain and probed backfat thickness. Heritability estimates from pooled data (Table XVIII) rank almost identically to the genetic correlation estimates from variance component analysis. 
TABLE XX

NUMBERS REQUIRED FOR AN APPROXIMATE STANDARD

ERROR OF .2 ON GENETIC CORRELATION

COEFFICIENTS ESTIMATED FROM

VARIANCE COMPONENTS

\begin{tabular}{lcccccc}
\hline$r_{g}{ }^{a}$ & $n b_{t} c$ & $t=.05$ & $t=.04$ & $t=.03$ & $t=.004$ & $N^{d}$ \\
\hline .1 & 1.02 & 20 & 25 & 34 & 254 & 99 \\
.3 & 1.15 & 23 & 29 & 38 & 287 & 82 \\
.5 & 1.49 & 30 & 37 & 50 & 373 & 54 \\
.7 & 2.39 & 48 & 60 & 80 & 598 & 25 \\
.9 & 7.08 & 142 & 177 & 236 & 1770 & 4 \\
\hline
\end{tabular}

$a_{r_{g}}=$ genetic correlation.

$b_{n}=$ number of progeny per sire in each (purebed and crossbred) class.

$c_{t}=$ intra-class correlation coefficient.

$b$ product minimizes the standard error on the genetic correlation coefficient, allowing solution for $n$ given $t$.

$d_{N}=$ number of sires with $n$ purebred and $n$ crossbred progeny required for an approximate standard error of .2 on the genetic correlation coefficient, given nt. 
Genetic correlation coefficients obtained from mixed model solutions (Table XIX) were of comparable magnitude to each other for all traits except probed backfat thickness. Averaged over the two data sets, these correlations were .40 for birth weight, .45 for 21 -day weight (1444 data set only), .47 for 42-day weight and postweaning average daily gain, and .85 for probed backfat thickness. Genetic correlations obtained by this method were, in all cases, greater than those from variance component analysis. The scale of this increase appears to be proportional to the magnitude of the variance of the correlation estimated from variance components (the larger the variance the greater the relative increase across methods).

Confidence intervals on the true correlation between estimated sire breeding values for purebred and crossbred progeny (Appendix A, Table XLIII) indicate the correlation to be less than unity $(P<.05)$ for all traits in these data. Upper limits of this interval ranged from .55 for birth weight to .95 for probed backfat thickness, both in the 1620 data set. It should be stressed, however, that these confidence intervals are based upon estimated rather than true breeding values, and that no account has been taken of the variance associated with these estimates.

Correlation coefficients of sire ranking based upon breeding value for purebred and crossbred progeny (Table XIX) are of the same order of magnitude as the corresponding genetic correlations. Averaged over the two data sets, these rank correlations were .36 for birth weight, .53 for 21-day weight (1444 data set only), .43 for 42day weight, .49 for postweaning average daily gain, and .86 for probed backfat thickness. 
Genetic and rank correlation coefficients by breed of sire from mixed model solutions are presented in Appendix A (Tables XLIV to XLVIII) Weighted average correlations across breed of sire are, in a11 but two cases (42-day weight and probed backfat thickness in the 1620 data set), greater than correlation coefficients obtained from pooled analyses, representing a 20 percent increase over all traits. Given, however, that breed of sire did not represent a significant source of variation in the data, except in the case of probed backfat thickness in the 1620 data set (where the weighted average genetic correlation is in fact four percent lower than that from the pooled analysis), then the pooled correlation coefficients represent the best estimates of the true population parameters.

Comparison With Results of Other Workers

Few estimates of the genetic correlation between purebred and corssbred progeny groups of swine exist in the literature. Standal (1968) reported estimated genetic correlations of .70 for birth weight and .83 for 21-day weight, higher than estimates found in this study. While genetic parameter estimates reported by Stanislaw et al. (1967) yield an estimated genetic correlation of 1.25 for 56 -day weight, Wong et a1. (1971) reported negative genetic correlations for weaning weight. The results for 42-day weight in this study, while negative in one case from variance component analysis, are positive and of intermediate magnitudes for the other three cases. Genetic correlation estimates of $.33, .38$, and .55 reported by Stanislaw et a1. (1967) and Wong et al. (1971) for postweaning average daily gain are in general agreement with estimates obtained in this study, although Standal's 
(1968) estimate of 1.33 is noticeably higher. Estimates of genetic correlation for probed backfat thickness of $.21, .41, .75$, and $>1.0$ have been reported by Robison et al. (1964), Stanislaw et al. (1967), Standal (1968), and Wong et al. (1971); estimates obtained in this study falling within this range. In contrast to most of these estimates, Robison (personal communication, 1980), analyzing data from 1,779 purebred and crossbred Duroc and Yorkshire sired pigs, obtained genetic correlation estimates of less than -1.0 for the preweaning traits investigated in this study, and estimates of -.32 and .35 for postweaning average daily gain and probed backfat thickness, respectively.

\section{Discussion}

Reciprocal recurrent selection is designed to exploit heterosis attributable to overdominance, and theoretically has no advantage over independent or family selection techniques if applied to traits for which there is no overdominance. Methods such as reciprocal recurrent selection are indicated only when individual and family selection becomes relatively ineffective, due to the lower selection intensity per unit of time when selection is based upon test-cross progeny performance (Dickerson, 1952).

Bowman (1960), assuming diploid segregation, lack of multiple alleles and no epistasis, demonstrated that a negative regression of a sire's crossbred progeny on his purebred progeny performance could only occur when overdominance was present. However, positive or zero regressions do not rule out the presence of overdominance.

Correlation coefficients are the same as regression coefficients under equality of variances, and negative correlations reflect negative 
covariances common to both parameters. The negative genetic correlation coefficients obtained from variance component analyses for birth weight and 42-day weight in the 1620 data set, and for 21-day weight in the 1444 data set, might suggest the presence of overdominance. The positive correlations from variance component analyses for all other traits, and for a 11 traits from mixed model analyses, offer uncertain conclusions. However, the general lack of high genetic correlation between purebred and crossbred performance for the traits studied suggests the possibility of different sets of genes for purebred versus crossbred combining ability.

\section{Expected Response to Selection}

Robertson (1959) indicated that the correlation between sire breeding values for purebred and crossbred progeny gives a measure of the practical rather than the statistical significance of the sire by type interaction. The practical significance of this interaction is not so much that it is a consequence of change in sire ranking for purebred versus crossbred progeny, but rather the implications such a change may have on selection practices.

The ratio of change in the crossbred genotypic mean from selection for specific combining ability to change in the crossbred genotypic mean from intra-population selection ( $R$ ), a comparison of direct with indirect selection, can be expressed as follows (Falconer, 1969):

$$
R=\frac{i_{c} \cdot h_{c}}{i p \cdot h p \cdot r g}=k \cdot \frac{h_{c}}{h_{p} \cdot r_{g}}
$$


where $i$ represents the standardized selection differential, $h$ the square root of heritability, $r_{g}$ the genetic correlation, and the subscripts $p$ and $c$ refer to purebred and crossbred populations, respectively.

Comstock (1961) indicated that the ratio of standardized selection differentials ( $k$ ) would almost certainly be less than unity. This is due to the fact that the proportion of families from which breeding animals would be taken under the specific combining ability scheme would be larger than the proportion of individuals saved for breeding under mass selection unless the former was a very large program. Comstock suggested that a plausible range for this ratio might be .4 to .8 , being larger where programs are large.

Where $R$ from the above formula is greater than one or less than zero (negative values of $R$ indicating the presence of overdominance), the comparison is in favor of selection for specific combining ability. Where $R$ is between zero and one, intra-population selection is favored to improve the cross.

Using heritabilities and genetic correlations estimated in this study and $k$ values of .4 and .8 in the above formula, selection for specific cumbining ability was compared with mass selection for the traits investigated. Results of this comparison are presented in Table XXI.

Where the genetic correlation estimate from variance component analyses was used in obtaining this comparison, the ratio of expected genetic progress from selection for specific combining ability to mass selection was outside of the zero to one range in all cases, except for probed backfat thickness in the 1620 data set. If genetic 
TABLE XXI

RATIO OF EXPECTED RESPONSE PER GENERATION (R)

COMPARING SELECTION FOR SPECIFIC COMBINING

ABILITY WITH MASS SELECTION TO

IMPROVE CROSSBREDS

\begin{tabular}{lccccc}
\hline Traita & Data Set & \multicolumn{2}{c}{$r_{g}{ }^{b}(V C A)$} & \multicolumn{2}{c}{$r_{g}$ (MMS) $^{c}$} \\
\hline BW & 1444 & $\frac{k=.4}{11.01}$ & $\frac{k=.8}{22.02}$ & $\frac{k=.8}{.80}$ & $\frac{1.60}{3}$ \\
BW & 1620 & -1.79 & -3.58 & 1.17 & 2.33 \\
W21 & 1444 & -2.12 & -4.24 & .54 & 1.09 \\
W42 & 1444 & 1.04 & 2.08 & .76 & 1.53 \\
W42 & 1620 & -.88 & -1.76 & .48 & .95 \\
ADG & 1444 & 1.29 & 2.59 & .78 & 1.56 \\
ADG & 1620 & 1.10 & 2.20 & 1.00 & 2.01 \\
BF & 1444 & 1.41 & 2.82 & .54 & 1.08 \\
BF & 1620 & .45 & .91 & .30 & .61 \\
\hline
\end{tabular}

$a_{B W}=$ Birth Weight; $W 21=21$-day Weight; $W 42=42$-day Weight; $A D G=$ Postweaning Average Daily Gain; $B F=$ Probed Backfat Thickness at $99.8 \mathrm{~kg}$.

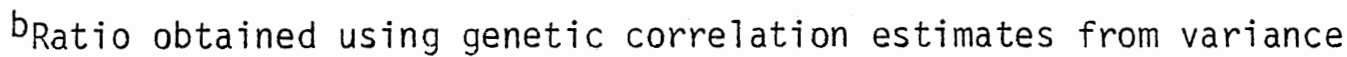
component analyses; $k$ is the ratio of standardized selection differentials.

$\mathrm{C}_{\text {Ratio obtained using genetic correlation estimates from mixed }}$ model solutions for breeding values; $k$ is as above. 
correlations are indeed as low as suggested by these estimates, selection for specific combining ability would appear to be favorable to mass selection for birth weight, 21 - and 42-day weights, and postweaning average daily gain, even at $k$ equal to .4. However, the lack of precision of these correlation estimates would make it rash to draw firm conclusions of this nature from these results.

In contrast to the above results, when genetic correlation estimates from mixed model analyses were used to obtain this ratio of expected response, selection for specific combining ability was favored over mass selection (at $k$ equal to .4) only for birth weight in the 1620 data set. Increasing the value of $k$ to .8 increased the favorability of selection for specific combining ability, expected genetic response by this method exceeding that for mass selection for a11 traits except 42-day wejght and probed backfat thickness in the 1620 data set (a7though only marginally so for 21-day weight and probed backfat thickness in the 1444 data set).

It might be noted, however, that Rempe1 (1969) maintained the value of .8 was too high and unlikely to be attainable in the light of his experience. Standal (1968) considered a case where 20 breeding boars were selected per generation in a program with a testing capacity of 2,000 pigs per generation, and estimated $k$ to be .66 . In addition, generation interval is not taken into account in these calculations. Standal suggested that selection for specific combining ability will increase the generation interval 20 to 50 percent over that for mass selection, reducing the advantage of this method over mass selection by the same amount. 
Recalculation of the ratio of response comparing selection for specific combining ability with mass selection taking $k$ equal to .6 and allowing for a 35 percent increase in generation interval for the specific combining ability method results in ratios of 1.3 and 1.1 for birth weight and average daily gain in the 1620 data set, and less than one in all other cases.

Literature reports of estimates of the expected response to alternative selection methods in general indicate no clear advantage for selection for specific combining ability over mass selection for improvement of crossbred performance in swine. Data analyzed by Standal (1968), while indicating a possible advantage of selection for specific combining ability for 21-day weight and backfat thickness, suggested mass selection to be superior to this method for birth weight, postweaning average daily gain, age at 90 kilograms, and five additional carcass traits. Rempel. (1969), Wong (1969), and Wong et a1. (1971), studying litter size, weaning weight, average daily gain, feed efficiency, backfat thickness, and a performance index, report a consistent expected advantage of reciprocal recurrent selection over mass selection for weaning weight only. Stanislaw et al. (1977) found that while selection for specific combining ability might be superior to mass selection for postweaning average daily gain, the converse was true for 56-day weight and probed backfat thickness.

Results of experimental evaluation of selection for specific combining abitity in swine have been reported by Biswas et a1. (1971), Krehbiel et a1. (1971a, 1971b), Hetzer et a1. (1977), and Bereskin and Hetzer (1981). Of the various pre- and postweaning traits investigated, selection for specific combining ability appeared to offer no 
consistent advantage over mass selection, with the possible exception of preweaning and litter traits--particularly litter size born.

Viewing the results of this study in the light of those presented by other workers, evidence for any clear advantage of selection for specific combining ability over mass selection for improved crossbred performance in swine is decidedly lacking.

In considering reciprocal recurrent selection, or any other program for selection for combining ability, the difficulties in operating such programs effectively--particularly for a large number of small herds--should not be underestimated. Some comments made by Fredeen (1966) in his critique of animal breeding research would seem particularly pertinent to this discussion. He maintains that:

- . we undertook experiments based on the methods of recurrent and reciprocal recurrent selection before the theoretical validity of these methods had been verified with laboratory species. Moreover, at the time this research was initiated, we already had substantial evidence that cross-breeding, a practical and relatively simple procedure, would serve to gain the desired ends in litter size and maternal performance. By aiming too high and by attempting to maximize performance through use of complex selection and breeding techniques before thoroughiy examining the utility of simple procedures, we have unduly compromised and confused the kind of advice we are able to provide the industry (p. 545).

Certainly, provided the additive genetic variance within purebred populations is high, and the genetic correlation between purebred and crossbred performance is at least moderately high, it would seem unlikely that reciprocal recurrent selection has very much to offer to practical swine breeding. 


\section{CHAPTER $V$}

\section{SUMMARY}

Two data sets (1444 and 1620), totalling 7,073 purebred and crossbred progeny records, were analyzed separately in this study. The 1444 data set consisted of records on 1,184 purebred and 2,275 crossbred pigs sired by 22 Duroc, 22 Hampshire, and 23 Yorkshire boars and farrowed during the spring and fal1 of 1971 and 1973. The 1620 data set cons isted of records on 1,074 purebred and 2,540 crossbred progeny of 10 Duroc, 9 Landrace, 8 Spotted, and 8 Yorkshire sires produced during the fall of 1976 and the spring and fall of 1977 and 1978.

In both data sets litters were farrowed in confinement during March and Apri1 (spring farrowing) and September and October (fal1 farrowing). Creep feed was made available from 21 days of age and litters weaned at approximately 42 days of age. Pigs were weighed on gain-test two (1620 data set) or three (1444 data set) weeks postweaning, and off test at approximately 99.8 kilograms live weight (90.7 kilograms for gilts in the 1620 data set). The data collected were pig birth weight, adjusted 21-day weight (1444 data set only), adjusted 42-day weight, and postweaning average daily gain and probed backfat thickness adjusted to 99.8 kilograms off test live weight.

Models assumed in the analyses included year-season farrowed, sex, type (purebred or crossbred), breed of dam, parity, breed of sire, sire (nested within breed of sire in the 1620 data set and year-season 
by breed of sire in the 1444 data set), sire by type interaction, and several other interaction terms. Litter size born was included as a covariable in preweaning trait analyses.

The protected LSD procedure was used to test differences between generalized least squares means for genetic effects. In the 1444 data set, Hampshire and Duroc dams produced heavier pigs at birth than did Yorkshire dams; al though Duroc dams had 1ighter pigs at 21 days of age than did Hampshire or Yorkshire dams. Pigs born to Duroc dams had a faster postweaning average daily gain and higher probed backfat thickness than pigs with Hampshire or Yorkshire dams. In the 1620 data set, Yorkshire dams had lighter pigs both at birth and 42days of age than Landrace, Duroc, or Spotted dams. Pigs with Duroc or Spotted dams had a faster postweaning average daily gain than those with Yorkshire or Landrace dams. Pigs with Landrace or Duroc dams probed fatter off test than pigs with Yorkshire dams, with the Spotted dam mean intermediate. Breed of sire differences indicated that Duroc or Yorkshire sired pigs were fatter at 99.8 kilograms than Hampshire sired pigs in the 1444 data set. In the 1620 data set, pigs with Spotted or Landrace sires probed fatter than pigs with Duroc sires, with the Yorkshire sire mean intermediate. Type means indicated the advantage of crossbred pigs over purebreds for weight at birth, 21and 42-days of age and for postweaning average daily gain.

Sire and sire by type interaction were significant sources of variation for all traits analyzed. Unbiased sire and sire by type interaction variance component estimates suggested the presence of some non-additive genetic components for preweaning traits. Paternal half-sib estimates of heritability were similar for the purebreds and 
crossbreds, indicating the existence of a similar amount of additive genetic variation in both populations. Averaged over both data sets and types, these heritability estimates were .48 for birth weight, .71 for 21-day weight, .63 for 42-day wejght, .46 for postweaning average daily gain, and .49 for probed backfat thickness--somewhat higher for the preweaning traits than most literature estimates. Heritability estimates from pooled (purebred and crossbred) analyses were low, averaging -.02 for birth weight, -.06 for 21-day weight, .07 for 42-day weight, .15 for postweaning average daily gain, and .17 for probed backfat thickness. These heritability estimates suggest a low accuracy of selection for simultaneous improvement of both purebred and crossbred progeny performance.

Variance component estimates were also used to estimate the correlation between sire breeding values for purebred and crossbred progeny. These genetic correlations averaged -.07 for birth weight, -.12 for 21-day wejght, .04 for 42-day weight, .34 for postweaning average daily gain, and .46 for probed backfat thickness over the two data sets. The large standard errors associated with these estimates resulted in 7 ittle evidence that the true parameters deviated from unity.

Best linear unbiased predictors of sire breeding value for purebred and crossbred progeny were obtained from mixed model solutions, and the correlation between these breeding values calculated. Averaged over the two data sets, these correlations were .40 for birth weight, .45 for 21-day weight, .47 for 42-day weight and postweaning average daily gain, and .85 for probed backfat thickness. Sires were also ranked according to these breeding values and the rank correlations 
calculated. Averaged over the two data sets, these correlations were .36 for birth weight, .53 for 21 -day weight, .43 for 42-day weight, .49 for postweaning average daily gain, and .86 for probed backfat thickness.

Using genetic parameter estimates obtained in this study, the expected response in crossbred populations to selection for specific combining ability was compared with mass selection for the traits investigated. If genetic correlations are as low as indicated by variance component analyses, selection for specific combining ability might indeed by superior to mass selection for the traits studied. However, if genetic correlations are of the order indicated by mixed model analyses, then selection for specific combining ability would seem to offer no clear practical advantage over mass selection for these traits.

It was concluded that, while sire ranking may change appreciably when based upon purebred or crossbred progeny, provided the genetic correlation is at least moderately high then selection for specific combining ability probably has little to offer practical swine breeding for the traits investigated. 


\section{BIBLIOGRAPHY}

Bär, A. J., J. H. Goodnight, J. P. Sal1, and J. T. Helwig (eds.). 1976. The four types of estimable functions used in SAS. A User's Guide to SAS 76, Appendix 9. Raleigh, NC: SAS Institute, Inc.

Bassett, J.W. and M. Shelton. 1966. Crossbreeding influence on heritability estimates. J. Anim. Sci. 25:877 (Abstr.).

Be11, A. E. and C. H. Moore. 1958. Further comparisons of reciprocal recurrent selection with conventional methods of selection for improvement of quantitative characteristics. Proc. Xth Intern. cong. Genet. 2:20.

Be11, A. E. and C. H. Moore. 1972. Reciprocal recurrent selection for pupal weight in Tribolium in comparison with conventional methods. Egypt. J. Genet. Cytol. 1:92.

Bell, A. E., C. H. Moore, and D. C. Warren. 1950. Systems of breeding designed to give maximum heterosis in chickens. Poult. Sci. 29:749.

Be 11, A. E., C.H. Moore, and D. C. Warren. 1955. The evaluation of new methods for the improvement of quantitative characteristics. Cold Spring Harbor Symp. Quant. Biol. 20:197.

Be11, A. E., C. H. Moore, B. B. Bohren, and D. C. Warren. 1952. Systems of breeding designed to utilize heterosis in the domestic fow 1. Poult. Sci. 31:11.

Benyshek, L. L. 1979. Sire by breed of dam interaction for weaning weight in Limous in sire evaluation. J. Anim. Sci. 49:63.

Bereskin, B. and H. 0. Hetzer. 1981. Reciprocal recurrent selection in swine: postweaning growth. J. Anim. Sci. 53(6):1446.

Biswas, D. K. and J. V. Craig. 1969. Relationship between purebred and crossibed paternal half-sisters' performance in chickens. Pouit. Sci. 48:524.

Biswas, D. K., A. B. Chapman, N. L. First, and H. L. Self. 1971. Intrapopulation versus reciprocal recurrent selection in swine. J. Anim. Sci. 32:840.

Bowman, J. C. 1960. Recurrent selection I. The detection of overdominance. Heredity. 14:197. 
Bowman, J. C. 1962. Recurrent selection II. An experimental study with mice and Drosophila. Genetical Res. 3:333.

Brown, W. P. and A. E. Bell. 1961. Genetic analys is of a plateaued population of Drosophila melanagaster. Genetics 46:407.

Buchanan, D. S. and M. K. Nielsen. 1979. Sire by environment interactions in beef cattie field data. J. Anim. Sci. 48(2):307.

Comstock, R. E. 1956. Genetic variance for eight week weight in strains and crosses. Poult. Sci. 35:1137 (Abstr.).

Comstock, R. E. 1960. Problems and evidence in swine breeding. J. Anim. Sci. 19:75.

Comstock, R. E. 1961. Reciprocal recurrent selection (RRS) with reference to swine breeding. 24th An. Rep. Reg. Swine Breed. Lab., Ames, Iowa. 85.

Comstock, R. E. and H. F. Robinson. 1957. Findings relative to reciprocal recurrent selection. Proc. Int. Genet. Symp. 1956. 461 .

Comstock, R. E., H. F. Robinson, and P. H. Harvey. 1949. A breeding procedure designed to make maximum use of both general and specific combining ability. Agron. J. 41:360.

Dickerson, G. E. 1952. Inbred lines for heteros is tests? In Heterosis, J. W. Gowen (ed.). Ames: Iowa State College Press. 330 .

Dickerson, G. E. 1962. Implications of genetic-environmental interaction in animal breeding. Anim. Prod. 4:47.

Dickerson, G. E., H. O. Hetzer, E. V. Krehbiel, and A. E. Flower. 1974. Effectiveness of reciprocal selection for performance of crosses between Montana no. 1 and Yorkshire swine. III. Expected and actual response. J. Anim. Sci. 39:24.

Dickerson, G. E., C. T. Blunn, A. B. Chapman, R. M. Kottman, J. L. Krider, E. J. Warwick, J. A. Whately, Jr., in collaboration with M. L. Baker, J. L. Lush, and L. M. Winters. 1954. Evaluation of selection in developing inbred lines of swine. Mo. Agr. Exp. Sta. Res. Bu17. 551. North Central Reg. Pub7. 38 .

Dim, N. I. 1974. Progeny testing of dairy cattle on purebreds and crossbreds. 1st World Congress on Genetics Applied to Livestock Production, Contributed Papers. E. Garsi (ed.). 3:667.

Dunn, R. J., W. T. Magee, K. E. Gregory, L. V. Cundiff, and R. M. Koch. 1970. Genetic parameters in straightbred and crossbred beef cattle. J. Anim. Sci. 31:656. 
Edwards, R. L. and I. T. Omtvedt. 1971. Genetic analysis of a swine control population. II. Estimates of population parameters. J. Anim. Sci. 32(2):185.

Enfield, F. D. 1960. Quantitative inheritance in poultry with special reference to genetic correlations between purebred and crossbred half-sib families. (Ph.D. dissertation, University of Minnesota.) Diss. Abstr. 21:715.

Enfield, F. D. and W. E. Rempe1. 1962. Covariance of sire effects in purebred and crossbred populations of swine. J. Anim. Sci. 21:971 (Abstr).

Falconer, D. S. 1952. The problem of environment and selection. Amer. Natur. 86:293.

Falconer, D. S. 1960. Introduction to Quantitative Genetics. New York: Ronald Press.

Fredeen, H. T. 1966. Where should we be going in animal breeding research? J. Anim. Sci. 25(1):543.

Gaugler, H. R. 1980. Sow productivity comparisons for four breeds of swine in the production of purebred and crossbred litters. (MS thesis, Oklahoma State University.)

Gregory, K. E., L. A. Swiger, R. M. Koch, L. J. Sumption, W. W. Rowden, and J.E. Ingal1s. 1965. Heteros is in preweaning traits of beef cattie. 24:21.

Gregory, K. E., L. A. Swiger, R. M. Koch, L. J. Sumption, J. E. Ingalls, W. W. Rowden, and J. A. Rothl isberger. 1966a. Heterosis effects on growth rate of beef heifers. J. Anim. Sci. $25: 290$.

Gregory, K. E. L. A. Swiger, L. J. Sumption, R. M. Koch, J. E. Ingalls, W. W. Rowden, and J. A. Rothlisberger. 1966b. Heteros is effects on growth rate and feed efficiency of beef steers. J. Anim. Sci. 25:299.

Griesbach, L. 1962. A test of the reciprocal recurrent selection technique with chicken broilers. Can. J. Anim. Sci. 42:145.

Hale, R. S. and G. A. Clayton. 1965. A diallel crossing experiment with two breeds of laying fowl. Brit. Poul. Sci. 6:153.

Hansson, A. and G. Lindkvist. 1962. Selection for general and specific combining ability with regard to body weight in mice. An. Roy. Agr. Col1. Swed. 28:215.

Helwig, J. T. and K. A. Council (eds.). 1979. A User's Guide to SAS 79. Raleigh, NC: SAS Institute, Inc. 
Henderson, C. R. 1953. Estimation of variance and covariance components. Biometrics. 9:226.

Henderson, C. R. 1963. Selection index and expected advance. In: W. D. Hanson and H. F. Robinson (eds.), Statistical Genetics and Plant Breeding. (NAS-NRC, Washington, D.C.) Pub. 982:141.

Henderson, C. R. 1973. Sire evaluation and genetic trends. Proc. of the Animal Breeding and Genetics Symposium in Honor of Dr. J. L. Lush. ASAS-ADSA, p. 10.

Henderson, C. R., 0. Kempthorne, S. R. Searle, and C. M. von Krosigk. 1959. The estimation of environmental trends from records subject to culling. Biometrics. 15:192.

Hetzer, H. 0., R. H. Miller, and R. C. Kling. 1977. Effectiveness of reciprocal recurrent selection for improving preweaning performance in swine. J. Anim. Sci. 45(5):989.

Hu11, F. H. 1945. Recurrent selection for specific combining ability in corn. J. Amer. Soc. Agron. 37:134.

Hupp, H. D., R. C. Carter, J. A. Gaines, J. S. Copenhaver, W. H. McClure, and F. S. McClaugherty. 1977. Recurrent selection in Hampshire sheep: I. Realized genetic parameters. ASAS, 69th Ann. Meet. (Abstr.) 23.

Hutchens, L. K. 1980. Age and weight at puberty of purebred and crossbred gilts involving four breeds and their genetic and phenotypic relationships with growth characteristics. (MS thesis, OKlanoma State University.)

Hutchens, L. K. and R. L. Hintz. 1981. A summary of genetic and phenotypic statistics for pubertal and growth characteristics in swine. Tech. Bu11. T-155, Agri. Exp. Stn., Oklahoma State University.

Hutchens, L. K., R. L. Hintz, and R. L. Johnson. 1981. Genetic and phenotypic relationships between pubertal and growth characteristics of gilts. J. Anim. Sci. 53(4):946.

Jilek, A. F., W. C. Burns, M. Koger, and W. T. Butts. 1968. Sire by breed of dam interaction in cattle. J. Anim. Sci. 27:1127.

Johnson, R. K. and I. T. Omtvedt. 1973. Evaluation of purebreds and two-breed crosses in swine: reproductive performance. J. Anim. Sci. $37(6): 1279$.

Johnson, R. K., I. T. Omtvedt, and L. E. Walters. 1973. Evaluation of purebreds and two-breed crosses in swine: feedlot performance and carcass inerit. J. Anim. Sci. 37(1):18. 
Koger, M., A. F. Jilek, W. C. Burns, and J. R. Crockett. 1975. Sire effects for specific combining ability in purebred and crossbred cattle. J. Anim.Sci. 40:230.

Kojima, K. and T. M. Kelleher. 1963. A comparison of purebred and crossbred selection schemes with two populations of Drosophila pseudoobscura. Genetics. 48:55.

Krause, E., Y. Yamada, and A. E. Be11. 1965. Genetic parameters in two populations of chickens under reciprocal recurrent selection. Brit. Poult. Sci. 6:197.

Krehbiel, E. V., H. 0. Hetzer, A. E. Flower, G. E. Dickerson, W. R. Harvey, and L. A. Swiger. 1971a. Effectiveness of reciprocal selection for performance of crosses between Montana no. 1 and Yorkshire swine. I. Preweaning traits. J. Anim. Sci. 32:191.

Krehbiel, E. V., H. O. Hetzer, A. E. Flower, G. E. Dickerson, W. R. Harvey, and L. A. Swiger. 1971b. Effectiveness of reciprocal selection for performance of crosses between Montana no. 1 and Yorkshire swine. II. Postweaning traits. J. Anim. Sci. $32: 211$.

Kreuger, W. F., C. B. Ryan, J. D. Williams, and J. H. Quisenberry. 1961. Three cycles of intra and cross-line selection for a high and low heritability trait. Poult. Sci. 40:1422.

Louca, A. and 0. W. Robison. 1967. Components of variance and covariance in purebred and crossbred swine. J. Anim. Sci. 26:267.

Massey, M. E. and L. L. Benyshek. 1981. Interactions involving sires, breed of dam and age of dam for performance characteristics in Limousin catt7e. J. Anim. Sci. 53(4):940 and 54(5):1104. (erratum.)

McNew, R. W. and A. E. Be11. 1976. Comparison of crossbred and pure-bred selection for a heterotic trait in highly selected populations of Tribolium. J. Heredity. 67:275.

Merg1, R. 1977. Genetic relations between performance of purebred and crossbred hens. Part 3. Genetic relations between laying performance of hybrids and laying performance and fertility parameters of purebreds. Archiv. für Geflugelkunde. 41(5):201. (Anim. Breed. Abstr. 1979. 47(4):211, No. 2023).

Migue 1, C. and T. C. Cartwright. 1963. Comparison of heritabilities in crossbred and purebred cattle. J. Anim. Sci. 22:821 (Abstr.) 
Nunn, T. R., D. D. Kress, P. J. Burfening, and D. Vaniman. 1978. Region by sire interaction for reproduction traits in beef catt7e. J. Anim. Sci. 46(4):957.

Omtvedt, I. T. 1971. Selection for crossing ability in swine. Misc. Pub. No. 85: 166. Agri. Exp. Stn., Oklahoma State University.

Pani, S. N., G. F. Krause, and J. F. Lasley. 1973. Genotype $x$ environment interactions in beef sire evaluation: the importance of sire by year interactions for postweaning traits. J. Anim. Sci. 36(4):622.

Pirchner, F. 1976. Genetic correlations between purebred and crossbred performance in poultry. Bulletin Technique. Dept. de Genetique Animale, Institut National de la Recherche Agronomique. No. 24:63. (Anim. Breed. Abstr. 1977, 45(1):73 No. 420).

Rasmuson, M. 1956. Recurrent reciprocal selection. Results of three model experiments on Drosophila for improvement of quantitative characters. Hereditas (Lund). 42:397.

Rempe1, W. E. 1969. Selection for crossbred performance. 32nd An. Rep. Reg. Swine Breed. Lab. Ames, Iowa. 107.

Robertson, A. 1959. The sampling variance of the genetic correlation coefficient. Biometrics. 15:469.

Robison, 0.W. (ed.) 1981. Guidelines for uniform swine improvement programs. USDA SEA Program Aid 1157.

Robison, O. W., A. Louca, and J. E. Legates. 1964. Purebred and crossbred performance of paternai half-sibs of swine. J. Anim. Sci. 23:853. (Abstr.)

Saadah, H. K., J. V. Craig, L. T. Smith, and S. Wearden. 1968. Effectiveness of alternative breeding systems for increasing rate of egg production in chickens. PouT. Sci. 47:1057.

Salah, E., E. Galal, L. N. Hazel, G. M. Sidwe11, and C. E. Terrill. 1970. Correlation between purebred and crossbred half-sibs in sheep. J. Anim. Sci. 30:475.

Shrestha, J. N. B. 1974. Evaluation of breeding schemes employed for the production of crossbred market pigs. Dis. Abstr. Int. $34 \mathrm{~B}: 3025-\mathrm{B}$.

Snedecor, G. W. and W. G. Cochran. 1967. Statistical Methods, 6th ed. Ames, Iowa: Iowa State University Press.

Sorensen, P. 1977. Genotype-level of protein interaction for growth rate in broilers. Br. Pouit. Sci. 18:625. 
Standal, N. 1968. Studies on breeding and selection schemes in pigs. I. Selection on performance of purebred versus crossbred progeny. Acta Agric. Scand. 18:222.

Stanislaw, C. M. 1966. A covariance analysis between purebred and crossbred populations of swine. (Ph.D. dissertation, Oklahoma State University.)

Stanislaw, C. M., I. T. Omtvedt, R. L. Willham, and J. A. Whatley, Jr. 1967. A study of some genetic parameters in purebred and crossbred populations of swine. J. Anim. Sci. 26:16.

Strang, G. S. and C. Smith. 1979. A note on the heritability of litter traits in pigs. Anim. Prod. 28:403.

Stuber, C. W. and C. C. Cockerham. 1966. Genetic effects and variances in hybrid populations. Genetics. 54:1279.

Swiger, L. A., W. R. Harvey, D. O. Everson, and K. E. Gregory. 1964. The variance of intraclass correlation involving groups with one observation. Biometrics. 20:818.

Tanjik, E. S. and P. Horst. 1979. Importance of high environmental temperature for the occurrence of genotype $x$ environment interaction in litter size and weight and growth in mice. I. The ef fect of high temperature on the traits studied. Zeitschrift für Tierzuchtung und Zuchtungsbiologie. 95(3/4):246. (Anim. Breed. Abstr. 1980. 48(3):151, No. 1389.)

Taylor, J. C., R. H. Miller, and H. O. Hetzer. 1965. Genetic correlations between straightbred and crossbred swine. J. Anim. Sci. 24(2):852. (Abstr.)

Tess, M. W., D. D. Kress, P. J. Burfening, and R. L. Friedrich. 1979. Sire by environment interactions in Simmental-sired calves. J. Anim. Sci. 49(4):964.

Valarezo, J. M. and B. Quijandria. 1979. Genetic parameters for production characteristics in Duroc piglets. Memoria, Asociacion Latinsamerkana de Produccion Animal. (1978). 13:152. (Anim. Breed. Abstr. 47(10):609, No. 5571.)

Vese 1y, J. A. and 0. W. Robison. 1970. Genotype-sex interactions in sheep. J. Anim. Sci. 31:273.

Vinson, W. E., E. J. Eisen, and O. W. Robison. 1969. Predicted response to selection for crossbred performance in mice. J. Anim. Sci. 28:725.

Warwick, E. J. and J. E. Legates. 1979. Breeding and Improvement of Farm Animals. 7th ed. New York: McGraw-Hill Book Co. 
Whatley, J. A. Jr., S. P. Wilson, and I. T. Omtvedt. 1960. Performance tests with purebred and crossbred pigs from two 1 ines of breeding. Misc. Pub. MP-57:50. Agr. Exp. Stn., Oklahoma State University.

Willis, M. B., 0. Santiago, and A. Santos. 1970. Genotype-nutrition interactions in beef cattle. Cuban J. Agric. Sci. 4:155.

Wilson, S. P., J. A. Whatley Jr., J. V. Whiteman, and R. D. Morrison. 1962. Influence of sire and line of breeding on sow productivity. J. Anim. Sci. 21:119.

Wong, W. C. 1969. Inheritance of performance traits in purebred and crossbred populations of swine. Dis. Abstr. Int. 30B:1524B. (Ph.D. dissertation, University of Minnesota.)

Wong, W. C. and W. J. Boylan. 1970. Intrapopulation selection and correlated response in crossbreds of Tribolium castaneum. Genetics. 64:69.

Wong, W. C., W. J. Boylan, and W. E. Rempel. 1971. Purebred versus. crossbred performance as a basis of selection in swine. J. Anim. Sci. 32:605.

Yamada, Y. 1962. Genotype by environment interaction and genetic correlation of the same trait under different environments. Jap. Jour. Genet. 37:498.

Young, L. D., R. K. Johnson, I. T. Omtvedt, and L. E. Walters. 1976a. Postweaning performance and carcass merit of purebred and two-breed cross pigs. J. Anim. Sci. 42(5):1124.

Young, L. D., R. K. Johnson, and I. T. Omtvedt. 1976b. Reproductive performance of swine bred to produce purebred and two-breed cross litters. J. Anim. Sci. 42(5):1133. 
APPENDIXES 
APPENDIX A

TABLES 
TABLE XXII

ADJUSTMENT FACTORS

1. 1444 Data Set

a. Age at $99.8 \mathrm{~kg}$ : additive adjustment factor of $.907 \mathrm{~kg}$ gain per day.

b. Probed backfat thickness at $99.8 \mathrm{~kg}$ : additive adjustment factor of $.224 \mathrm{~mm}$ per $\mathrm{kg}$ live weight.

2. 1620 Data Set

a. Adjusted 42-day weight: $\quad$ 442 $=\frac{\text { Actual weight } \times 27.7}{\text { Actual age }-74.3} \mathrm{~kg}$.

b. Age at $99.8 \mathrm{~kg}$ :

$$
\underset{99.8}{\text { Age }=} \frac{99.8-w_{i}}{\left[\frac{w_{i}}{\text { age }-x}\right]}+\text { age (days) }
$$

c. Probed backfat thickness at $99.8 \mathrm{~kg}$ :

$$
B F=\frac{B F_{i}}{w_{i}} \times 99.8(\mathrm{~mm})
$$

Note: age $=$ off test age (days)

$$
\begin{aligned}
w_{i} & =\text { off test weight }(\mathrm{kg}) \\
x & =36 \text { for barrows and boars; } 31 \text { for gilts } \\
\mathrm{BF}_{\mathrm{w}_{i}} & =\text { probed backfat thickness at off test weight (mm) }
\end{aligned}
$$


TABLE XXIII

1444 DATA SET - NUMBER OF SIRES, LITTERS, AND

PROGENY WITH BIRTH WEIGHT RECORDS BY FAR-

ROWING SEASON AND SIRE BREED

\begin{tabular}{cccccc}
\hline $\begin{array}{l}\text { Farrowing } \\
\text { Seasona }\end{array}$ & $\begin{array}{l}\text { Sire } \\
\text { Breed }\end{array}$ & $\begin{array}{c}\text { No. of } \\
\text { Siresc }\end{array}$ & \multicolumn{3}{c}{ No. of Litters (Progeny) } \\
\hline 711 & D & 5 & $11(86)$ & $20(198)$ & $31(284)$ \\
711 & H & 4 & $10(73)$ & $18(180)$ & $28(253)$ \\
711 & Y & 5 & $9(74)$ & $21(200)$ & $30(274)$ \\
711 & Total & 14 & $30(233)$ & $59(578)$ & $89(811)$ \\
712 & D & 6 & $13(113)$ & $21(178)$ & $34(291)$ \\
712 & H & 6 & $11(99)$ & $17(162)$ & $28(261)$ \\
712 & Y & 6 & $9(72)$ & $20(206)$ & $29(278)$ \\
712 & Total & 18 & $33(284)$ & $58(546)$ & $91(830)$ \\
731 & D & 5 & $9(66)$ & $16(148)$ & $25(214)$ \\
731 & H & 6 & $12(97)$ & $21(222)$ & $33(319)$ \\
731 & Y & 6 & $12(131)$ & $21(211)$ & $33(342)$ \\
731 & Total & 17 & $33(294)$ & $58(581)$ & $91(875)$ \\
732 & D & 6 & $12(128)$ & $21(204)$ & $33(332)$ \\
732 & H & 6 & $11(100)$ & $14(116)$ & $25(216)$ \\
732 & Y & 6 & $14(145)$ & $28(250)$ & $42(395)$ \\
732 & Totai & 18 & $37(373)$ & $63(570)$ & $100(943)$ \\
\hline
\end{tabular}

afirst two numbers indicate year; third number the season ( $1=$ spring; $2=f a 11)$.

$b_{D}=$ Duroc; $H=$ Hampshire; $Y=$ Yorkshire.

${ }^{C}$ The total number of sires involved equals the sum of the farrowing season sub-totals, sires being used for only one breeding season. 
TABLE XXIV

1444 DATA SET - NUMBER OF SIRES, LITTERS, AND PROGENY WITH 21-AND 42-DAY WEIGHT RECORDS

BY FARROWING SEASON AND SIRE BREED

\begin{tabular}{|c|c|c|c|c|c|}
\hline Farrowing & Sire & No. of & & Litters & eny) \\
\hline Season ${ }^{\mathrm{a}}$ & & & Purebred & Crossbred & Total \\
\hline 711 & D & 5 & $9(42)$ & $20(148)$ & $29(190)$ \\
\hline 711 & $H$ & 4 & $7(24)$ & $18(126)$ & $25(150)$ \\
\hline 711 & $y$ & 5 & $9(58)$ & $21(153)$ & $30(211)$ \\
\hline 711 & Total & 14 & $25(124)$ & $59(427)$ & $84(551)$ \\
\hline 712 & D & 6 & $12(54)$ & $21(133)$ & $33(187)$ \\
\hline 712 & H & 5 & $9(50)$ & $15(102)$ & $24(152)$ \\
\hline 712 & $Y$ & 6 & $9(53)$ & $20(149)$ & $29(202)$ \\
\hline 712 & Total & 17 & $30(157)$ & $56(384)$ & $86(541)$ \\
\hline 731 & D & 5 & $9(49)$ & $16(124)$ & $25(173)$ \\
\hline 731 & $H$ & 6 & $12(75)$ & $27(165)$ & $33(240)$ \\
\hline 731 & Y & 6 & $11(89)$ & $20(153)$ & $37(242)$ \\
\hline 731 & Total & 17 & $32(213)$ & $57(442)$ & $89(655)$ \\
\hline 732 & D & 6 & $12(71)$ & $20(155)$ & $32(226)$ \\
\hline 732 & H & 5 & $10(55)$ & $13(84)$ & $23(139)$ \\
\hline 732 & $Y$ & 6 & $14(121)$ & $27(187)$ & $41(308)$ \\
\hline 732 & Total & 17 & $36(247)$ & $60(426)$ & $96(673)$ \\
\hline
\end{tabular}

afirst two numbers indicate year, third number the season (1=spring; $2=f a 11)$.

$b_{D}=$ Duroc; $H=$ Hampshire; $Y=$ Yorkshire.

${ }^{C}$ The total number of sires involved equals the sum of the farrowing season sub-totals, sires being used for only one breeding season. 
TABLE XXV

1444 DATA SET - NUMBER OF SIRES, LITTERS, AND

PROGENY WITH POSTWEANING AVERAGE DAILY

GAIN RECORDS BY FARROWING SEASON

AND SIRE BREED

\begin{tabular}{|c|c|c|c|c|c|}
\hline Farrowing & Sire & No. of & & Litters & eny) \\
\hline & & Siresc & Purebred & Crossbred & Total \\
\hline 711 & D & 5 & $9(35)$ & $20(139)$ & $29(174)$ \\
\hline 711 & $H$ & 4 & $7(23)$ & $18(126)$ & $25(149)$ \\
\hline 711 & $Y$ & 5 & $9(49)$ & $21(145)$ & $30(194)$ \\
\hline 711 & Total & 14 & $25(107)$ & $59(410)$ & $84(517)$ \\
\hline 712 & D & 6 & $12(44)$ & $21(123)$ & $33(167)$ \\
\hline 712 & $H$ & 5 & $9(33)$ & $15(84)$ & $24(117)$ \\
\hline 712 & $Y$ & 6 & $8(34)$ & $18(114)$ & $26(148)$ \\
\hline 712 & Total & 17 & $29(111)$ & $54(321)$ & $83(432)$ \\
\hline 731 & D & 5 & $8(38)$ & $16(107)$ & $24(145)$ \\
\hline 731 & $H$ & 6 & $12(57)$ & $21(133)$ & $33(190)$ \\
\hline 731 & Y & 6 & $12(68)$ & $21(137)$ & $33(205)$ \\
\hline 731 & Total & 17 & $32(163)$ & $58(377)$ & $90(540)$ \\
\hline 732 & $D$ & 6 & $12(65)$ & $21(151)$ & $33(216)$ \\
\hline 732 & $H$ & 5 & $10(46)$ & $13(77)$ & $23(123)$ \\
\hline 732 & Y & 6 & $14(106)$ & $28(176)$ & $42(282)$ \\
\hline 732 & Total & 17 & $36(217)$ & $62(404)$ & $98(621)$ \\
\hline
\end{tabular}

a First two numbers indicate year; third number the season (1=spring; $2=f a 17$ ).

$b_{D}=$ Duroc; $H=$ Hampshire; $Y=$ Yorkshire.

${ }^{c}$ The total number of sires involved equals the sum of the farrowing season sub-totals, sires being used for only one breeding season. 
TABLE XXVI

\section{DATA SET - NUMBER OF SIRES, LITTERS, AND PROGENY WITH PROBED BACKFAT THICKNESS \\ RECORDS BY FARROWING SEASON \\ AND SIRE BREED}

\begin{tabular}{cccccc}
\hline $\begin{array}{l}\text { Farrowing } \\
\text { Seasona }\end{array}$ & $\begin{array}{l}\text { Sire } \\
\text { Breed }\end{array}$ & $\begin{array}{c}\text { No. of } \\
\text { Sires }\end{array}$ & \multicolumn{3}{c}{ No. of Litters (Progeny) } \\
\hline 711 & D & 5 & $8(23)$ & $20(97)$ & $28(120)$ \\
711 & H & 3 & $6(17)$ & $13(54)$ & $19(71)$ \\
711 & Y & 5 & $9(32)$ & $20(83)$ & $29(115)$ \\
711 & Total & 13 & $23(72)$ & $53(234)$ & $76(306)$ \\
712 & D & 4 & $7(22)$ & $16(60)$ & $23(82)$ \\
712 & H & 4 & $8(18)$ & $12(43)$ & $20(61)$ \\
712 & Y & 5 & $7(24)$ & $15(63)$ & $22(87)$ \\
712 & Total & 13 & $22(64)$ & $43(166)$ & $65(230)$ \\
731 & D & 5 & $8(30)$ & $16(75)$ & $24(105)$ \\
731 & H & 6 & $11(37)$ & $22(91)$ & $33(128)$ \\
731 & Y & 6 & $11(41)$ & $21(93)$ & $32(134)$ \\
731 & Total & 17 & $30(108)$ & $59(259)$ & $89(367)$ \\
732 & D & 6 & $12(27)$ & $20(85)$ & $32(112)$ \\
732 & H & 4 & $9(18)$ & $10(41)$ & $19(59)$ \\
732 & Y & 6 & $14(54)$ & $27(87)$ & $41(141)$ \\
732 & Total & 16 & $35(99)$ & $57(213)$ & $92(312)$ \\
\hline
\end{tabular}

a First two numbers indicate year; third number the season (1=spring; $2=f a 11)$.

$b_{D}=$ Duroc $; H=$ Hampshire; $Y=$ Yorkshire.

${ }^{c}$ The total number of sires involved equals the sum of the farrowing season sub-totals, sires being used for only one breeding season. 


\section{TABLE XXVII}

1620 DATA SET - NUMBER OF SIRES, LITTERS, AND

PROGENY WITH BIRTH WEIGHT RECORDS BY

FARROWING SEASON AND SIRE BREED

\begin{tabular}{|c|c|c|c|c|c|}
\hline \multirow{2}{*}{$\begin{array}{l}\text { Farrowing } \\
\text { Seasona }\end{array}$} & \multirow{2}{*}{$\begin{array}{l}\text { Sire } \\
\text { Breedb }\end{array}$} & \multirow{2}{*}{$\begin{array}{l}\text { No. of } \\
\text { Sires }\end{array}$} & \multicolumn{3}{|c|}{ No. of Litters (Progeny) } \\
\hline & & & Purebred & Crossbred & Total \\
\hline 762 & $D$ & 4 & $5(59)$ & $15(148)$ & $20(207)$ \\
\hline 762 & $L$ & 4 & $4(40)$ & $15(140)$ & $19(180)$ \\
\hline 762 & $S$ & 3 & $4(40)$ & $10(127)$ & $14(167)$ \\
\hline 762 & $Y$ & 3 & $3(36)$ & $11(111)$ & $14(147)$ \\
\hline 762 & Total & 14 & $16(175)$ & $51(526)$ & $67(701)$ \\
\hline 771 & $D$ & 4 & $8(86)$ & $13(137)$ & $27(223)$ \\
\hline 771 & $L$ & 4 & $7(83)$ & $12(119)$ & $19(202)$ \\
\hline 771 & $S$ & 4 & $5(47)$ & $17(209)$ & $22(256)$ \\
\hline 771 & $Y$ & 4 & $6(73)$ & $14(120)$ & $20(193)$ \\
\hline 771 & Total & 16 & $26(289)$ & $56(585)$ & $82(874)$ \\
\hline 772 & $D$ & 4 & $5(59)$ & $15(146)$ & $20(205)$ \\
\hline 772 & $L$ & 5 & $7(68)$ & $13(138)$ & $20(206)$ \\
\hline 772 & $S$ & 4 & $5(44)$ & $13(135)$ & $18(179)$ \\
\hline 772 & $Y$ & 4 & $5(68)$ & $12(117)$ & $17(185)$ \\
\hline 772 & Total & 17 & $22(239)$ & $53(536)$ & $75(775)$ \\
\hline 781 & $D$ & 4 & $5(56)$ & $9(101)$ & $14(157)$ \\
\hline 781 & $L$ & 4 & $5(52)$ & $13(133)$ & $18(185)$ \\
\hline 781 & $S$ & 4 & $7(61)$ & $9(101)$ & $16(162)$ \\
\hline 781 & $Y$ & 4 & $5(50)$ & $16(176)$ & $21(226)$ \\
\hline 781 & Total & 16 & $22(219)$ & $47(511)$ & $69(730)$ \\
\hline 782 & $D$ & 4 & $5(35)$ & $13(109)$ & $18(144)$ \\
\hline 782 & $L$ & 3 & $6(63)$ & $10(98)$ & $16(161)$ \\
\hline 782 & $S$ & 3 & $3(22)$ & $6(69)$ & $9(91)$ \\
\hline 782 & $Y$ & 4 & $4(32)$ & $11(106)$ & $15(138)$ \\
\hline 782 & Total & 14 & $18(152)$ & $40(382)$ & $58(534)$ \\
\hline
\end{tabular}

afirst two nos. indicate year; third no. the season $(1=s p r i n g ; 2=f a 11)$.

$b_{D}=$ Duroc; $L=$ Landrace; $S=$ Spotted $Y=$ Yorkshire.

CThe total number of sires involvea does not equal the sum of the farrowing season sub-totals, sires being used for one to four breeding seasons. 
TABLE XXVIII

1620 DATA SET - NUMBER OF SIRES, LITTERS, AND

PROGENY WITH 42-DAY WEIGHT RECORDS BY

FARROWING SEASON AND SIRE BREED

\begin{tabular}{|c|c|c|c|c|c|}
\hline Farrowing & Sire & No. of & No. & Litters ( & eny) \\
\hline & & & Purebred & Crossbred & Total \\
\hline 762 & D & 4 & $5(36)$ & $15(117)$ & $20(153)$ \\
\hline 762 & $L$ & 4 & $4(35)$ & $15(114)$ & $19(149)$ \\
\hline 762 & $S$ & 3 & $4(24)$ & $10(80)$ & $14(104)$ \\
\hline 762 & $Y$ & 3 & $3(23)$ & $11(90)$ & $14(113)$ \\
\hline 762 & Total & 14 & $16(718)$ & $51(401)$ & $67(519)$ \\
\hline 771 & $D$ & 4 & $8(48)$ & $13(104)$ & $21(152)$ \\
\hline 771 & $L$ & 4 & $7(67)$ & $12(89)$ & $19(156)$ \\
\hline 771 & $S$ & 4 & $5(40)$ & $17(149)$ & $22(189)$ \\
\hline 771 & Y & 4 & $6(54)$ & $14(103)$ & $20(157)$ \\
\hline 771 & Total & 16 & $26(209)$ & $56(445)$ & $82(654)$ \\
\hline 772 & D & 4 & $5(23)$ & $15(105)$ & $20(128)$ \\
\hline 772 & $L$ & 5 & $7(49)$ & $12(100)$ & 19(149) \\
\hline 772 & $S$ & 4 & $5(29)$ & $13(101)$ & $18(130)$ \\
\hline 772 & Y & 4 & $5(40)$ & $12(90)$ & $17(130)$ \\
\hline 772 & Total & 17 & $22(141)$ & $52(396)$ & $74(537)$ \\
\hline 781 & $D$ & 4 & $5(37)$ & $9(74)$ & $14(111)$ \\
\hline 781 & $L$ & 4 & $4(30)$ & $13(99)$ & $17(129)$ \\
\hline 781 & $s$ & 4 & $6(41)$ & $9(74)$ & $15(175)$ \\
\hline 781 & Y & 4 & $5(26)$ & $16(112)$ & $21(138)$ \\
\hline 781 & Total & 16 & $20(134)$ & $47(359)$ & $67(493)$ \\
\hline 782 & D & 4 & $5(26)$ & $13(83)$ & $18(109)$ \\
\hline 782 & $L$ & 2 & $5(42)$ & $5(27)$ & $10(69)$ \\
\hline 782 & S & 3 & $3(15)$ & $6(53)$ & $9(68)$ \\
\hline 782 & Y & 4 & $4(17)$ & $11(76)$ & $15(93)$ \\
\hline 782 & Total & 13 & $17(100)$ & $35(239)$ & $52(339)$ \\
\hline
\end{tabular}

afirst two nos. indicate year; third no. the season ( $7=$ spring; $2=f a 11$ ).

$b_{D}=$ Duroc; $L=$ Landrace; $S=$ Spotted $; Y=$ Yorkshire.

${ }^{\mathrm{C}}$ The total number of sires involved does not equal the sum of the farrowing season sub-totals, sires being used for one to four breeding seasons. 
TABLE XXIX

1620 DATA SET - NUMBER OF SIRES, LITTERS, AND

PROGENY WITH POSTWEANING AVERAGE DAILY GAIN

AND PROBED BACKFAT THICKNESS RECORDS BY

BY FARROWING SEASON AND SIRE BREED

\begin{tabular}{|c|c|c|c|c|c|}
\hline Farrowing & Sire & No. of & & Litters & geny) \\
\hline & & & Purebred & Crossbred & Total \\
\hline 762 & D & 4 & $5(26)$ & $15(70)$ & $20(96)$ \\
\hline 762 & L & 4 & $4(26)$ & $15(75)$ & $19(101)$ \\
\hline 762 & $S$ & 3 & $4(22)$ & $10(49)$ & $14(71)$ \\
\hline 762 & $Y$ & 3 & $3(19)$ & $11(55)$ & $14(74)$ \\
\hline 762 & Total & 14 & $16(93)$ & $57(249)$ & $67(342)$ \\
\hline 771 & $D$ & 4 & $8(35)$ & $13(64)$ & $27(99)$ \\
\hline 771 & L & 4 & $7(37)$ & $12(51)$ & $19(88)$ \\
\hline 771 & $s$ & 4 & $5(30)$ & $17(74)$ & $22(104)$ \\
\hline 771 & Y & 4 & $6(30)$ & $14(65)$ & $20(95)$ \\
\hline 771 & Total & 16 & $26(132)$ & $56(254)$ & $82(386)$ \\
\hline 772 & D & 4 & $4(18)$ & $15(60)$ & $19(78)$ \\
\hline 772 & L & 5 & $6(29)$ & $12(50)$ & $18(79)$ \\
\hline 772 & $s$ & 4 & $5(19)$ & $13(62)$ & 18(81) \\
\hline 772 & $Y$ & 4 & $5(19)$ & $12(53)$ & $17(72)$ \\
\hline 772 & Total & 17 & $20(85)$ & $52(225)$ & $72(310)$ \\
\hline 781 & $D$ & 4 & $4(25)$ & $9(48)$ & $13(73)$ \\
\hline 781 & L & 4 & $4(28)$ & $13(65)$ & $17(93)$ \\
\hline 781 & $S$ & 4 & $6(27)$ & $9(51)$ & $15(78)$ \\
\hline 781 & Y & 4 & $5(16)$ & $16(64)$ & $2](80)$ \\
\hline 781 & Total & 16 & $19(96)$ & $47(228)$ & $66(324)$ \\
\hline 782 & D & 4 & $5(23)$ & $11(55)$ & $16(78)$ \\
\hline 782 & $L$ & 2 & $5(27)$ & $4(17)$ & $9(38)$ \\
\hline 782 & $S$ & 3 & $2(8)$ & $6(36)$ & $8(44)$ \\
\hline 782 & Y & 3 & $2(7)$ & $9(34)$ & $17(47)$ \\
\hline 782 & Total & 12 & $14(59)$ & $30(142)$ & $44(201)$ \\
\hline
\end{tabular}

afirst two nos. indicate year; third no. the season $(1=\operatorname{spring}, 2=f a 11)$.

$b_{D}=$ Duroc; $L=$ Landrace; $S=$ Spotted; $Y=$ Yorkshire.

${ }^{\mathrm{C}}$ The total number of sires involved does not equal the sum of the farrowing season sub-totals, sires being used for one to four breeding seasons. 
TABLE XXX

HERITABILITY AND VARIANCE COMPONENT RATIOS

\begin{tabular}{lccccc}
\hline Trait $^{a}$ & Data Set & $\frac{V_{e}{ }^{b}}{V_{s t}}$ & $n^{2^{c}}$ & \multicolumn{1}{c}{$V_{e}{ }^{d}$} & $\frac{V_{e}^{\prime}}{V_{s}}$ \\
\hline BW & 1444 & 7.244 & $.19^{\prime}$ & 20.053 & 184.741 \\
BW & 1620 & 8.520 & $.19^{\prime}$ & 20.053 & -60.429 \\
W21 & 1444 & 5.537 & $.16^{234}$ & 24.000 & -60.282 \\
W42 & 1444 & 8.034 & $.15^{\prime}$ & 25.667 & 15.846 \\
W42 & 1620 & 8.802 & $.15^{\prime}$ & 25.667 & -53.816 \\
ADG & 1444 & 13.003 & $.38^{\prime}$ & 9.526 & 27.395 \\
ADG & 1620 & 12.800 & $.38^{\prime}$ & 9.526 & 22.493 \\
BF & 1444 & 9.261 & $.39^{\prime}$ & 9.256 & 21.071 \\
BF & 1620 & 22.382 & $.39^{\prime}$ & 9.256 & 21.846 \\
\hline
\end{tabular}

$\mathrm{a}_{\mathrm{BW}}=$ Birth Weight; $W 21=21$-day Weight; $W 42=42$-day Weight; $A D G=$ Postweaning Average Daily Gain; BF = Probed Backfat Thickness at $99.8 \mathrm{~kg}$.

batio of residual to sire within breed of sire (1620 data set)/yearseason by breed of sire (1444 data set) by type interaction variance component estimates obtained from analyses of these data.

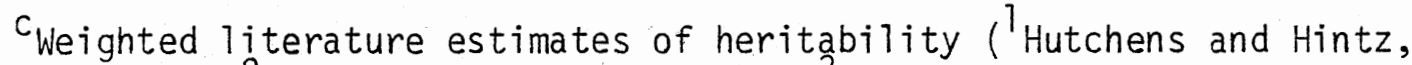
1981; 2Edwards and Omtvedt, 1971; 3Strang and Smith, 1979;

4 Valarezo and Quijandria, 1979).

dRatio of residual to sire variance components estimated from $c$ as:

$$
\frac{V_{e}}{V_{s}}=\frac{4-\hat{h}^{2}}{\hat{h}^{2}}
$$

eRatio of residual to sire (nested as in b) variance component estimates obtained from analyses of this data but not used in favor of literature estimates. 
TABL.E XXXI

OBSERVED SIGNIFICANCE LEVELS OF DIFFERENCES BETWEEN BREED OF DAM GENERALIZED LEAST SQUARES MEANS

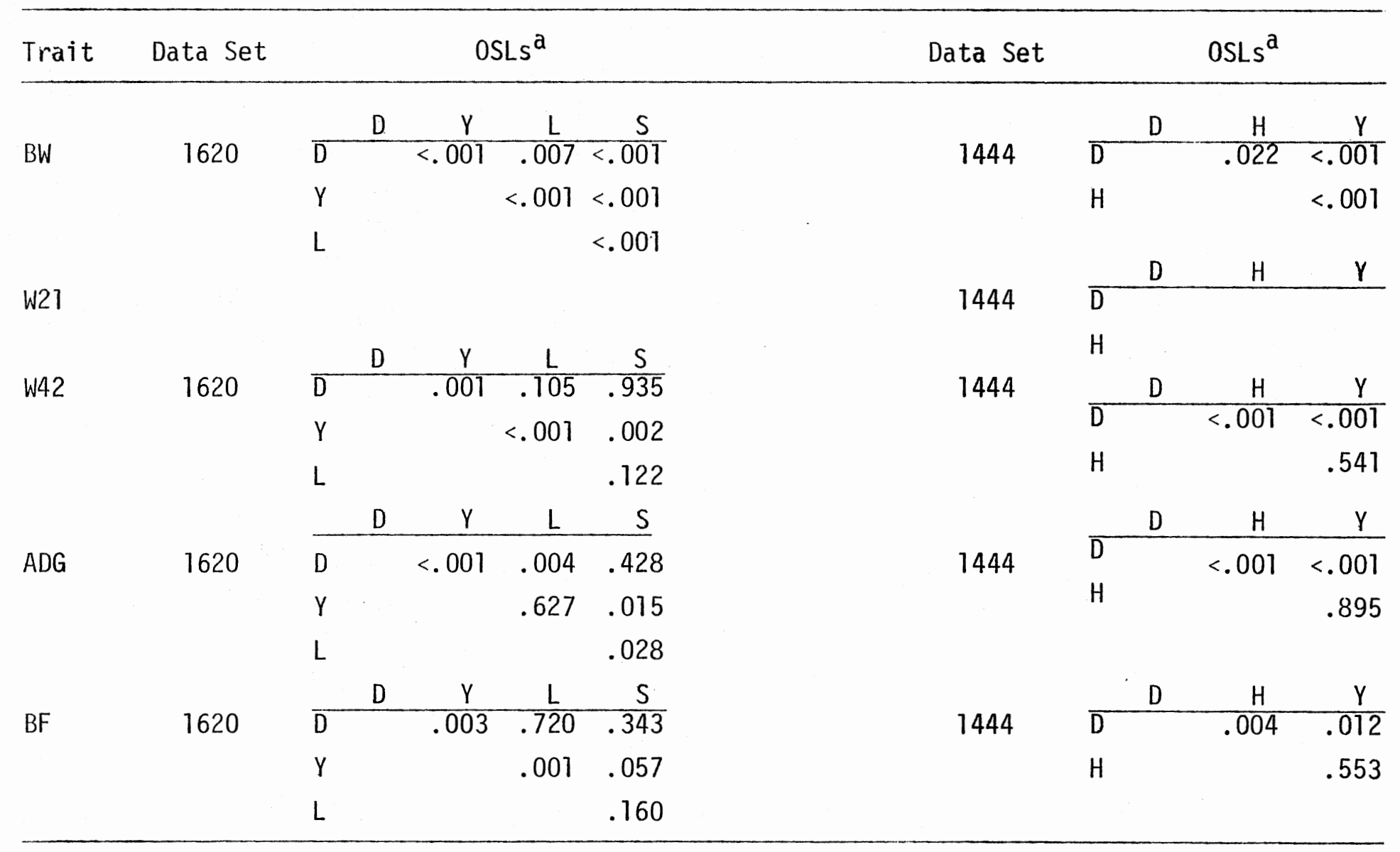

$\mathrm{aD}=$ Duroc $; H=$ Hampshire; $L=$ Landrace; $S=$ Spotted; $Y=$ Yorkshire. 
TABLE XXXII

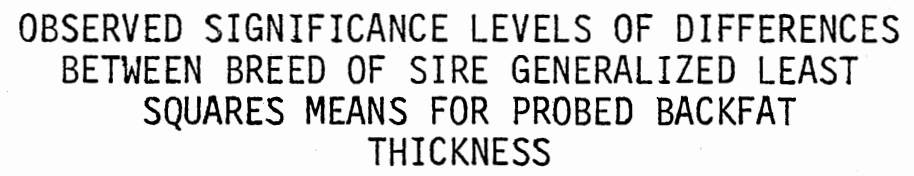

\begin{tabular}{|c|c|c|c|c|}
\hline \multicolumn{2}{|l|}{ Data Set } & \multicolumn{3}{|c|}{ OSLs ${ }^{a}$} \\
\hline \multirow{3}{*}{1444} & & D & $\mathrm{H}$ & $Y$ \\
\hline & & & $<.001$ & .209 \\
\hline & & & & .001 \\
\hline \multirow{4}{*}{1620} & D & $y$ & $L$ & $\mathrm{~S}$ \\
\hline & $\bar{D}$ & .284 & $<.001$ & .010 \\
\hline & y & & .003 & .167 \\
\hline & L & & & .108 \\
\hline
\end{tabular}


TABLE XXXIII

VARIANCE COMPONENT COEFFICIENTS (k-VALUES) ${ }^{a}$

FOR PUREBRED AND CROSSBRED ANALYSES

\begin{tabular}{lccc}
\hline Trait & Data Set & $k_{\mathrm{PBB}}{ }^{\mathrm{C}}$ & $k_{\mathrm{CB}}{ }^{\mathrm{d}}$ \\
\hline BW & 1444 & 16.87 & 32.01 \\
W21/W42 & 1444 & 10.86 & 24.42 \\
ADG & 1444 & 8.72 & 22.01 \\
BF & 1444 & 5.44 & 13.75 \\
& & & \\
BW & 1620 & 18.90 & 48.80 \\
W42 & 1620 & 12.60 & 36.18 \\
ADG/BF & 1620 & 8.26 & 21.69 \\
\hline
\end{tabular}

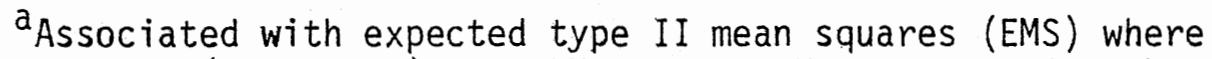
EMS (sire term) $=V_{e}+k V_{S}, V_{e}$ and $V_{S}$ representing the residual and sire components of variance, respectively.

$b_{B W}=$ Birth Weight; $W 21=21$-day Weight, $W 42=42$-day Weight; $A D G=$ Postweaning Average Daily Gain; $B F=$ Probed Backfat Thickness at $99.8 \mathrm{~kg}$.

$c_{k}$ value from purebred analyses.

$d_{k}$ value from crossbred analyses. 
TABLE XXXIV

VARIANCE COMPONENT COEFFICIENTS (k-VALUES) $)^{a}$

FOR POOLED ANALYSES

\begin{tabular}{lcccc}
\hline Trait $^{b}$ & Data Set & $k_{s t}{ }^{a}$ & $k_{s t}{ }^{a}$ & $k_{s}{ }^{a}$ \\
\hline BW & 1444 & 20.84 & 28.42 & 49.26 \\
W21/W42 & 1444 & 14.30 & 21.31 & 35.62 \\
ADG & 1444 & 11.80 & 19.12 & 30.92 \\
BF & 1444 & 7.42 & 11.91 & 19.32 \\
BW & 1620 & 30.84 & 44.10 & 72.35 \\
W42 & 1620 & 20.96 & 32.72 & 51.96 \\
ADG/BF & 1620 & 13.36 & 19.98 & 32.16 \\
\hline
\end{tabular}

a Associated with expected type II mean squares (EMS) where EMS (sire term) $=V_{e}+k_{s t}, V_{s t}+k_{s} V_{s}$; EMS (sire by type interaction term) $=V_{e}+k_{s t} V_{s t}$ and $V_{s}, V_{s t}$, and $V_{e}$ are the sire, sire by type interaction, and residual variance components, respectively.

$\mathrm{b}_{\mathrm{BW}}=$ Birth Weight; $W 21=21$-day Weight; $W 42=42$-day Weight; $A D G=$ Postweaning Average Daily Gain; $B F=$ Probed Backfat Thickness at $99.8 \mathrm{~kg}$. 


\section{TABLE XXXV}

1444 DATA SET - DUROC SIRE BREEDING VALUES OBTAINED FROM MIXED MODEL SOLUTIONS

\begin{tabular}{|c|c|c|c|c|c|c|c|c|c|c|}
\hline \multirow{3}{*}{ Sire } & \multicolumn{10}{|c|}{ Trait ${ }^{a}$} \\
\hline & \multicolumn{2}{|c|}{$\mathrm{BW}$} & \multicolumn{2}{|c|}{ W21 } & \multicolumn{2}{|c|}{$W 42$} & \multicolumn{2}{|c|}{$\overline{A D G}$} & \multicolumn{2}{|c|}{$\mathrm{BF}$} \\
\hline & $\frac{B V 1^{b}}{1.19}$ & $\frac{B V 2^{C}}{1.20}$ & $\frac{B V 1^{b}}{4.05}$ & $\frac{B V 2^{C}}{4.68}$ & $\frac{B V 7^{b}}{10.16}$ & $\frac{B V 2^{C}}{12.34}$ & $\frac{B V 7^{b}}{.628}$ & $\frac{B V 2^{C}}{.706}$ & $\frac{\mathrm{BV}^{\mathrm{b}}}{39.43}$ & $\frac{\mathrm{BV}^{\mathrm{C}}}{33.04}$ \\
\hline 2 & 1.16 & 1.10 & 3.91 & 4.53 & 9.95 & 11.37 & .633 & .728 & 37.23 & 32.70 \\
\hline 3 & 1.29 & 1.56 & 4.42 & 4.98 & 10.76 & 12.32 & .630 & .689 & 32.65 & 30.77 \\
\hline 4 & 1.24 & 1.31 & 4.36 & 4.80 & 10.31 & 11.72 & .659 & .741 & 37.14 & 32.82 \\
\hline 5 & 1.16 & 1.13 & 3.79 & 4.44 & 8.49 & 10.66 & .650 & .759 & 39.22 & 33.58 \\
\hline 6 & 1.35 & 1.23 & 4.69 & 4.44 & 9.97 & 10.71 & .682 & .717 & 33.65 & 32.14 \\
\hline 7 & 1.24 & 1.27 & 3.78 & 4.96 & 10.31 & 13.13 & .649 & .756 & 37.68 & 33.16 \\
\hline 8 & 1.06 & 1.26 & 4.59 & 5.18 & 9.78 & 11.71 & .652 & .740 & 34.58 & 32.72 \\
\hline 9 & 1.18 & 1.08 & 4.36 & 4.62 & 9.65 & 10.44 & .663 & .748 & 30.68 & 31.48 \\
\hline 10 & 1.41 & 1.18 & 5.02 & 5.17 & 8.95 & 9.86 & .621 & .682 & 26.68 & 27.02 \\
\hline 11 & 1.29 & 1.27 & 4.40 & 5.14 & 9.86 & 12.22 & .654 & .741 & 29.41 & 29.68 \\
\hline 12 & 1.22 & 1.26 & 4.34 & 4.95 & 11.18 & 12.47 & .652 & .713 & 33.70 & 32.30 \\
\hline 13 & 1.19 & 1.15 & 4.14 & 4.80 & 9.03 & 10.01 & .644 & .719 & 33.34 & 31.38 \\
\hline 14 & 1.37 & 1.26 & 5.14 & 5.43 & 11.38 & 10.78 & .647 & .718 & 27.85 & 26.82 \\
\hline 15 & 1.16 & 1.18 & 3.89 & 4.33 & 8.57 & 9.98 & .627 & .715 & 33.90 & 31.88 \\
\hline
\end{tabular}


TABLE XXXV (Continued)

\begin{tabular}{|c|c|c|c|c|c|c|c|c|c|c|}
\hline \multirow[b]{2}{*}{ Sire } & \multicolumn{10}{|c|}{ Trait } \\
\hline & \multicolumn{2}{|c|}{ BW } & \multicolumn{2}{|c|}{ W21 } & \multicolumn{2}{|c|}{ W42 } & \multicolumn{2}{|c|}{$\overline{A D G}$} & \multicolumn{2}{|c|}{$B F$} \\
\hline 16 & $\frac{\mathrm{BV} 7^{\mathrm{b}}}{1.36}$ & $\frac{B V 2^{C}}{1.39}$ & $\frac{\mathrm{BV} 1^{\mathrm{b}}}{5.44}$ & $\frac{B V 2^{C}}{5.64}$ & $\frac{\mathrm{BV}^{\mathrm{b}}}{10.02}$ & $\frac{\mathrm{BV}^{\mathrm{C}}}{11.54}$ & $\frac{\mathrm{BV} 7^{\mathrm{b}}}{.678}$ & $\frac{B V 2^{C}}{.764}$ & $\frac{\mathrm{BV}^{\mathrm{b}}}{28.44}$ & $\frac{\mathrm{BV} 2 \mathrm{C}}{29.66}$ \\
\hline 17 & 1.30 & 1.24 & 5.12 & 5.04 & 10.06 & 11.13 & .667 & .750 & 28.15 & 27.88 \\
\hline 18 & 1.47 & 1.37 & 5.04 & 4.80 & 11.75 & 11.19 & .644 & .704 & 34.40 & 33.25 \\
\hline 19 & 1.36 & 1.46 & 4.66 & 5.19 & 11.17 & 11.94 & .655 & .653 & 30.63 & 30.43 \\
\hline 20 & 1.34 & 1.45 & 5.41 & 6.39 & 11.98 & 14.23 & .673 & .786 & 28.61 & 28.13 \\
\hline 21 & 1.05 & 1.28 & 3.61 & 4.76 & 8.91 & 10.73 & .700 & .819 & -- & -- \\
\hline 22 & 1.16 & 1.09 & 4.28 & 4.62 & 8.91 & 9.58 & .674 & .751 & -- & -- \\
\hline
\end{tabular}

$a_{B W}=$ Birth Weight $(\mathrm{kg}) ; W 21=21$-day Weight $(\mathrm{kg}) ; W 42=42$-day Weight $(\mathrm{kg}) ; A D G=$ Postweaning Average Daily Gain (kg/day); BF = Probed Backfat Thickness at $99.8 \mathrm{~kg}(\mathrm{~mm})$.

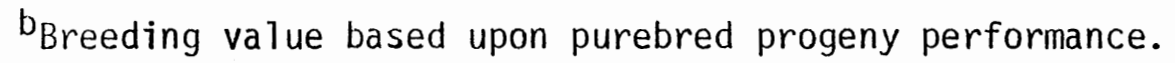

${ }^{C}$ Breeding value based upon crossbred progeny performance. 
TABLE XXXVI

1444 DATA SET - HAMPSHIRE SIRE BREEDING VALUES OBTAINED FROM MIXED MODEL SOLUTIONS

\begin{tabular}{|c|c|c|c|c|c|c|c|c|c|c|}
\hline \multirow{3}{*}{ Sire } & \multicolumn{10}{|c|}{ Traita } \\
\hline & \multicolumn{2}{|c|}{$\mathrm{BW}$} & \multicolumn{2}{|c|}{ W21 } & \multicolumn{2}{|c|}{ W42 } & \multicolumn{2}{|c|}{$\overline{A D G}$} & \multicolumn{2}{|c|}{$\mathrm{BF}$} \\
\hline & $\mathrm{BV} 7^{\mathrm{b}}$ & $\underline{B V} 2^{C}$ & BVI ${ }^{b}$ & $\mathrm{BV} 2^{\mathrm{C}}$ & $\mathrm{BV}{ }^{\mathrm{b}}$ & $\mathrm{BV} 2^{\mathrm{C}}$ & BVIb & BV2C & $\mathrm{BV} 7^{\mathrm{b}}$ & $\mathrm{BV}^{\mathrm{C}}$ \\
\hline 1 & 1.16 & 1.19 & 3.91 & 4.26 & 8.54 & 10.04 & .679 & .717 & 26.84 & 28.43 \\
\hline 2 & 1.04 & 1.24 & 4.31 & 4.39 & 9.23 & 9.73 & .656 & .708 & 29.01 & 30.14 \\
\hline 3 & 0.97 & 1.31 & 4.41 & 5.07 & 10.01 & 10.87 & .684 & .749 & 31.74 & 29.95 \\
\hline 4 & 1.08 & 1.14 & 4.45 & 4.73 & 10.55 & 9.72 & .683 & .712 & 33.05 & 31.07 \\
\hline 5 & 1.07 & 1.14 & 5.14 & 4.94 & 10.63 & 10.58 & .641 & .718 & 24.46 & 24.47 \\
\hline 6 & 1.24 & 1.31 & 6.00 & 4.86 & 10.88 & 10.12 & .622 & .706 & 24.66 & 24.96 \\
\hline 7 & 1.11 & 1.24 & 4.17 & 5.04 & 9.32 & 11.22 & .676 & .691 & 26.14 & 27.84 \\
\hline 8 & 1.38 & 1.52 & 5.27 & 5.54 & 11.46 & 11.55 & .608 & .640 & 33.40 & 30.49 \\
\hline 9 & 1.32 & 1.24 & 5.04 & 5.13 & 10.84 & 10.69 & .658 & .660 & 32.37 & 30.57 \\
\hline 10 & 0.97 & 1.30 & 4.94 & 5.52 & 12.01 & 11.76 & .683 & .754 & 32.38 & 34.01 \\
\hline 11 & 1.12 & 1.38 & 5.26 & 5.53 & 10.12 & 11.21 & .673 & .728 & 26.83 & 27.65 \\
\hline 12 & 1.29 & 1.40 & 5.16 & 6.12 & 11.94 & 12.90 & .637 & .656 & 30.94 & 27.69 \\
\hline 13 & 1.28 & 1.28 & 5.48 & 5.51 & 12.52 & 11.29 & .616 & .640 & 32.15 & 28.72 \\
\hline 14 & 1.17 & 1.48 & 3.69 & 5.35 & 8.41 & 10.23 & .561 & .596 & 31.80 & 28.19 \\
\hline 15 & 1.33 & 1.40 & 4.98 & 5.29 & 10.44 & 11.15 & .650 & .745 & 27.99 & 28.56 \\
\hline
\end{tabular}


TABLE XXXVI (Continued)

\begin{tabular}{|c|c|c|c|c|c|c|c|c|c|c|}
\hline \multirow{3}{*}{ Sire } & \multicolumn{10}{|c|}{ Trait } \\
\hline & \multicolumn{2}{|c|}{ BW } & \multicolumn{2}{|c|}{ W21 } & \multicolumn{2}{|c|}{ W42 } & \multicolumn{2}{|c|}{ ADG } & \multicolumn{2}{|c|}{$\mathrm{BF}$} \\
\hline & $\frac{\mathrm{BV}]^{\mathrm{b}}}{1.23}$ & $\frac{\mathrm{BV} 2^{\mathrm{C}}}{1.27}$ & $\frac{B V 1^{b}}{5.68}$ & $\frac{B V 2^{C}}{5.47}$ & $\frac{\mathrm{BV} 7^{\mathrm{b}}}{11.33}$ & $\frac{B V 2^{C}}{11.42}$ & $\frac{\mathrm{BV} 1^{\mathrm{b}}}{.609}$ & $\frac{\mathrm{BV} \mathrm{V}^{\mathrm{C}}}{.63 \mathrm{~T}}$ & $\frac{\mathrm{BV} 7^{\mathrm{b}}}{33.60}$ & $\frac{B V 2^{C}}{31.05}$ \\
\hline 17 & 1.22 & 1.27 & 5.14 & 4.10 & 10.32 & 9.53 & .632 & .720 & 24.94 & 25.40 \\
\hline 18 & 0.95 & 1.29 & 3.50 & 4.41 & 8.35 & 9.93 & .664 & .691 & -- & -- \\
\hline 19 & 0.89 & 1.14 & 4.21 & 4.92 & 10.01 & 10.75 & .684 & .743 & -- & -- \\
\hline 20 & 1.11 & 1.20 & 5.96 & 5.05 & 11.89 & 11.77 & .677 & .753 & -- & -- \\
\hline 21 & 1.34 & 1.47 & -- & -- & -- & -- & -- & -- & -- & -. \\
\hline 22 & 0.86 & 1.12 & -- & -. & $\ldots$ & -- & -- & -- & -. & -- \\
\hline
\end{tabular}

$a_{B W}=$ Birth Weight $(\mathrm{kg}) ; W 21=21$-day Weight $(\mathrm{kg}) ;$ W42 $=42$-day Weight $(\mathrm{kg}) ; A D G=$ Postweaning Average Daily Gain ( $\mathrm{kg} /$ day); BF = Probed Backfat Thickness at $99.8 \mathrm{~kg}(\mathrm{~mm})$.

bBreeding value based upon purebred progeny performance.

${ }^{C_{B}}$ Breeding value based upon crossbred progeny performance. 
TABLE XXXVII

1444 DATA SET - YORKSHIRE SIRE BREEDING VALUES OBTAINED FROM MIXED MODEL SOLUTIONS

\begin{tabular}{|c|c|c|c|c|c|c|c|c|c|c|}
\hline \multirow{3}{*}{ Sire } & \multicolumn{10}{|c|}{ Traita } \\
\hline & \multicolumn{2}{|c|}{$\overline{B W}$} & \multicolumn{2}{|c|}{ W21 } & \multicolumn{2}{|c|}{ W42 } & \multicolumn{2}{|c|}{$\overline{A D G}$} & \multicolumn{2}{|c|}{$\overline{B F}$} \\
\hline & $\frac{\mathrm{BV}^{\mathrm{b}}}{1.10}$ & $\frac{\mathrm{BV}^{\mathrm{C}}}{1.08}$ & $\frac{\mathrm{BV}]^{\mathrm{b}}}{5.10}$ & $\frac{B V 2^{C}}{4.73}$ & $\frac{\mathrm{BV} 7^{\mathrm{b}}}{11.45}$ & $\frac{\mathrm{BV}^{\mathrm{C}}}{10.95}$ & $\frac{\mathrm{BV}]^{\mathrm{b}}}{.630}$ & $\frac{B V 2^{C}}{.729}$ & $\frac{\mathrm{BV} 1^{\mathrm{b}}}{32.44}$ & $\frac{\mathrm{BV}^{\mathrm{C}}}{34.66}$ \\
\hline 2 & 1.30 & 1.35 & 4.58 & 4.95 & 10.82 & 10.93 & .599 & .634 & 33.88 & 33.42 \\
\hline 3 & 1.34 & 1.38 & 4.62 & 5.23 & 11.73 & 11.98 & .692 & .730 & 28.00 & 30.26 \\
\hline 4 & 1.34 & 1.38 & 5.09 & 5.16 & 11.79 & 12.03 & .667 & .694 & 33.62 & 32.57 \\
\hline 5 & 1.05 & 1.06 & 4.35 & 4.81 & 10.21 & 10.73 & .665 & .733 & 34.49 & 38.71 \\
\hline 6 & 1.26 & 1.10 & 4.72 & 4.85 & 10.47 & 10.40 & .680 & .729 & 30.91 & 30.99 \\
\hline 7 & 1.21 & 1.23 & 5.25 & 5.24 & 12.37 & 12.15 & .659 & .726 & 34.00 & 35.70 \\
\hline 8 & 1.43 & 1.42 & 4.81 & 5.93 & 11.34 & 12.46 & .622 & .635 & 32.17 & 31.61 \\
\hline 9 & 1.17 & 1.04 & 4.85 & 4.88 & 11.40 & 10.24 & .651 & .682 & 32.00 & 32.24 \\
\hline 10 & 1.38 & 1.24 & 5.50 & 4.34 & 11.45 & 9.64 & .621 & .674 & 29.62 & 30.26 \\
\hline 11 & 1.45 & 1.41 & 5.31 & 5.37 & 11.78 & 10.83 & .680 & .662 & 25.52 & 27.96 \\
\hline 12 & 1.14 & 1.08 & 4.43 & 4.73 & 10.69 & 10.46 & .674 & .719 & 31.59 & 33.37 \\
\hline 13 & 1.06 & 1.11 & 4.71 & 4.06 & 10.86 & 9.54 & .645 & .715 & 33.12 & 36.39 \\
\hline 14 & 1.36 & 1.38 & 4.84 & 5.36 & 11.10 & 11.32 & .735 & .725 & 25.45 & 27.53 \\
\hline 15 & 1.34 & 1.27 & 5.71 & 5.37 & 9.95 & 11.43 & .660 & .650 & 25.03 & 27.75 \\
\hline
\end{tabular}




\section{TABLE XXXVII (Continued)}

\begin{tabular}{|c|c|c|c|c|c|c|c|c|c|c|}
\hline \multirow{2}{*}{ Sire } & \multicolumn{10}{|c|}{ Trait $^{a}$} \\
\hline & \multicolumn{2}{|c|}{$\mathrm{BW}$} & \multicolumn{2}{|c|}{ W21 } & \multicolumn{2}{|c|}{ W42 } & \multicolumn{2}{|c|}{$\overline{A D G}$} & \multicolumn{2}{|c|}{$\mathrm{BF}$} \\
\hline 16 & $\frac{\mathrm{BV} 7^{\mathrm{b}}}{1.38}$ & $\frac{B V 2^{C}}{1.31}$ & $\frac{\mathrm{BV} 7^{\mathrm{b}}}{5.48}$ & $\frac{B V 2^{C}}{5.33}$ & $\frac{\mathrm{BV} 7^{\mathrm{b}}}{12.76}$ & $\frac{\mathrm{BV} 2^{\mathrm{C}}}{12.55}$ & $\frac{\mathrm{BV}]^{\mathrm{b}}}{.649}$ & $\frac{\mathrm{BV} 2^{\mathrm{C}}}{.660}$ & $\frac{\mathrm{BV} 1^{\mathrm{b}}}{33.03}$ & $\frac{\mathrm{BV} 2^{\mathrm{C}}}{32.02}$ \\
\hline 17 & 1.22 & 1.20 & 4.78 & 4.80 & 10.71 & 10.36 & .665 & .687 & 32.61 & 33.32 \\
\hline 18 & 1.42 & 1.42 & 5.44 & 5.43 & 12.35 & 11.47 & .654 & .641 & 32.88 & 31.96 \\
\hline 19 & 1.17 & 1.28 & 4.57 & 4.67 & 11.02 & 10.18 & .651 & .717 & 32.34 & 31.21 \\
\hline 20 & 1.38 & 1.27 & 4.73 & 5.06 & 10.84 & 11.37 & .690 & .657 & 27.05 & 28.05 \\
\hline 21 & 1.38 & 1.43 & 5.24 & 4.42 & 11.28 & 9.17 & .760 & .718 & 26.90 & 27.05 \\
\hline 22 & 1.37 & 1.34 & 4.96 & 5.23 & 10.70 & 11.18 & .626 & .659 & 31.79 & 32.80 \\
\hline 23 & 1.22 & 1.07 & 4.11 & 4.70 & 10.14 & 9.91 & .635 & .674 & -- & -- \\
\hline
\end{tabular}

$\mathrm{a}_{\mathrm{BW}}=$ Birth Weight $(\mathrm{kg}) ; \mathrm{W} 21=21$-day Weight $(\mathrm{kg}) ;$ W42 $=42$-day Weight $(\mathrm{kg}) ;$ ADG = Postweaning Average Daily Gain ( $\mathrm{kg} /$ day); $\mathrm{BF}=$ Probed Backfat Thickness at $99.8 \mathrm{~kg}(\mathrm{~mm})$.

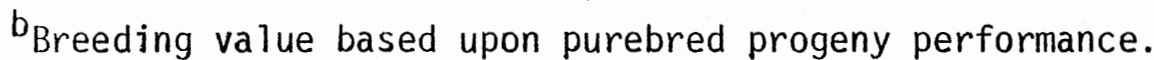

$\mathrm{C}_{\text {Breeding value based upon crossbred progeny performance. }}$ 
TABLE XXXVIII

1620 DATA SET - SIRE BREEDING VALUES OBTAINED

FROM MIXED MODEL SOLUTIONS

\begin{tabular}{|c|c|c|c|c|c|c|c|c|c|}
\hline \multirow[b]{3}{*}{$\frac{B O S b}{D}$} & \multirow[b]{3}{*}{$\frac{\text { Sire }}{1}$} & \multicolumn{8}{|c|}{ Trait ${ }^{\mathrm{a}}$} \\
\hline & & \multicolumn{2}{|c|}{$\overline{B W}$} & \multicolumn{2}{|c|}{ W42 } & \multicolumn{2}{|c|}{$\overline{A D G}$} & \multicolumn{2}{|c|}{$\mathrm{BF}$} \\
\hline & & $\frac{\mathrm{BV} 7^{\mathrm{C}}}{1.29}$ & $\frac{B V 2 d}{1.44}$ & $\frac{B \vee T^{C}}{9.90}$ & $\frac{B 2^{d}}{11.52}$ & $\frac{\mathrm{BV} 7^{\mathrm{C}}}{.652}$ & $\frac{\mathrm{BV} 2^{\mathrm{d}}}{.770}$ & $\frac{\mathrm{BV}{ }^{\mathrm{C}}}{25.27}$ & $\frac{\mathrm{BV}^{\mathrm{d}}}{25.29}$ \\
\hline D & 2 & 1.34 & 1.33 & 13.08 & 13.19 & .656 & .749 & 24.64 & 24.43 \\
\hline D & 3 & 1.43 & 1.41 & 10.55 & 12.09 & .635 & .734 & 25.64 & 26.43 \\
\hline D & 4 & 1.40 & 1.57 & 10.49 & 10.76 & .649 & .774 & 23.05 & 24.06 \\
\hline$D$ & 5 & 1.42 & 1.69 & 8.70 & 11.01 & .612 & .727 & 26.53 & 25.59 \\
\hline D & 6 & 1.24 & 1.36 & 9.08 & 10.68 & .612 & .709 & 24.82 & 25.78 \\
\hline$D$ & 7 & 1.24 & 1.43 & 10.78 & 12.60 & .656 & .761 & 24.69 & 24.77 \\
\hline D & 8 & 1.26 & 1.60 & 10.26 & 12.89 & .635 & .757 & 24.72 & 25.00 \\
\hline D & 9 & 1.30 & 1.49 & 9.88 & 12.26 & .584 & .706 & 24.82 & 23.92 \\
\hline$D$ & 10 & 1.42 & 1.36 & 12.32 & 12.06 & .640 & .720 & 25.62 & 25.38 \\
\hline$L$ & 1 & 1.16 & 1.26 & 10.11 & 11.84 & .646 & .663 & 27.57 & 28.24 \\
\hline$L$ & 2 & 1.31 & 1.40 & 11.01 & 11.98 & .696 & .727 & 26.42 & 26.71 \\
\hline$L$ & 3 & 1.29 & 1.46 & 11.59 & 11.34 & .641 & .670 & 29.40 & 29.98 \\
\hline L & 4 & 1.38 & 1.53 & 11.49 & 12.45 & .630 & .686 & 29.14 & 29.63 \\
\hline$L$ & 5 & 1.29 & 1.38 & 9.58 & 11.61 & .669 & .695 & 28.13 & 28.71 \\
\hline$L$ & 6 & 1.56 & 1.38 & 11.31 & 10.86 & .649 & .685 & 26.75 & 27.71 \\
\hline
\end{tabular}


TABLE XXXVIII (Continued)

\begin{tabular}{|c|c|c|c|c|c|c|c|c|c|}
\hline \multirow[b]{3}{*}{$B O S^{b}$} & \multirow[b]{3}{*}{ Sire } & \multicolumn{6}{|c|}{ Trait } & \multirow{2}{*}{\multicolumn{2}{|c|}{$\overline{B F}$}} \\
\hline & & \multicolumn{2}{|c|}{$\mathrm{BW}$} & \multicolumn{2}{|c|}{$W 42$} & \multicolumn{2}{|c|}{$\overline{A D G}$} & & \\
\hline & & $\frac{B V 7^{C}}{0.98}$ & $\frac{B V 2^{d}}{1.14}$ & $\frac{\mathrm{BV} 1^{\mathrm{C}}}{9.78}$ & $\frac{\mathrm{BV}^{\mathrm{d}}}{10.64}$ & $\frac{\mathrm{BV} 7^{\mathrm{C}}}{.688}$ & $\frac{B V 2^{d}}{.736}$ & $\frac{\mathrm{BV}^{\mathrm{C}}}{27.16}$ & $\frac{B V 2^{d}}{27.50}$ \\
\hline $\mathrm{L}$ & 8 & 1.37 & 1.46 & 10.81 & 12.10 & .680 & .738 & 26.77 & 27.83 \\
\hline$L$ & 9 & 1.21 & 1.50 & -- & -- & -- & -- & -- & -- \\
\hline$S$ & 1 & 1.36 & 1.30 & 9.53 & 11.37 & .679 & .729 & 27.02 & 28.95 \\
\hline$S$ & 2 & 1.29 & 1.27 & 9.77 & 12.05 & .645 & .712 & 25.62 & 27.17 \\
\hline$S$ & 3 & 1.17 & 1.43 & 10.69 & 11.33 & .606 & .695 & 24.47 & 26.12 \\
\hline$S$ & 4 & 1.42 & 1.56 & 10.01 & 12.02 & .668 & .757 & 26.13 & 27.97 \\
\hline$S$ & 5 & 1.48 & 1.51 & 10.14 & 11.89 & .637 & .702 & 26.19 & 27.51 \\
\hline$S$ & 6 & 1.39 & 1.47 & 10.15 & 11.13 & .668 & .740 & 25.69 & 27.20 \\
\hline$S$ & 7 & 1.37 & 1.55 & 9.67 & 12.09 & .682 & .755 & 26.06 & 28.15 \\
\hline$S$ & 8 & 1.39 & 1.51 & 10.67 & 11.76 & .646 & .713 & 27.04 & 27.82 \\
\hline$Y$ & 1 & 1.44 & 1.23 & 10.13 & 11.58 & .655 & .745 & 26.41 & 27.02 \\
\hline$Y$ & 2 & 1.47 & 1.36 & 10.97 & 11.58 & .633 & .754 & 22.80 & 23.35 \\
\hline$Y$ & 3 & 1.35 & 1.30 & 11.29 & 10.90 & .661 & .720 & 26.84 & 27.41 \\
\hline$y$ & 4 & 1.40 & 1.49 & 9.83 & 10.36 & .632 & .760 & 26.14 & 26.18 \\
\hline$Y$ & 5 & 1.30 & 1.36 & 10.80 & 11.43 & .619 & .720 & 26.73 & 27.49 \\
\hline$Y$ & 6 & 1.28 & 1.38 & 11.85 & 12.61 & .702 & .771 & 24.71 & 25.88 \\
\hline
\end{tabular}


TABLE XXXVIII (Continued)

\begin{tabular}{|c|c|c|c|c|c|c|c|c|c|}
\hline \multirow[b]{3}{*}{$\frac{B O S^{b}}{Y}$} & \multirow[b]{3}{*}{$\frac{\text { Sire }}{7}$} & \multicolumn{8}{|c|}{ Traita } \\
\hline & & \multicolumn{2}{|c|}{$\overline{B W}$} & \multicolumn{2}{|c|}{ W42 } & \multicolumn{2}{|c|}{$\overline{A D G}$} & \multicolumn{2}{|c|}{$\overline{\mathrm{BF}}$} \\
\hline & & $\frac{\mathrm{BV} 7 \mathrm{C}}{1.53}$ & $\frac{\mathrm{BV}^{\mathrm{d}}}{1.44}$ & $\frac{\mathrm{BV} 1^{\mathrm{C}}}{9.61}$ & $\frac{B V 2^{d}}{9.76}$ & $\frac{\mathrm{BV} 1^{\mathrm{C}}}{.647}$ & $\frac{\mathrm{BV} 2^{\mathrm{d}}}{.717}$ & $\frac{B V 7^{C}}{24.68}$ & $\frac{\mathrm{BV}^{\mathrm{d}}}{25.05}$ \\
\hline$Y$ & 8 & 1.55 & 1.28 & 9.60 & 9.31 & -- & -- & -- & -- \\
\hline
\end{tabular}

$a_{B W}=$ Birth Weight $(\mathrm{kg}) ;$ W42 = 42-day Weight $(\mathrm{kg}) ; A D G=$ Postweaning Average Daily Gain (kg/day); $\mathrm{BF}=$ Probed Backfat Thickness at $99.8 \mathrm{~kg}(\mathrm{~mm})$.

$b_{\text {Breed of sire: }} D=$ Duroc, $L=$ Landrace; $S=$ Spotted; $Y=$ Yorkshire.

${ }^{\mathrm{C}}$ Breeding value based upon purebred progeny performance.

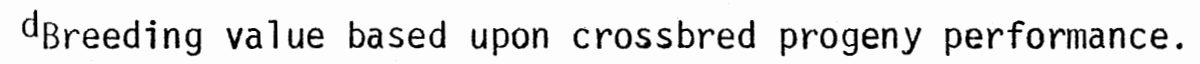


TABLE XXXIX

1444 DATA SET - DUROC SIRE RANKS BASED UPON BREEDING VALUES OBTAINED FROM MIXED MODEL SOLUTIONS

\begin{tabular}{|c|c|c|c|c|c|c|c|c|c|c|}
\hline \multirow{3}{*}{ Sire } & \multicolumn{10}{|c|}{ Trait ${ }^{\mathrm{a}}$} \\
\hline & \multicolumn{2}{|c|}{ BW } & \multicolumn{2}{|c|}{ W21 } & \multicolumn{2}{|c|}{ W42 } & \multicolumn{2}{|c|}{$A D G$} & \multicolumn{2}{|c|}{$\mathrm{BF}$} \\
\hline & $\mathrm{R}]^{\mathrm{b}}$ & $\mathrm{R} 2^{\mathrm{C}}$ & $\mathrm{R} 7^{\mathrm{b}}$ & $\mathrm{R} 2^{\mathrm{C}}$ & $\mathrm{R} 7^{\mathrm{b}}$ & $\mathrm{R}^{\mathrm{C}}$ & $\mathrm{R} 7^{\mathrm{b}}$ & $\mathrm{R}^{\mathrm{C}}$ & $\mathrm{R}]^{\mathrm{b}}$ & $\mathrm{R} 2^{\mathrm{C}}$ \\
\hline 1 & $\overline{47}$ & $\overline{47}$ & $\overline{57}$ & $\overline{51}$ & $\overline{42}$ & $\overline{7}$ & $\overline{54}$ & $\overline{39}$ & $T$ & $\overline{12}$ \\
\hline 2 & 47 & 59 & 58 & 55 & 51 & 23 & 50 & 22 & 4 & 16 \\
\hline 3 & 28 & 1 & 44 & 32 & 30 & 8 & 52 & 45 & 22 & 31 \\
\hline 4 & 33 & 23 & 48 & 45 & 39 & 16 & 28 & 14 & 5 & 13 \\
\hline 5 & 50 & 56 & 61 & 56 & 63 & 43 & 40 & 4 & 2 & 6 \\
\hline 6 & 15 & 45 & 36 & 57 & 49 & 41 & 10 & 31 & 13 & 20 \\
\hline 7 & 32 & 35 & 62 & 33 & 40 & 2 & 41 & 5 & 3 & 11 \\
\hline 8 & 58 & 38 & 39 & 22 & 53 & 17 & 36 & 16 & 6 & 15 \\
\hline 9 & 42 & 63 & 47 & 54 & 54 & 46 & 26 & 11 & 37 & 25 \\
\hline 10 & 5 & 50 & 25 & 23 & 58 & 58 & 59 & 47 & 52 & 55 \\
\hline 11 & 27 & 34 & 46 & 25 & 52 & 9 & 33 & 15 & 40 & 39 \\
\hline 12 & 36 & 37 & 50 & 34 & 21 & 5 & 35 & 36 & 12 & 18 \\
\hline 13 & 40 & 52 & 55 & 44 & 57 & 54 & 45 & 27 & 17 & 26 \\
\hline 14 & 11 & 36 & 17 & 9 & 17 & 37 & 43 & 30 & 47 & 56 \\
\hline 15 & 49 & 51 & 60 & 62 & 61 & 55 & 55 & 34 & 10 & 23 \\
\hline
\end{tabular}


TABLE XXXIX (Continued)

\begin{tabular}{|c|c|c|c|c|c|c|c|c|c|c|}
\hline \multirow{3}{*}{ Sire } & \multicolumn{10}{|c|}{ Trait ${ }^{\mathrm{a}}$} \\
\hline & \multicolumn{2}{|c|}{$\mathrm{BW}$} & \multicolumn{2}{|c|}{ W21 } & \multicolumn{2}{|c|}{ W42 } & \multicolumn{2}{|c|}{$\overline{A D G}$} & \multicolumn{2}{|c|}{$\mathrm{BF}$} \\
\hline & $\frac{\mathrm{R} 7^{\mathrm{b}}}{14}$ & $\frac{\mathrm{R} 2^{\mathrm{C}}}{13}$ & $\frac{R T^{b}}{8}$ & $\frac{\mathrm{R} 2{ }^{\mathrm{C}}}{4}$ & $\frac{\mathrm{R} 1^{\mathrm{b}}}{46}$ & $\frac{\mathrm{R}^{\mathrm{C}}}{19}$ & $\frac{\mathrm{R} 7^{\mathrm{b}}}{14}$ & $\frac{\mathrm{R} 2^{\mathrm{C}}}{3}$ & $\frac{\mathrm{R}^{\mathrm{b}}}{43}$ & $\frac{\mathrm{R} 2^{\mathrm{C}}}{40}$ \\
\hline 17 & 25 & 40 & 20 & 30 & 45 & 32 & 21 & 9 & 44 & 48 \\
\hline 18 & 1 & 18 & 24 & 43 & 11 & 29 & 46 & 41 & 8 & 10 \\
\hline 19 & 12 & 5 & 37 & 21 & 22 & 13 & 32 & 57 & 38 & 34 \\
\hline 20 & 19 & 6 & 10 & 1 & 6 & 1 & 19 & 2 & 42 & 45 \\
\hline 21 & 61 & 29 & 64 & 46 & 59 & 39 & 3 & 1 & -- & -- \\
\hline 22 & 46 & 61 & 52 & 53 & 60 & 62 & 18 & 8 & -- & -- \\
\hline
\end{tabular}

$a_{B W}=$ Birth Weight; $W 21=21$-day Weight; $W 42=42$ day Weight; $A D G=$ Postweaning Average Daily Gain; $\mathrm{BF}=$ Probed Backfat Thickness at $99.8 \mathrm{~kg}$.

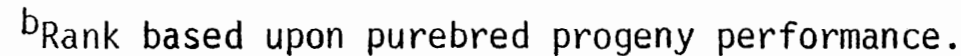

$\mathrm{C}_{\text {Rank }}$ based upon crossbred progeny performance. 
TABLE XL

1444 DATA SET - HAMPSHIRE SIRE RANKS BASED UPON BREEDING

VALUES OBTAINED FROM MIXED MODEL SOLUTIONS

\begin{tabular}{|c|c|c|c|c|c|c|c|c|c|c|}
\hline \multirow[b]{2}{*}{ Sire } & \multicolumn{10}{|c|}{ Trait $^{a}$} \\
\hline & \multicolumn{2}{|c|}{$\mathrm{BW}$} & \multicolumn{2}{|c|}{ W21 } & \multicolumn{2}{|c|}{ W42 } & \multicolumn{2}{|c|}{ ADG } & \multicolumn{2}{|c|}{$\overline{B F}$} \\
\hline 1 & $\frac{\mathrm{R} \mathrm{T}^{\mathrm{b}}}{48}$ & $\frac{\mathrm{R}^{\mathrm{C}}}{49}$ & $\frac{\mathrm{R}^{\mathrm{b}}}{59}$ & $\frac{\mathrm{R} 2^{\mathrm{C}}}{63}$ & $\frac{R T^{b}}{62}$ & $\frac{\mathrm{R}^{\mathrm{C}}}{53}$ & $\frac{\mathrm{R} 7^{\mathrm{b}}}{13}$ & $\frac{\mathrm{R} 2^{\mathrm{C}}}{32}$ & $\frac{\mathrm{RI}^{\mathrm{b}}}{50}$ & $\frac{\mathrm{R} 2^{\mathrm{C}}}{43}$ \\
\hline 2 & 62 & 41 & 51 & 60 & 56 & 59 & 31 & 38 & 41 & 37 \\
\hline 3 & 63 & 27 & 45 & 27 & 47 & 35 & 6 & 10 & 33 & 38 \\
\hline 4 & 56 & 53 & 42 & 48 & 35 & 60 & 8 & 37 & 19 & 28 \\
\hline 5 & 57 & 55 & 18 & 36 & 34 & 44 & 47 & 28 & 59 & 59 \\
\hline 6 & 37 & 24 & 1 & 39 & 25 & 52 & 58 & 40 & 58 & 58 \\
\hline 7 & 54 & 39 & 54 & 31 & 55 & 27 & 16 & 44 & 53 & 49 \\
\hline 8 & 6 & 2 & 12 & 5 & 13 & 18 & 63 & 60 & 16 & 33 \\
\hline 9 & 22 & 43 & 23 & 26 & 28 & 42 & 30 & 53 & 26 & 32 \\
\hline 10 & 64 & 25 & 28 & 7 & 5 & 15 & 9 & 6 & 25 & 5 \\
\hline 11 & 52 & 15 & 13 & 6 & 44 & 28 & 20 & 21 & 51 & 52 \\
\hline 12 & 26 & 12 & 16 & 2 & 7 & 3 & 48 & 56 & 35 & 51 \\
\hline 13 & 29 & 27 & 7 & 8 & 2 & 26 & 61 & 61 & 29 & 41 \\
\hline 14 & 44 & 3 & 63 & 15 & 64 & 50 & 65 & 65 & 31 & 44 \\
\hline 15 & 21 & 11 & 26 & 17 & 37 & 31 & 39 & 12 & 46 & 42 \\
\hline
\end{tabular}


TABLE XL (Continued)

\begin{tabular}{|c|c|c|c|c|c|c|c|c|c|c|}
\hline \multirow{3}{*}{ Sire } & \multicolumn{10}{|c|}{ Trait } \\
\hline & \multicolumn{2}{|c|}{ BW } & \multicolumn{2}{|c|}{ W21 } & \multicolumn{2}{|c|}{ W42 } & \multicolumn{2}{|c|}{$\overline{A D G}$} & \multicolumn{2}{|c|}{$\mathrm{BF}$} \\
\hline & $\frac{R]^{b}}{34}$ & $\frac{\mathrm{R} 2^{\mathrm{C}}}{30}$ & $\frac{\mathrm{R} 7^{\mathrm{b}}}{4}$ & $\frac{\mathrm{R}^{2}{ }^{\mathrm{C}}}{11}$ & $\frac{\mathrm{R} 7^{\mathrm{b}}}{19}$ & $\frac{\mathrm{R} 2^{\mathrm{C}}}{22}$ & $\frac{\mathrm{R} 7^{\mathrm{b}}}{62}$ & $\frac{\mathrm{R} 2^{\mathrm{C}}}{64}$ & $\frac{R 7^{b}}{15}$ & $\frac{\mathrm{R} 2^{\mathrm{C}}}{29}$ \\
\hline 17 & 38 & 32 & 19 & 64 & 38 & 64 & 51 & 25 & 57 & 57 \\
\hline 18 & 65 & 26 & 65 & 59 & 65 & 56 & 25 & 43 & -- & -- \\
\hline 19 & 66 & 54 & 53 & 37 & 48 & 38 & 7 & 13 & -- & -- \\
\hline 20 & 53 & 46 & 2 & 29 & 8 & 14 & 15 & 7 & -- & -- \\
\hline 21 & 20 & 4 & -- & - & -- & -- & -- & -- & -- & - \\
\hline 22 & 67 & 57 & -- & -- & -- & -- & -- & -- & -- & -- \\
\hline
\end{tabular}

$\mathrm{a}_{\mathrm{BW}}=$ Birth Weight; $W 21=21$-day Weight; $W 42=42$-day Weight; $A D G=$ Postweaning Average Daily Gain; $\mathrm{BF}=$ Probed Backfat Thickness at $99.8 \mathrm{~kg}$.

bank based upon purebred progeny performance.

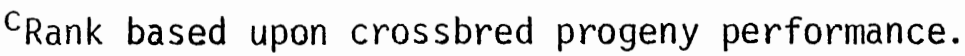


TABLE XLI

1444 DATA SET - YORKSHIRE SIRE RANKS BASED UPON BREEDING VALUES OBTAINED FROM MIXED MODEL SOLUTIONS

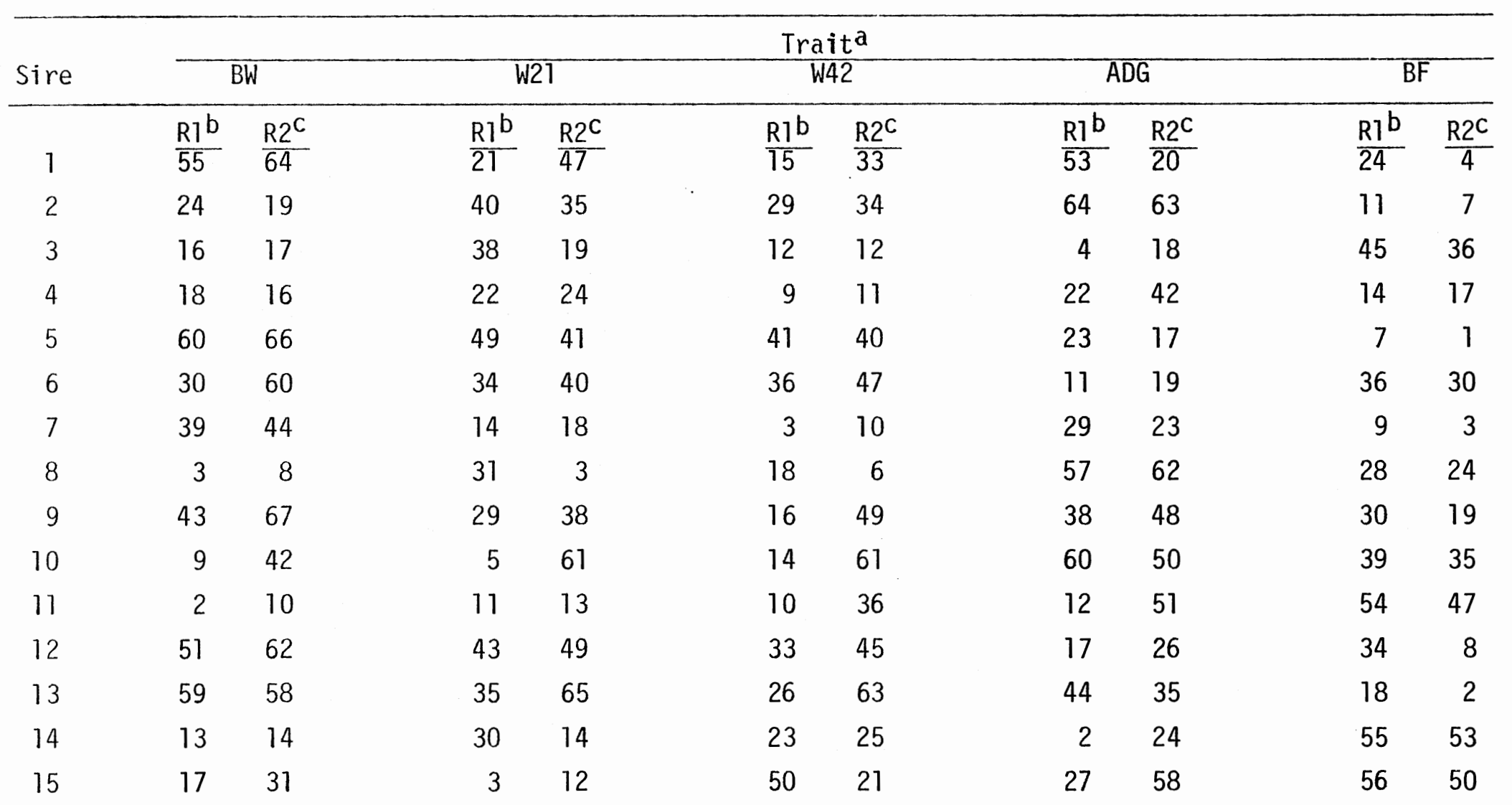


TABLE XLI (Continued)

\begin{tabular}{|c|c|c|c|c|c|c|c|c|c|c|}
\hline \multirow{3}{*}{ Sire } & \multicolumn{10}{|c|}{ Traita } \\
\hline & \multicolumn{2}{|c|}{$\mathrm{BW}$} & \multicolumn{2}{|c|}{ W21 } & \multicolumn{2}{|c|}{ W42 } & \multicolumn{2}{|c|}{$\overline{A D G}$} & \multicolumn{2}{|c|}{$\mathrm{BF}$} \\
\hline & $R\}^{b}$ & $\underline{R} 2^{C}$ & $\mathrm{R}^{\mathrm{b}}$ & $\mathrm{R} 2^{\mathrm{C}}$ & $\mathrm{RI}{ }^{\mathrm{b}}$ & $\mathrm{R} 2^{\mathrm{C}}$ & $R 7^{b}$ & $\underline{\mathrm{R}} 2^{\mathrm{C}}$ & $\mathrm{R}]^{\mathrm{b}}$ & $\mathrm{R}^{\mathrm{C}}$ \\
\hline 16 & $\overline{8}$ & $\overline{22}$ & $\overline{6}$ & $\overline{16}$ & 7 & $\overline{4}$ & $\overline{42}$ & $\overline{52}$ & $\overline{20}$ & 21 \\
\hline 17 & 37 & 48 & 32 & 42 & 31 & 48 & 24 & 46 & 23 & 9 \\
\hline 18 & 4 & 9 & 9 & 10 & 4 & 20 & 34 & 59 & 21 & 22 \\
\hline 19 & 45 & 28 & 41 & 52 & 24 & 51 & 37 & 33 & 27 & 27 \\
\hline 20 & 10 & 33 & 33 & 28 & 27 & 24 & 5 & 55 & 48 & 46 \\
\hline 21 & 7 & 7 & 15 & 58 & 20 & 65 & 1 & 29 & 49 & 54 \\
\hline 22 & 23 & 20 & 27 & 20 & 32 & 30 & 56 & 54 & 32 & 14 \\
\hline 23 & 35 & 65 & 56 & 50 & 43 & 57 & 49 & 49 & -- & -- \\
\hline
\end{tabular}

$a_{B W}=$ Birth Weight; $W 21$ - 21-day Weight; $W 42=42$-day Weight; ADG - Postweaning Average Daily Gain; $\mathrm{BF}=$ Probed Backfat Thickness at $99.8 \mathrm{~kg}$.

$b_{\text {Rank based upon purebred progeny performance. }}$

${ }^{C_{\text {Rank }}}$ based upon crossbred progeny performance. 
TABLE XLII

1620 DATA SET - SIRE RANKS BASED UPON BREEDING VALUES

OBTAINED FROM MIXED MODEL SOLUTIONS

\begin{tabular}{|c|c|c|c|c|c|c|c|c|c|}
\hline \multirow[b]{3}{*}{$\frac{B O S^{b}}{D}$} & \multirow[b]{3}{*}{$\frac{\text { Sire }}{1}$} & \multicolumn{8}{|c|}{ Trait $^{a}$} \\
\hline & & \multicolumn{2}{|c|}{$\mathrm{BW}$} & \multicolumn{2}{|c|}{ W42 } & \multicolumn{2}{|c|}{$\overline{A D G}$} & \multicolumn{2}{|c|}{$\mathrm{BF}$} \\
\hline & & $\frac{\mathrm{R} 7^{\mathrm{C}}}{24}$ & $\frac{\mathrm{R} 2 \mathrm{~d}}{15}$ & $\frac{\mathrm{RI}^{\mathrm{C}}}{23}$ & $\frac{\mathrm{R} 2^{\mathrm{d}}}{20}$ & $\frac{\mathrm{RI}^{\mathrm{C}}}{14}$ & $\frac{\mathrm{R} 2^{\mathrm{d}}}{3}$ & $\frac{\mathrm{RI}^{\mathrm{C}}}{23}$ & $\frac{\mathrm{R} 2 \mathrm{~d}}{26}$ \\
\hline$D$ & 2 & 20 & 28 & 1 & 1 & 11 & 9 & 30 & 30 \\
\hline D & 3 & 7 & 19 & 15 & 8 & 25 & 14 & 20 & 19 \\
\hline D & 4 & 12 & 3 & 16 & 29 & 16 & 1 & 32 & 31 \\
\hline D & 5 & 9 & 1 & 34 & 26 & 31 & 16 & 12 & 24 \\
\hline$D$ & 6 & 31 & 24 & 33 & 30 & 30 & 24 & 25 & 23 \\
\hline D & 7 & 30 & 17 & 12 & 4 & 12 & 4 & 28 & 29 \\
\hline$D$ & 8 & 29 & 2 & 17 & 2 & 24 & 6 & 26 & 28 \\
\hline$D$ & 9 & 22 & 11 & 24 & 6 & 33 & 25 & 24 & 32 \\
\hline$D$ & 10 & 10 & 26 & 2 & 10 & 22 & 18 & 22 & 25 \\
\hline$L$ & 1 & 34 & 33 & 21 & 15 & 19 & 33 & 4 & 5 \\
\hline$L$ & 2 & 21 & 20 & 8 & 13 & 2 & 17 & 13 & 18 \\
\hline$L$ & 3 & 27 & 14 & 4 & 23 & 21 & 32 & 1 & 1 \\
\hline L & 4 & 15 & 6 & 5 & 5 & 28 & 29 & 2 & 2 \\
\hline L & 5 & 25 & 22 & 31 & 17 & 7 & 28 & 3 & 4 \\
\hline$L$ & 6 & 1 & 21 & 6 & 28 & 15 & 30 & 10 & 10 \\
\hline
\end{tabular}


TABLE XLII (Continued)

\begin{tabular}{|c|c|c|c|c|c|c|c|c|c|}
\hline \multirow[b]{3}{*}{$\frac{\text { BOSb }}{L}$} & \multirow[b]{3}{*}{$\frac{\text { Sire }}{7}$} & \multicolumn{8}{|c|}{ Trait } \\
\hline & & \multicolumn{2}{|c|}{$\mathrm{BW}$} & \multicolumn{2}{|c|}{ W42 } & \multicolumn{2}{|c|}{$\overline{A D G}$} & \multicolumn{2}{|c|}{$\mathrm{BF}$} \\
\hline & & $\frac{\mathrm{R}^{\mathrm{C}}}{35}$ & $\frac{\mathrm{R} 2^{\mathrm{d}}}{35}$ & $\frac{\mathrm{R}^{\mathrm{C}}}{26}$ & $\frac{\mathrm{R} 2^{\mathrm{d}}}{31}$ & $\frac{\mathrm{R} 7^{\mathrm{C}}}{3}$ & $\frac{\mathrm{R} 2^{\mathrm{d}}}{13}$ & $\frac{\mathrm{RT}^{\mathrm{C}}}{5}$ & $\frac{\mathrm{R} 2 \mathrm{~d}}{12}$ \\
\hline L & 8 & 16 & 13 & 10 & 7 & 5 & 12 & 9 & 8 \\
\hline L & 9 & 32 & 9 & -- & -- & -- & -- & -- & -- \\
\hline S & 1 & 18 & 29 & 32 & 22 & 6 & 15 & 7 & 3 \\
\hline S & 2 & 26 & 32 & 27 & 11 & 20 & 23 & 21 & 16 \\
\hline$S$ & 3 & 33 & 18 & 13 & 24 & 32 & 27 & 31 & 21 \\
\hline S & 4 & 8 & 4 & 22 & 12 & 9 & 5 & 17 & 7 \\
\hline s & 5 & 4 & 7 & 19 & 14 & 23 & 26 & 15 & 11 \\
\hline S & 6 & 13 & 12 & 18 & 25 & 8 & 11 & 19 & 15 \\
\hline$S$ & 7 & 17 & 5 & 28 & 9 & 4 & 7 & 18 & 6 \\
\hline S & 8 & 14 & 8 & 14 & 16 & 18 & 22 & 6 & 9 \\
\hline Y & 1 & 6 & 34 & 20 & 18 & 13 & 10 & 14 & 17 \\
\hline Y & 2 & 5 & 25 & 9 & 19 & 26 & 8 & 33 & 33 \\
\hline Y & 3 & 19 & 30 & 7 & 27 & 10 & 19 & 8 & 14 \\
\hline$\gamma$ & 4 & 11 & 10 & 25 & 32 & 27 & 31 & 16 & 20 \\
\hline Y & 5 & 23 & 27 & 11 & 21 & 29 & 20 & 11 & 13 \\
\hline Y & 6 & 28 & 23 & 3 & 3 & 1 & 2 & 27 & 22 \\
\hline
\end{tabular}


TABLE XLII (Continued)

\begin{tabular}{|c|c|c|c|c|c|c|c|c|c|}
\hline \multirow[b]{3}{*}{$\frac{\mathrm{BOS}^{\mathrm{b}}}{\mathrm{Y}}$} & \multirow[b]{3}{*}{$\frac{\text { Sire }}{7}$} & \multicolumn{8}{|c|}{ Trait ${ }^{a}$} \\
\hline & & \multicolumn{2}{|c|}{$\mathrm{BW}$} & \multicolumn{2}{|c|}{$W 42$} & \multicolumn{2}{|c|}{$\overline{A D G}$} & \multicolumn{2}{|c|}{$\mathrm{BF}$} \\
\hline & & $\frac{\mathrm{R}\rceil^{\mathrm{C}}}{3}$ & $\frac{\mathrm{R} 2^{\mathrm{d}}}{16}$ & $\frac{R 7^{C}}{29}$ & $\frac{\mathrm{R} 2^{\mathrm{d}}}{33}$ & $\frac{\mathrm{R} 1^{\mathrm{C}}}{17}$ & $\frac{\mathrm{R} 2^{\mathrm{d}}}{21}$ & $\frac{\mathrm{R}{ }^{\mathrm{C}} \mathrm{C}}{29}$ & $\frac{\mathrm{R} 2^{\mathrm{d}}}{27}$ \\
\hline$Y$ & 8 & 2 & 31 & 30 & 34 & -- & -- & -- & -- \\
\hline
\end{tabular}

$a_{B W}=$ Birth Weight; $W 42=42$-day Weight; $A D G=$ Postweaning Average Daily Gain; $B F=$ Probed Backfat Thickness at $99.8 \mathrm{~kg}$.

$\mathrm{b}_{\text {Breed of sire: }} D=$ Duroc; $L=$ Landrace; $S=$ Spotted; $Y=$ Yorkshire.

$\mathrm{C}_{\text {Rank based upon purebred progeny performance. }}$

$\mathrm{d}_{\text {Rank }}$ based upon crossbred progeny performance. 
TABLE XLIII

UPPER AND LOWER 95 PERCENT CONFIDENCE LIMITS

ON POPULATION CORRELATION COEFFICIENTS

\begin{tabular}{|c|c|c|c|c|c|c|c|}
\hline \multirow[b]{2}{*}{ Trait } & \multirow[b]{2}{*}{ Data Set } & \multicolumn{3}{|c|}{$r_{g}^{b}$} & \multicolumn{3}{|c|}{$r_{r}{ }^{c}$} \\
\hline & & $L L^{d}$ & $r_{g}$ & ULe & $L^{d}$ & $r_{r}$ & $U^{\mathrm{e}}$ \\
\hline$B W$ & 1444 & .33 & .53 & .68 & .35 & .55 & .70 \\
\hline$B W$ & 1620 & -.08 & .27 & .55 & -.17 & .17 & .48 \\
\hline W21 & 1444 & .24 & .45 & .63 & .33 & .53 & .68 \\
\hline W42 & 1444 & .24 & .46 & .63 & .21 & .43 & .61 \\
\hline W42 & 1620 & $.17^{\circ}$ & .48 & .71 & .09 & .42 & .66 \\
\hline$A D G$ & 1444 & .33 & .54 & .69 & .30 & .51 & .67 \\
\hline$A D G$ & 1620 & .06 & .40 & .65 & .13 & .46 & .69 \\
\hline$B F$ & 1444 & .68 & .80 & .88 & .75 & .85 & .91 \\
\hline$B F$ & 1620 & .80 & .90 & .95 & .73 & .86 & .93 \\
\hline
\end{tabular}

$a_{B W}=$ Birth Weight; $W 21=21$-day weight; $W 42=42$-day Weight; $A D G=$ Postweaning Average Daily Gain; BF = Probed Backfat Thickness at $99.8 \mathrm{~kg}$.

${ }^{b} r_{g}=$ product-moment correlation coefficient of sire breeding values for purebred and crossbred progeny obtained from mixed model solutions.

$c^{c} r_{r}=$ Spearman rank correlation coefficient, ranks based upon sire breeding values for purebred and crossbred progeny obtained from mixed model solutions.

d $95 \%$ confidence interval lower limit.

$e_{95 \%}$ confidence interval upper 1 imit. 
TABLE XLIV

GENETIC AND RANK CORRELATION ESTIMATES FOR

PIG BIRTH WEIGHT BY BREED OF SIRE

\begin{tabular}{clcc}
\hline Data Set & Breed of Sire & $r_{g}{ }^{a}$ & $r_{r}{ }^{b}$ \\
\hline 1444 & Duroc & .48 & .50 \\
1444 & Hampshire & .62 & .58 \\
1444 & Yorkshire & .84 & .81 \\
1444 & Pooled & .53 & .55 \\
& & & \\
1620 & Duroc & .17 & .05 \\
1620 & Landrace & .64 & .50 \\
1620 & Spotted & .50 & .71 \\
1620 & Yorkshire & -.07 & -.17 \\
1620 & Pooled & .27 & .17 \\
\hline
\end{tabular}

aproduct-moment correlation coefficient of sire breeding values for purebred and crossbred progeny obtained from mixed model solutions.

bspearman rank correlation coefficient, ranks based upon sire breeding values for purebred and crossbred progeny. 
TABLE XLV

GENETIC AND RANK CORRELATION ESTIMATES FOR 21-DAY PIG WEIGHT BY BREED OF SIRE

\begin{tabular}{cccc}
\hline Data Set & Breed of Sire & $r_{g}{ }^{a}$ & $r_{r}{ }^{b}$ \\
\hline 1444 & Duroc & .72 & .69 \\
1444 & Hampshire & .39 & .42 \\
1444 & Yorkshire & .26 & .42 \\
1444 & Pooled & .45 & .53 \\
\hline
\end{tabular}

aproduct-moment correlation coefficient of sire breeding values for pidrebred and crossbred progeny obtained from mixed model solutions.

${ }^{b}$ Spearman rank correlation coefficient, ranks based upon sire breeding values for purebred and crossbred progeny. 
TABLE XLVI

GENETIC AND RANK CORRELATION ESTIMATES FOR

42-DAY PIG WEIGHT BY BREED OF SIRE

\begin{tabular}{clcc}
\hline Data Set & Breed of Sire & $r_{g}{ }^{a}$ & $r_{r}{ }^{b}$ \\
\hline 1444 & Duroc & .69 & .73 \\
1444 & Hampshire & .66 & .66 \\
1444 & Yorkshire & .48 & .43 \\
1444 & Pooled & .46 & .43 \\
& & & \\
1620 & Duroc & .65 & .58 \\
1620 & Landrace & .26 & .21 \\
1620 & Spotted & -.29 & -.55 \\
1620 & Yorkshire & .84 & .79 \\
1620 & Pooled & .48 & .42 \\
\hline
\end{tabular}

aproduct-moment correlation coefficient of sire breeding values for purebred and crossbred progeny obtained from mixed model solutions.

bspearman rank correlation coefficient, ranks based upon sire breeding values for purebred and crossbred progeny. 
TABLE XLVII

GENETIC AND RANK CORRELATION ESTIMATES FOR POSTWEANING AVERAGE DAILY GAIN

BY BREED OF SIRE

\begin{tabular}{clcc}
\hline Data Set & Breed of Sire & $r_{g}{ }^{a}$ & $r_{r}{ }^{b}$ \\
\hline 1444 & Duroc & .68 & .64 \\
1444 & Hampshire & .81 & .72 \\
1444 & Yorkshire & .47 & .49 \\
1444 & Pooled & .54 & .51 \\
& & & \\
1620 & Duroc & .80 & .72 \\
1620 & Landrace & .87 & .74 \\
1620 & Spotted & .86 & .83 \\
1620 & Yorkshire & .59 & .61 \\
1620 & Pooled & .40 & .46 \\
\hline
\end{tabular}

aproduct-moment correlation coefficient of sire breeding values for purebred and crossbred progeny obtained from mixed model solutions.

${ }^{b}$ Spearman rank correlation coefficient, ranks based upon sire breeding values for purebred and crossbred progeny. 
TABLE XLVIII

GENETIC AND RANK CORRELATION ESTIMATES FOR PROBED BACKFAT THICKNESS AT $99.8 \mathrm{~kg}$ BY BREED OF SIRE

\begin{tabular}{clcc}
\hline Data Set & Breed of Sire & $r_{g}{ }^{a}$ & $r_{r}{ }^{b}$ \\
\hline 1444 & Duroc & .97 & .95 \\
1444 & Hampshire & .87 & .89 \\
1444 & Yorkshire & .87 & .86 \\
1444 & Pooled & .80 & .85 \\
& & & \\
1620 & Duroc & .67 & .68 \\
1620 & Landrace & .97 & .93 \\
1620 & Spotted & .88 & .71 \\
1620 & Yorkshire & .97 & .96 \\
1620 & Pooled & .90 & .86 \\
\hline
\end{tabular}

aproduct-moment correlation coefficient of sire breeding values for purebred and crossbred progeny obtained from mixed model solutions.

bspearman rank correlation coefficient, ranks based upon sire breeding values for purebred and crossbred progeny. 
APPENDIX B

FIGURES 


\begin{tabular}{|c|c|c|c|c|c|c|c|c|c|c|c|c|c|c|c|c|c|c|c|c|c|c|}
\hline Sire No. & 1 & 2 & 3 & 4 & 5 & 6 & 7 & 8 & 9 & 10 & 11 & 12 & 13 & 14 & 15 & 16 & 17 & 18 & 19 & 20 & 21 & 22 \\
\hline 1 & 1.0 & 0 & 0 & 0 & 0 & 0 & 0 & 0 & 0 & 0 & 0 & 0 & 0 & 0 & 0 & 0 & 0 & 0 & 0 & .125 & 0 & 0 \\
\hline 2 & 0 & 1.0 & 0 & 0 & 0 & 0 & 0 & .25 & .25 & 0 & 0 & 0 & 0 & 0 & 0 & .125 & 0 & 0 & 0 & 0 & .25 & 0 \\
\hline 3 & 0 & 0 & 1.0 & 0 & 0 & 0 & 0 & 0 & 0 & 0 & 0 & 0 & 0 & 0 & 0 & 0 & 0 & 0 & 0 & 0 & 0 & 0 \\
\hline 4 & 0 & 0 & 0 & 1.0 & .25 & .25 & 0 & 0 & 0 & 0 & 0 & 0 & 0 & 0 & .25 & 0 & 0 & 0 & 0 & 0 & 0 & 0 \\
\hline 5 & 0 & 0 & 0 & .25 & 1.0 & 0 & 0 & 0 & 0 & 0 & .125 & 0 & 0 & .25 & .25 & 0 & 0 & 0 & 0 & 0 & 0 & 0 \\
\hline 6 & 0 & 0 & 0 & .25 & 0 & 1.0 & 0 & 0 & 0 & 0 & 0 & 0 & 0 & 0 & 0 & 0 & 0 & 0 & 0 & 0 & 0 & 0 \\
\hline 7 & 0 & 0 & 0 & 0 & 0 & 0 & 1.0 & 0 & 0 & 0 & 0 & 0 & 0 & 0 & 0 & 0 & 0 & 0 & 0 & 0 & 0 & 0 \\
\hline 8 & 0 & .25 & 0 & 0 & 0 & 0 & 0 & 1.0 & .25 & 0 & 0 & 0 & 0 & 0 & 0 & .125 & 0 & 0 & 0 & 0 & .25 & 0 \\
\hline 9 & 0 & .25 & 0 & 0 & 0 & 0 & 0 & .25 & 1.0 & 0 & 0 & 0 & 0 & 0 & 0 & .125 & 0 & 0 & 0 & 0 & .25 & 0 \\
\hline 10 & 0 & 0 & 0 & 0 & 0 & 0 & 0 & 0 & 0 & 1.0 & .125 & .125 & 0 & .25 & 0 & 0 & 0 & .5 & .25 & 0 & 0 & 0 \\
\hline 11 & 0 & 0 & 0 & 0 & .125 & 0 & 0 & 0 & 0 & .125 & 1.0 & 0 & 0 & .25 & 0 & 0 & .25 & .125 & .125 & .25 & 0 & 0 \\
\hline 12 & 0 & 0 & 0 & 0 & 0 & 0 & 0 & 0 & 0 & .125 & 0 & 1.0 & 0 & 0 & 0 & 0 & 0 & .125 & 0 & 0 & 0 & 0 \\
\hline 13 & 0 & 0 & 0 & 0 & 0 & 0 & 0 & 0 & 0 & 0 & 0 & 0 & 1.0 & 0 & 0 & 0 & 0 & 0 & 0 & .125 & 0 & .25 \\
\hline 14 & 0 & 0 & 1) & 0 & .25 & 0 & 0 & 0 & 0 & .25 & .25 & 0 & 0 & 1.0 & 0 & 0 & 0 & .25 & .25 & 0 & 0 & 0 \\
\hline 13 & 0 & 0 & 0 & 25 & .25 & 0 & 0 & 0 & 0 & 0 & 0 & 0 & 0 & 0 & 1.0 & 0 & 0 & 0 & 0 & 0 & 0 & 0 \\
\hline 16 & 0 & .125 & (1) & 0 & 0 & 0 & 0 & .125 & .125 & 0 & 0 & 0 & 0 & 0 & 0 & 1.0 & 0 & 0 & 0 & 0 & .125 & 0 \\
\hline 17 & 0 & 0 & 0 & 0 & 0 & 0 & 0 & 0 & 0 & 0 & .25 & 0 & 0 & 0 & 0 & 0 & 1.0 & 0 & .25 & .25 & 0 & 0 \\
\hline 18 & 0 & 0 & 0 & 0 & 0 & 0 & 0 & 0 & 0 & .5 & .125 & .125 & 0 & .25 & 0 & 0 & 0 & 1.0 & .25 & 0 & 0 & 0 \\
\hline 19 & 0 & 0 & 0 & 0 & 0 & 0 & 0 & 0 & 0 & .25 & .125 & 0 & 0 & .25 & 0 & 0 & .25 & .25 & 1.0 & 0 & 0 & 0 \\
\hline 20 & $.12 i$ & 0 & 0 & 0 & 0 & 0 & 0 & 0 & 0 & 0 & .25 & 0 & .125 & 0 & 0 & 0 & .25 & 0 & 0 & 1.0 & 0 & .125 \\
\hline 21 & 0 & .25 & 0 & 0 & 0 & 0 & 0 & .25 & .25 & 0 & 0 & 0 & 0 & 0 & 0 & .125 & 0 & 0 & 0 & 0 & 1.0 & 0 \\
\hline 22 & 0 & 0 & 0 & 0 & 0 & 0 & 0 & 0 & 0 & 0 & 0 & 0 & .25 & 0 & 0 & 0 & 0 & 0 & 0 & .125 & 0 & 1.0 \\
\hline
\end{tabular}

*Average coefficient of relationship $=.033$.

Figure 1. Additive Relationship Matrix for Duroc Sires,* 1444 Data Set 


\begin{tabular}{|c|c|c|c|c|c|c|c|c|c|c|c|c|c|c|c|c|c|c|c|c|c|c|}
\hline sire No. & 1 & 2 & 3 & 4 & 5 & 6 & 7 & 8 & 9 & 10 & 11 & 12 & 13 & 14 & 15 & 16 & 17 & 18 & 19 & 20 & 21 & 22 \\
\hline 1 & 1.0 & .063 & 0 & 0 & 0 & 0 & 0 & 0 & 0 & 0 & 0 & 0 & 0 & 0 & 0 & 0 & 0 & 0 & 0 & 0 & 0 & 0 \\
\hline 2 & .063 & 1.0 & .063 & 0 & 0 & .031 & 0 & .031 & .031 & 0 & 0 & .031 & 0 & 0 & 0 & 0 & 0 & 0 & 0 & .063 & 0 & .063 \\
\hline 3 & 0 & .063 & 1.0 & 0 & 0 & .125 & 0 & .125 & .125 & 0 & 0 & .125 & 0 & 0 & 0 & 0 & 0 & 0 & 0 & .063 & 0 & .25 \\
\hline 4 & 0 & 0 & 0 & 1.0 & 0 & 0 & 0 & 0 & 0 & 0 & 0 & 0 & .25 & 0 & 0 & 0 & 0 & .25 & .5 & 0 & 0 & 0 \\
\hline 5 & 0 & 0 & 0 & 0 & 1.0 & 0 & 0 & 0 & 0 & 0 & 0 & 0 & 0 & 0 & 0 & 0 & 0 & 0 & 0 & 0 & 0 & .25 \\
\hline 6 & 0 & .031 & .125 & 0 & 0 & 1.0 & 0 & .063 & .063 & 0 & 0 & .5 & .25 & 0 & 0 & 0 & .25 & 0 & 0 & .281 & .125 & .125 \\
\hline 1 & 0 & 0 & 0 & 0 & 0 & 0 & 1.0 & 0 & 0 & 0 & 0 & 0 & 0 & 0 & .063 & .063 & 0 & 0 & 0 & 0 & .031 & 0 \\
\hline 8 & 0 & .031 & .125 & 0 & 0 & .063 & 0 & 1.0 & .5 & 0 & .125 & .063 & 0 & 0 & 0 & 0 & 0 & 0 & 0 & .031 & 0 & .125 \\
\hline 9 & 0 & .031 & .125 & 0 & 0 & .063 & 0 & .5 & 1.0 & 0 & .125 & .063 & 0 & 0 & 0 & 0 & 0 & 0 & 0 & .031 & 0 & .125 \\
\hline 10 & 0 & 0 & 0 & 0 & 0 & 0 & 0 & 0 & 0 & 1.0 & 0 & 0 & 0 & 0 & 0 & 0 & 0 & 0 & 0 & 0 & 0 & 0 \\
\hline 11. & 0 & 0 & 0 & 0 & 0 & 0 & 0 & .125 & .125 & 0 & 1.0 & 0 & 0 & 0 & 0 & 0 & 0 & 0 & 0 & 0 & 0 & 0 \\
\hline 12 & 0 & .031 & .125 & 0 & 0 & .5 & 0 & .063 & .063 & 0 & 0 & 1.0 & .25 & 0 & 0 & 0 & .25 & 0 & 0 & .281 & .125 & .125 \\
\hline 13 & 0 & 0 & 0 & .25 & 0 & .25 & 0 & 0 & 0 & 0 & 0 & .25 & 1.0 & 0 & 0 & 0 & .25 & .125 & .25 & .25 & .125 & 0 \\
\hline 14 & 0 & 0 & 0 & 0 & 0 & 0 & 0 & 0 & 0 & 0 & 0 & 0 & 0 & 1.0 & .25 & .25 & 0 & 0 & 0 & 0 & 0 & 0 \\
\hline 15 & 0 & 0 & 0 & 0 & 0 & 0 & .063 & 0 & 0 & 0 & 0 & 0 & 0 & .25 & 1.0 & .5 & 0 & 0 & 0 & 0 & .125 & 0 \\
\hline 10 & 0 & 0 & 0 & 0 & 0 & 0 & .063 & 0 & 0 & 0 & 0 & 0 & 0 & .25 & .5 & 1.0 & 0 & 0 & 0 & 0 & .125 & 0 \\
\hline 17 & 0 & 0 & 0 & 0 & 0 & .25 & 0 & 0 & 0 & 0 & 0 & .25 & .25 & 0 & 0 & 0 & 1.0 & 0 & 0 & .25 & .125 & 0 \\
\hline 18 & 0 & 0 & 0 & .25 & 0 & 0 & 0 & 0 & 0 & 0 & 0 & 0 & .125 & 0 & 0 & 0 & 0 & 1.0 & .25 & 0 & 0 & 0 \\
\hline 19 & 0 & 0 & 0 & .5 & 0 & 0 & 0 & 0 & 0 & 0 & 0 & 0 & .25 & 0 & 0 & 0 & 0 & .25 & 1.0 & 0 & 0 & 0 \\
\hline 20 & 0 & .063 & .063 & 0 & 0 & .281 & 0 & .031 & .031 & 0 & 0 & .281 & .25 & 0 & 0 & 0 & .25 & 0 & 0 & 1.0 & .125 & .063 \\
\hline 21 & 0 & 0 & 0 & 0 & .25 & .125 & .031 & 0 & 0 & 0 & 0 & .125 & .125 & 0 & .125 & .125 & .125 & 0 & 0 & .125 & 1.0 & 0 \\
\hline 22 & 0 & .063 & .25 & 0 & 0 & .125 & 0 & .125 & .125 & 0 & 0 & . 125 & 0 & 0 & 0 & 0 & 0 & 0 & 0 & .063 & 0 & 1.0 \\
\hline
\end{tabular}

*Average coefficient of relationship $=.041$.

Figure 2. Additive Relationship Matrix for Hampshire Sires,* 1444 Data Set 


\begin{tabular}{|c|c|c|c|c|c|c|c|c|c|c|c|c|c|c|c|c|c|c|c|c|c|c|c|}
\hline Sire No. & 1 & 2 & 3 & 4 & 5 & 6 & 1 & 8 & 9 & 10 & 11 & 12 & 13 & 14 & 15 & 16 & 17 & 18 & 19 & 20 & 21 & 22 & 23 \\
\hline 1 & 1.0 & 0 & 0 & 0 & 0 & 0 & 0 & 0 & 0 & 0 & 0 & 0 & 0 & 0 & 0 & 0 & 0 & 0 & 0 & 0 & 0 & 0 & .25 \\
\hline 2 & 0 & 1.0 & .125 & 0 & 0 & 0 & 0 & .125 & 0 & 0 & .125 & 0 & 0 & .125 & .063 & .125 & .125 & .063 & 0 & 0 & .125 & .063 & 0 \\
\hline 3 & 0 & .125 & 1.0 & 0 & 0 & 0 & 0 & .25 & 0 & 0 & .125 & 0 & 0 & 0 & .125 & .5 & 0 & .125 & 0 & 0 & 0 & .25 & 0 \\
\hline 4 & 0 & 0 & 0 & 1.0 & 0 & .25 & 0 & 0 & 0 & 0 & 0 & 0 & 0 & 0 & 0 & 0 & 0 & 0 & 0 & 0 & 0 & 0 & .25 \\
\hline b & 0 & 0 & 0 & 0 & 1.0 & 0 & .25 & 0 & 0 & 0 & 0 & 0 & 0 & 0 & 0 & 0 & 0 & 0 & 0 & 0 & 0 & 0 & 0 \\
\hline 6 & 0 & 0 & 0 & .25 & 0 & 1.0 & 0 & 0 & 0 & 0 & 0 & 0 & 0 & 0 & 0 & 0 & 0 & 0 & 0 & 0 & 0 & 0 & .25 \\
\hline 7 & 0 & 0 & 0 & 0 & .25 & 0 & 1.0 & 0 & 0 & 0 & 0 & 0 & 0 & 0 & 0 & 0 & 0 & 0 & 0 & 0 & 0 & 0 & 0 \\
\hline 8 & 0 & .125 & .25 & 0 & 0 & 0 & 0 & 1.0 & 0 & 0 & .125 & 0 & 0 & 0 & .125 & .25 & 0 & .125 & 0 & 0 & 0 & .125 & 0 \\
\hline$y$ & 0 & 0 & 0 & 0 & 0 & 0 & 0 & 0 & 1.0 & .5 & 0 & 0 & 0 & 0 & 0 & 0 & 0 & 0 & .25 & 0 & 0 & 0 & 0 \\
\hline 10 & 0 & 0 & 0 & 0 & 0 & 0 & 0 & 0 & .5 & 1.0 & 0 & 0 & 0 & 0 & 0 & 0 & 0 & 0 & .25 & 0 & 0 & 0 & 0 \\
\hline 11 & 0 & .125 & .125 & 0 & 0 & 0 & 0 & .125 & 0 & 0 & 1.0 & 0 & 0 & .375 & .063 & .125 & .125 & .063 & 0 & 0 & 0 & .063 & 0 \\
\hline 12 & 0 & 0 & 0 & 0 & 0 & 0 & 0 & 0 & 0 & 0 & 0 & 1.0 & 0 & 0 & 0 & 0 & .25 & 0 & 0 & 0 & 0 & 0 & 0 \\
\hline 13 & 0 & 0 & 0 & 0 & 0 & 0 & 0 & 0 & 0 & 0 & 0 & 0 & 1.0 & 0 & 0 & 0 & 0 & 0 & 0 & 0 & 0 & 0 & 0 \\
\hline 14 & 0 & .125 & 0 & 0 & 0 & 0 & 0 & 0 & 0 & 0 & $.3 / 5$ & 0 & 0 & 1.0 & 0 & 0 & .25 & 0 & 0 & 0 & 0 & 0 & 0 \\
\hline 15 & 0 & .063 & .125 & 0 & 0 & 0 & 0 & .125 & 0 & 0 & .063 & 0 & 0 & 0 & 1.0 & .125 & 0 & .063 & 0 & 0 & 0 & .063 & 0 \\
\hline 16 & 0 & .125 & .5 & 0 & 0 & 0 & 0 & .25 & 0 & 0 & .125 & 0 & 0 & 0 & .125 & 1.0 & 0 & .125 & 0 & 0 & 0 & .25 & 0 \\
\hline 17 & 0 & .125 & 0 & 0 & 0 & 0 & 0 & 0 & 0 & 0 & .125 & .25 & 0 & .25 & 0 & 0 & 1.0 & 0 & 0 & 0 & 0 & 0 & 0 \\
\hline 18 & 0 & .063 & 125 & 0 & 0 & 0 & 0 & .125 & 0 & 0 & .063 & 0 & 0 & 0 & .063 & .125 & 0 & 1.0 & 0 & 0 & 0 & .063 & 0 \\
\hline 19 & 0 & 0 & 0 & 0 & 0 & 0 & 0 & 0 & .25 & .25 & 0 & 0 & 0 & 0 & 0 & 0 & 0 & 0 & 1.0 & 0 & 0 & 0 & 0 \\
\hline 20 & 0 & 0 & 0 & 0 & 0 & 0 & 0 & 0 & 0 & 0 & 0 & 0 & 0 & 0 & 0 & 0 & 0 & 0 & 0 & 1.0 & 0 & 0 & 0 \\
\hline 21 & 0 & .123 & 0 & () & 0 & 0 & 0 & 0 & 0 & 0 & 0 & 0 & 0 & 0 & 0 & 0 & 0 & 0 & 0 & 0 & 1.0 & 0 & 0 \\
\hline 22 & 0 & .063 & .25 & 1) & 0 & 0 & 0 & .125 & 0 & 0 & .063 & 0 & 0 & 0 & .063 & .25 & 0 & .063 & 0 & 0 & 0 & 1.0 & 0 \\
\hline 23 & .25 & 0 & 0 & .25 & 0 & .25 & 0 & 0 & 0 & 0 & 0 & 0 & 0 & 0 & 0 & 0 & 0 & 0 & 0 & 0 & 0 & 0 & 1.0 \\
\hline
\end{tabular}

*Average coefficient of relationship $=.029$.

Figure 3. Additive Relationship Hatrix for Yorkshire Sires,* 1444 Data Set 


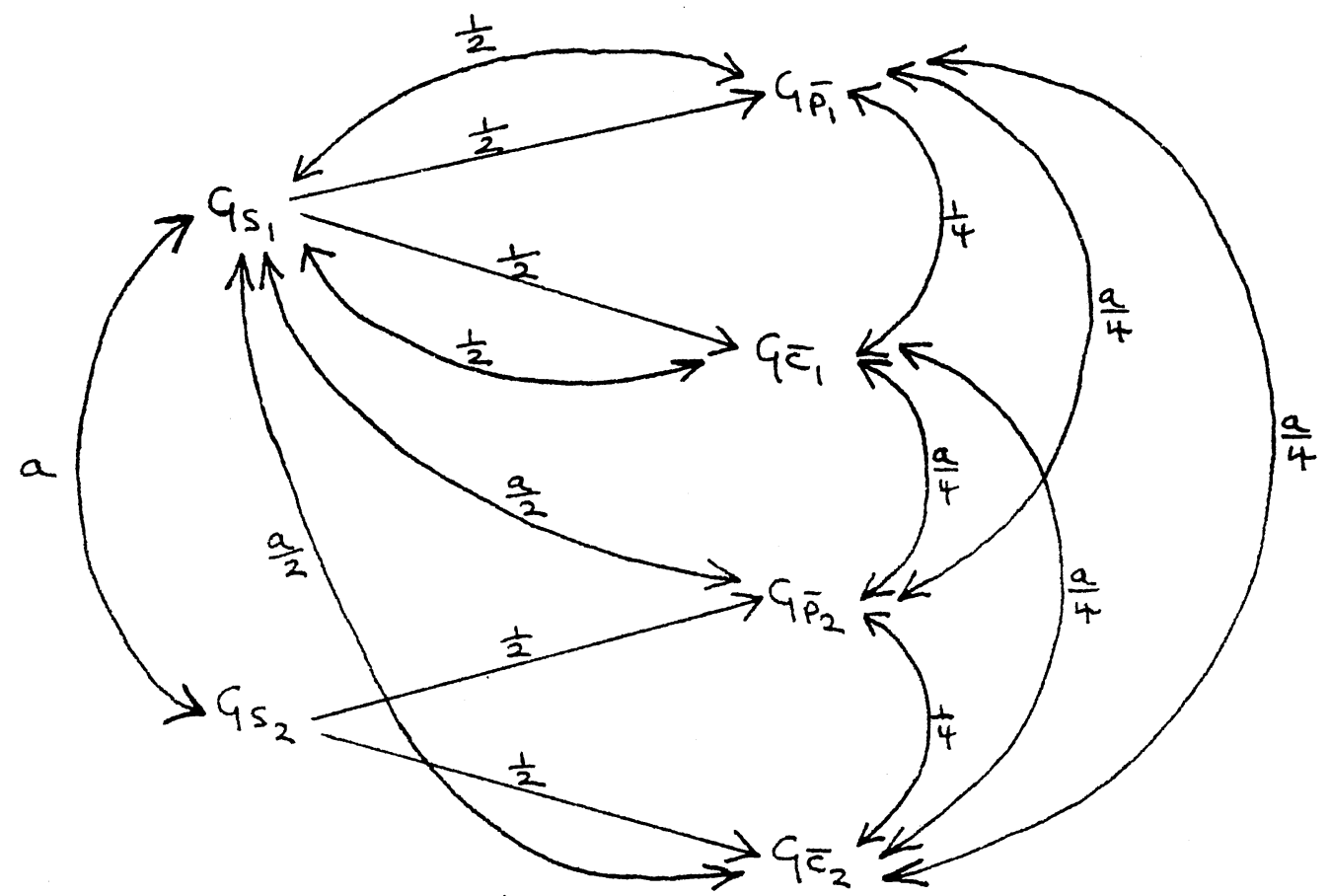

where:

$$
\begin{aligned}
& G_{S_{i}}=\text { additive genetic value of sire } i \text {; } \\
& G_{\overline{p_{i}}}=\underset{\text { mean additive genetic value of the } i^{\text {th }} \text { sire's purebred }}{ } \\
& G_{\bar{c}_{i}}=\underset{\text { mean additive genetic value of the }}{\text { progeny; }} \text { th sire's crossbred } \\
& a=\text { additive relationship between sires } 1 \text { and } 2 \text {. }
\end{aligned}
$$

(Single headed arrows represent paths; doubled headed curved arrows represent correlations.

Figure 4. Path Diagram Demonstrating the Correlations Between Sires' Additive Genetic Value and That of Their Offspring 
The matrix:

$$
\left[\begin{array}{cccc}
A_{1}^{-1} & \frac{V_{e}}{V_{s}} & C^{-1} & V_{e} \\
& & & \frac{V_{s}}{C^{-1}} \\
& \frac{V_{e}}{V_{s}} & A_{2}^{-1} & V_{e} \\
& & & \frac{V_{s t}}{}
\end{array}\right]
$$

discussed in Chapter III was constructed such that:

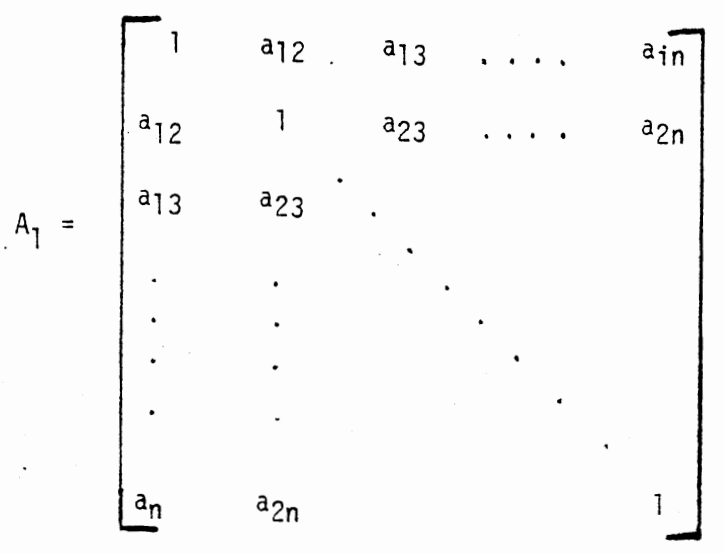

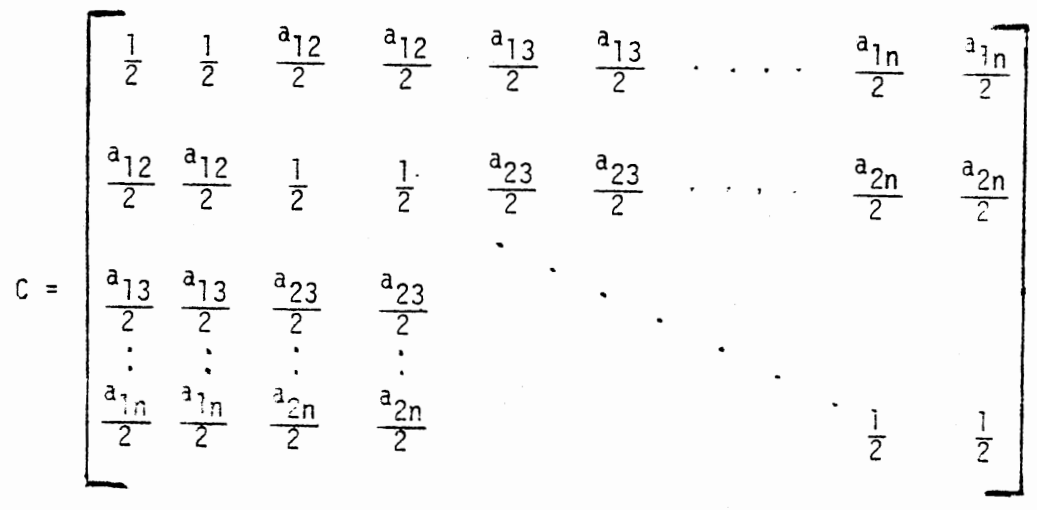

Figure 5. Variance - Covariance Matrices for the Sire and Sire by Type Interaction Terms 


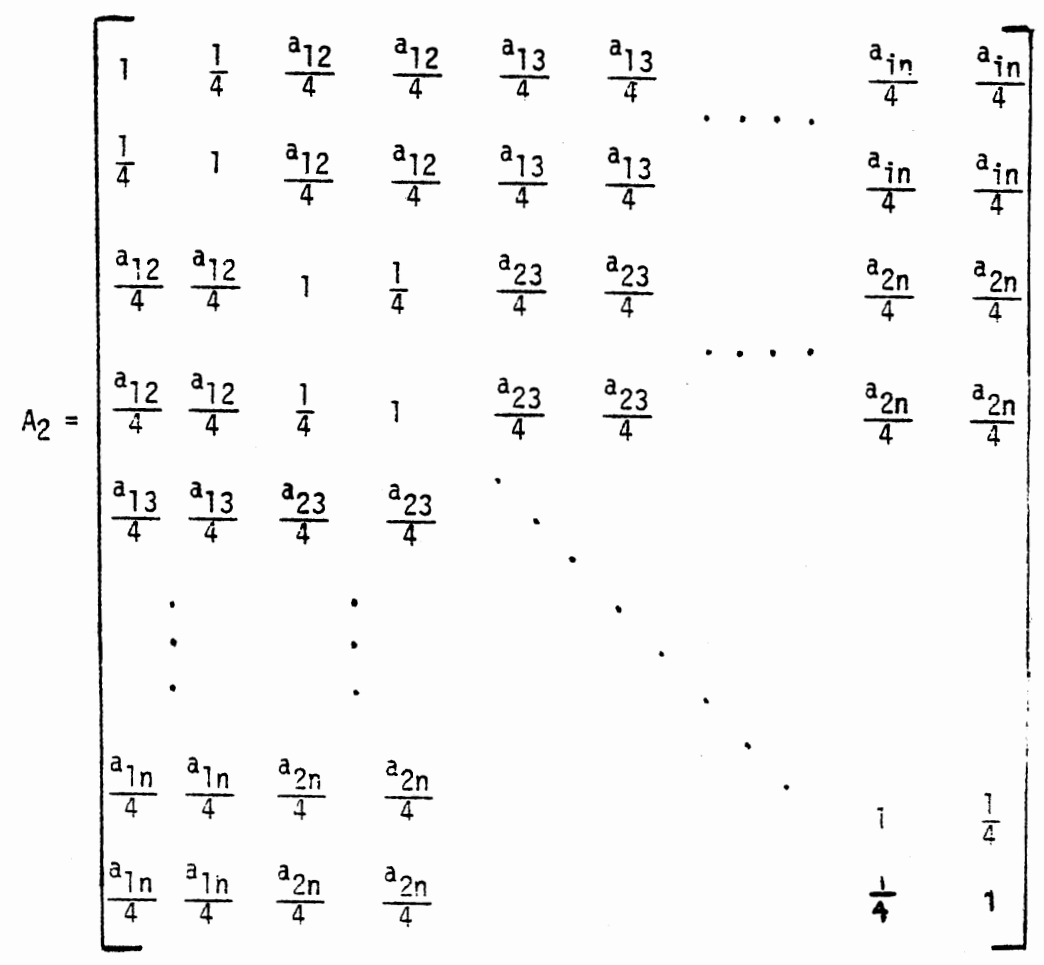

where: $a_{i j}=$ additive relationship between the $i^{\text {th }}$ and $j^{\text {th }}$ sire

$(=0$, $i \neq j$, for 1620 data set);

$n=$ total number of sires

$A=I_{n \times n}(1620$ data set $)$

Figure 5. (Continued) 


$$
\begin{gathered}
\text { VITA } \\
\text { David Gordon McLaren } \\
\text { Candidate for the Degree of } \\
\text { Master of Science }
\end{gathered}
$$

\section{Thesis: SIRE RANKING BASED UPON PUREBRED VERSUS CROSSBRED PROGENY PERFORMANCE IN SWINE}

Major Field: Animal Science

Biographical:

Personal Data: Born in Kent, England, November 24, 1951, the son of Donald A. and Mary M. McLaren.

Education: Graduated from Erith Grammar School, Erith, Kent, June, 1970; completed pre-clinical (medicine) qualifying examinations (2nd MbChb) at Bristol University, England, June, 1972; received the Higher National Diploma from the Welsh Agricultural College, Aberystwyth, Wales, June, 1980; completed requirements for the Master of Science degree at Oklahoma State University in December, 1982.

Experience: Worked as assistant herdsman on a swine unit, 19751976; on a beef and sheep farm, 1976-1977; and on a dairy farm, 1978-1979; graduate assistant, Department of Animal Science, Oklahoma State University, 1980-1982.

Professional Organizations: American Society of Animal Science; Phi Kappa Phi. 